\title{
Amyloid Beta and Tau: from Physiology to Pathology in Alzheimer's Disease
}

\section{Shiler Khaledi, Shamseddin Ahmadi}

Department of Biological Science, Faculty of Science, University of Kurdistan, Sanandaj, Iran

\section{ABSTRACT}

Introduction: Alzheimer's disease(AD), as the most common age-related neurodegenerative disease, affects $2 \%$ of general elderly populations. Amyloid plaques and neurofibrillary tangles are two main hallmarks of AD that are usually associated with cerebral amyloid angiopathy. Imbalance between $A \beta$ production from an amyloid precursor protein and its removal from the brain is the main cause of $A \beta$ accumulation and its pathogenesis. Intraneuronal $A \beta$ aggreagates result in endolysosomal-autophagic dysfunctions followed by formation of authophagic vacuoles and damaged mitochondria in neurons. Studies have also shown that there is an intense crosstalk between $A \beta$ and tau proteins. $A \beta$ aggregates inside and outsides of neurons and intra-neuronal hyper-phosphorylated tau induce dendritic spines collapse and synaptic degeneration, which finally lead to memory loss in AD patients. The amyloid plaques at early stages of $\mathrm{AD}$ are detected in the neocortex and hippocampus which extended to the other brain areas associated with conversion from preclinical to symptomatic AD. Other pathologic factors, such as glia-mdiated inflammation and neuronal death, in AD lead to decrease in neuronal functions leading to cognitive impairments. Conclusion: The better understanding of cellular and molecular mechanisms involved in AD and identifying sensitive and specific biomarkers can play main roles in early diagnosis, controlling the progression, and effective treatmnents of $\mathrm{AD}$. In this study, we review the latest findings on pathophysiology of $A \beta$ and tau proteins and their roles in pathogenesis of $A D$ as well as their importance as targets for treatment of AD.

\section{Key words:}

1. Alzheimer Disease

2. Amyloid beta-Peptides

3. Plaque, Amyloid

4. tau Proteins

5. Dendritic Spines

*Corresponding Author: Shamseddin Ahmadi

E-mail:sh.ahmadi@uok.ac.ir

doi: 10.18869/acadpub.shefa.4.4.67 


\title{
آميلوئيد بتا و تائو: از فيزيولوزى تا پاتولوزى در بيمارى آلزايمر
}

\author{
شيلر خالدى، شمسالدين احمدى"
}

كَروه علوم زيستى، دانشكده علوم، دانشَاه كردستان، سندج، ايران

كليد وازهها:

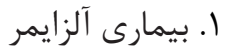

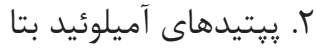

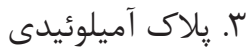

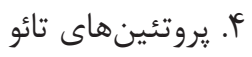

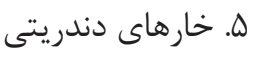

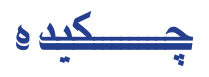

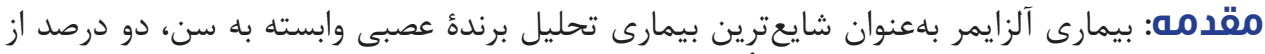

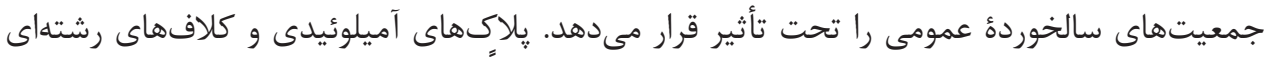

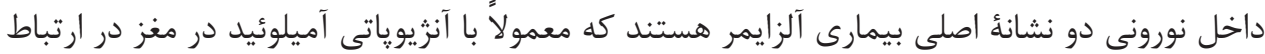

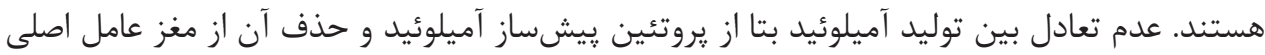

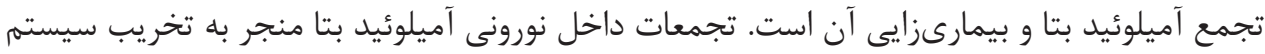

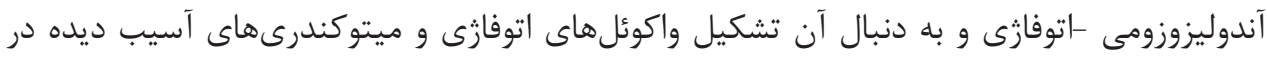

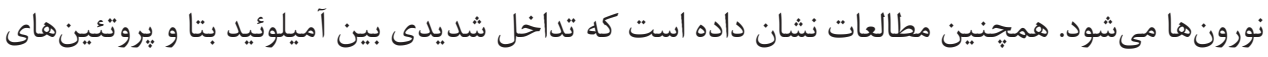

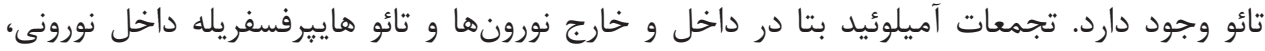

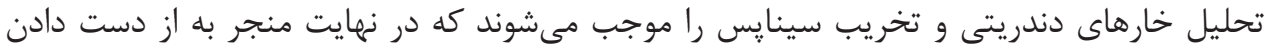

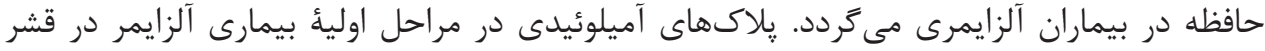

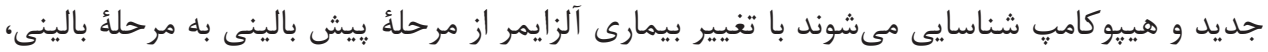

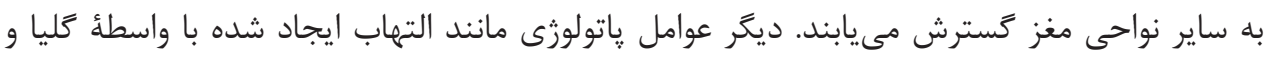

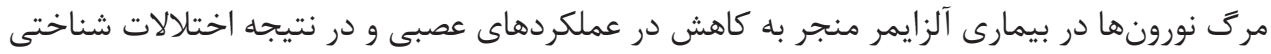

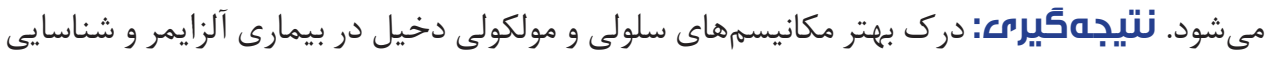

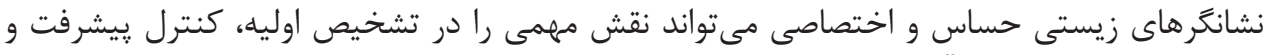

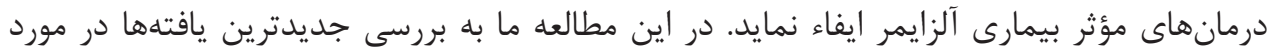

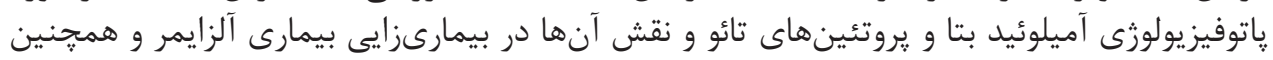

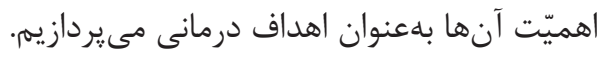

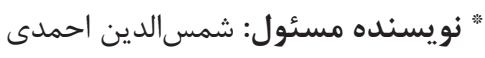
آدرس الكترونيكى: .sh.ahmadi@uok.ac.ir. 


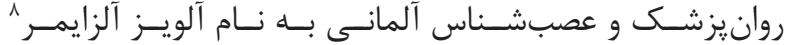

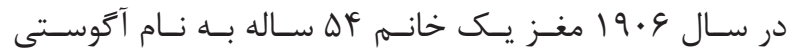

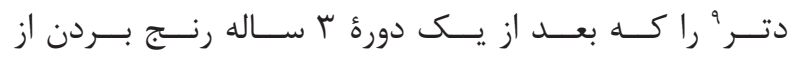

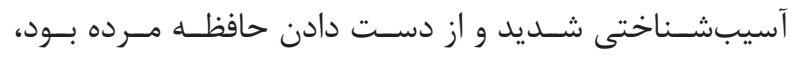

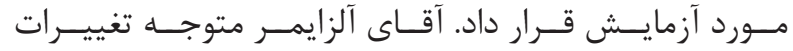

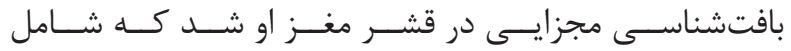

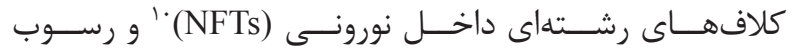

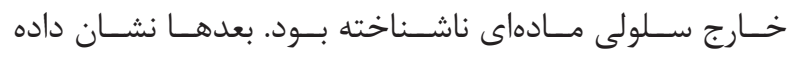

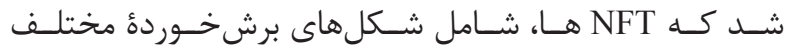

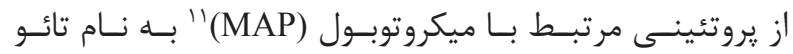

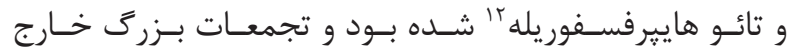

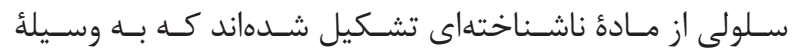

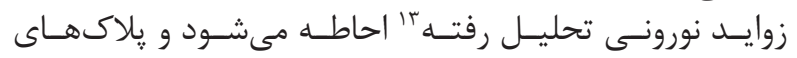

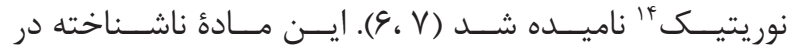

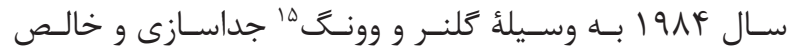

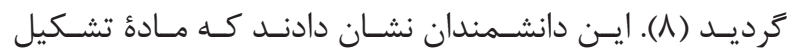

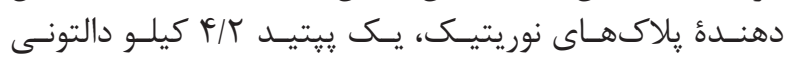

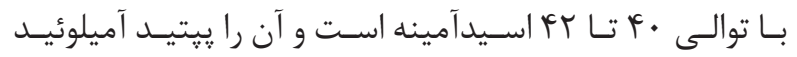

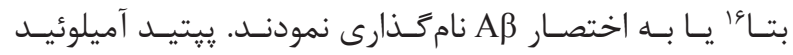

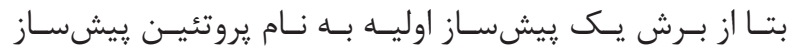

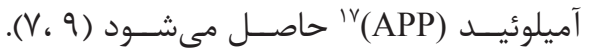
ويزُخى هاى آسيبشناسى بيمارى آلزايمر

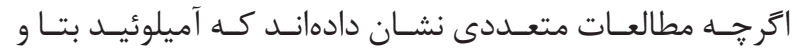

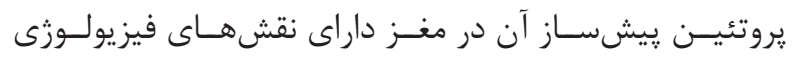

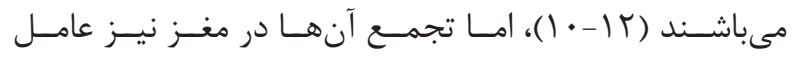

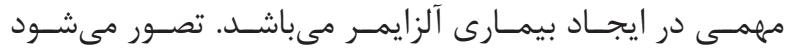

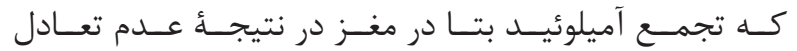

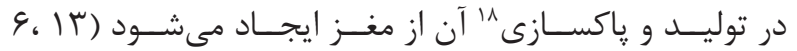

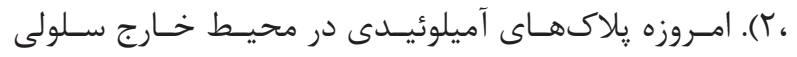

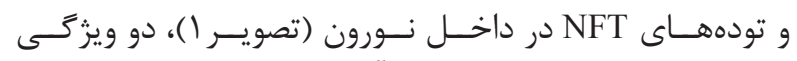

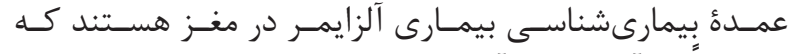

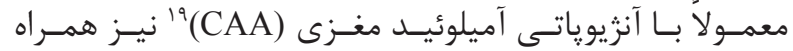

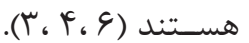

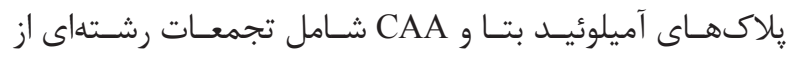

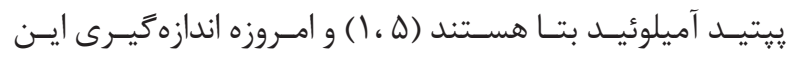

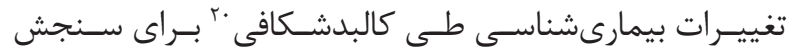

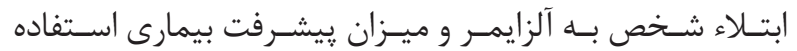

\footnotetext{
${ }^{1}$ Alzhimer's disease

${ }^{2}$ Neurodegenerative

${ }^{3}$ Episodic memory

${ }^{4}$ Declarative memory

${ }^{5}$ Non-declarative memory

${ }^{6}$ Dementia

${ }^{7}$ Early-onset AD

${ }^{8}$ Aloise Alzheimer

${ }^{9}$ Auguste Deter

${ }^{10}$ Neurofibrillary tangles
}

معرفى بيمارى آلزايمر

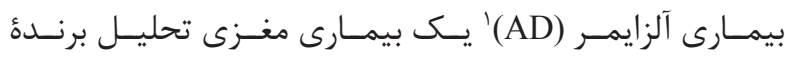

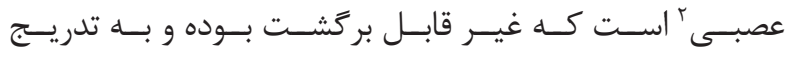

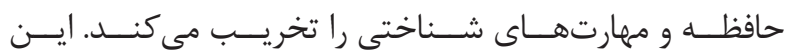

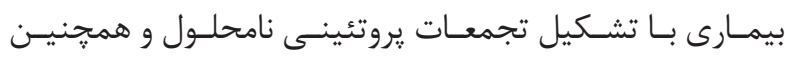

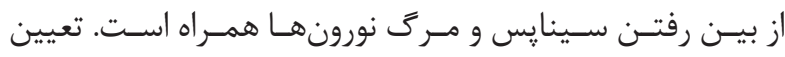

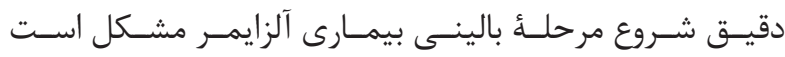

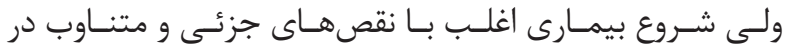

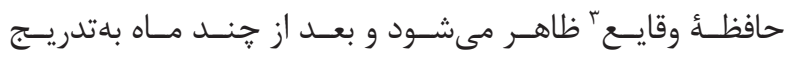

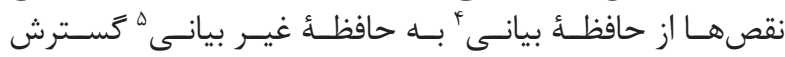

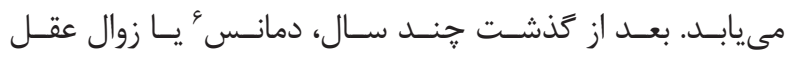

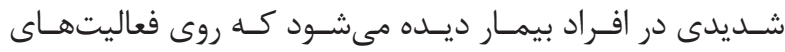

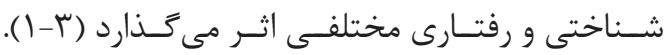

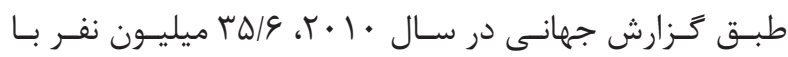

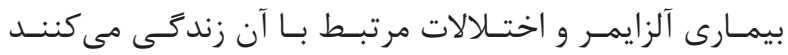

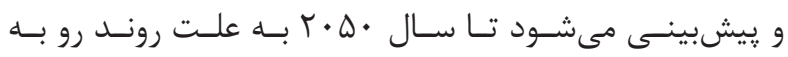

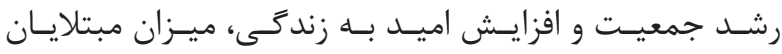

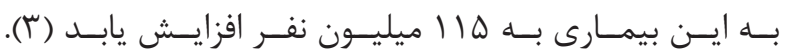

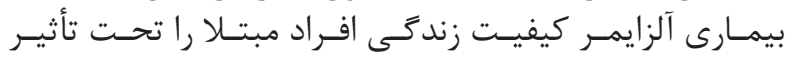

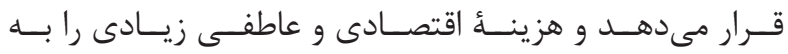

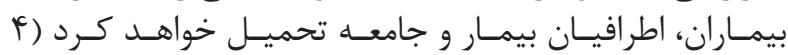

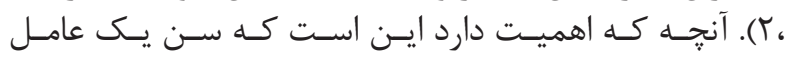

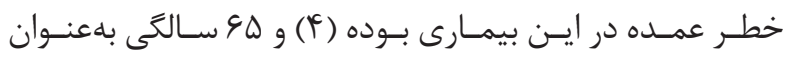

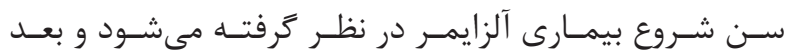

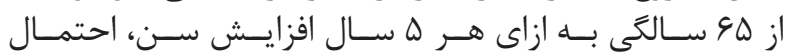

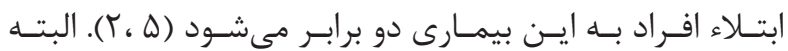

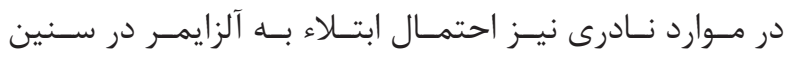

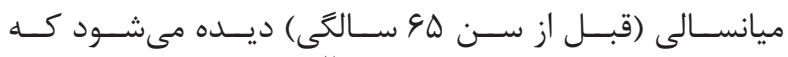

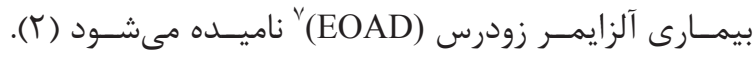

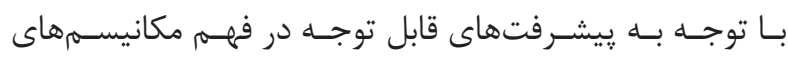

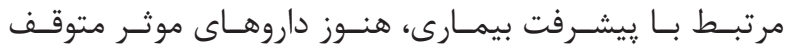

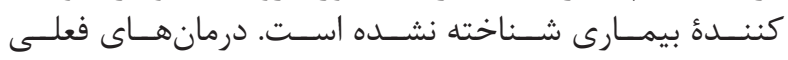

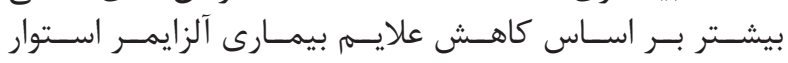

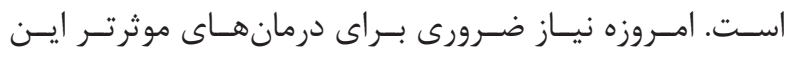

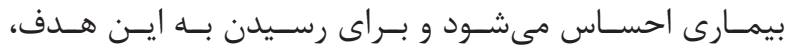

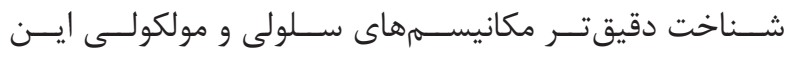

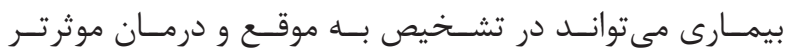

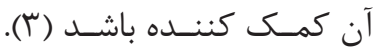

\footnotetext{
${ }^{11}$ Microtubule-associated protein

${ }^{12}$ Tau and hyperphosphorylated tau

${ }^{13}$ Dystrophic neuritic

${ }^{14}$ Neuritic plaque

${ }^{15}$ Glenner and Wong

${ }^{16}$ Amyloid beta

${ }^{17}$ Amyloid precursor protein

${ }^{18}$ Clearance

${ }^{19}$ Cereberal amyloid angiopathy

${ }^{20}$ Autopsy
} 


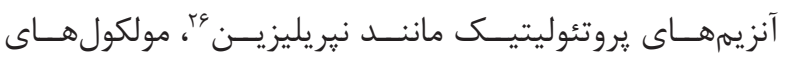

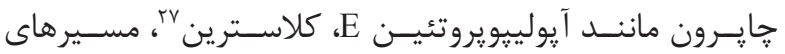

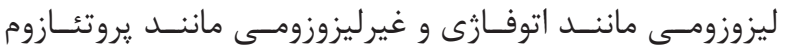

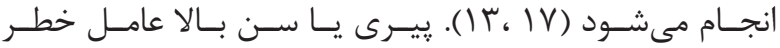

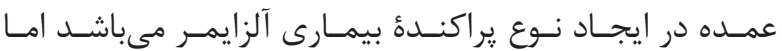

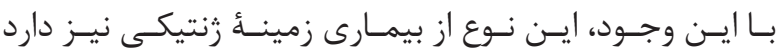

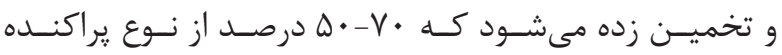

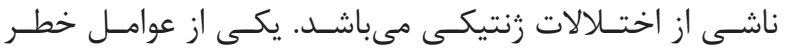

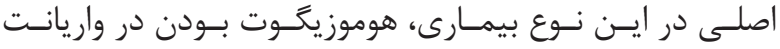

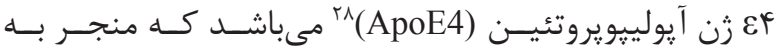

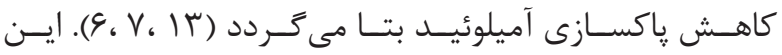

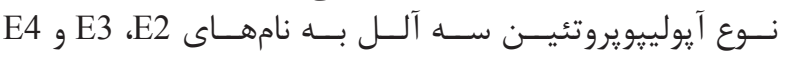

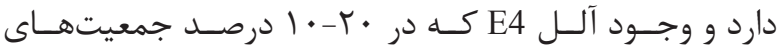

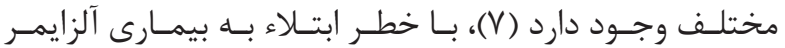

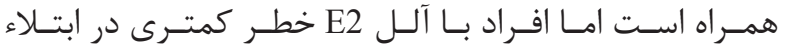

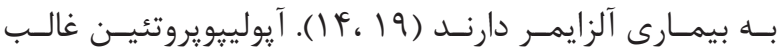

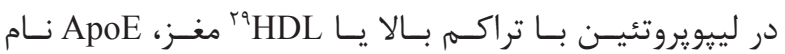

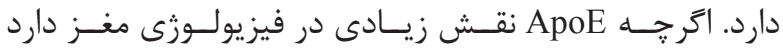

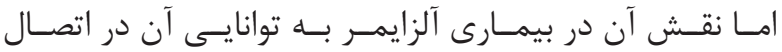

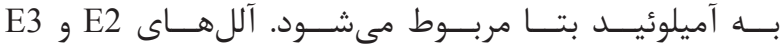

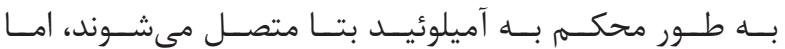

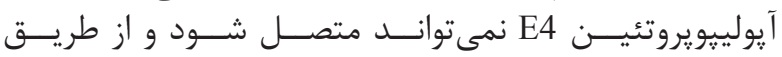

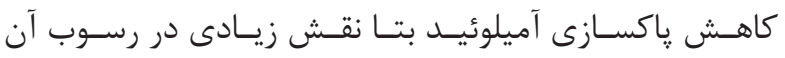

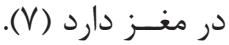

ساختار يروتئين بيشساز آميلوئيد

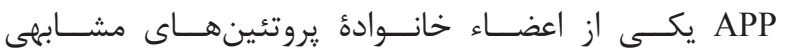

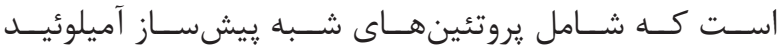

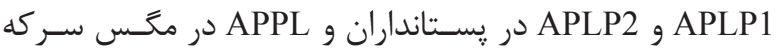

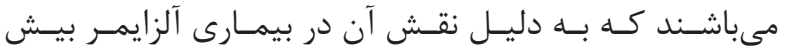

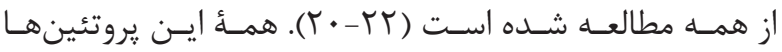

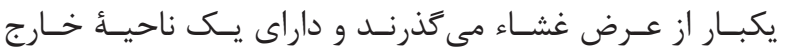

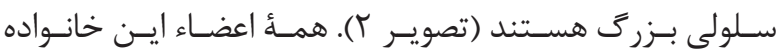

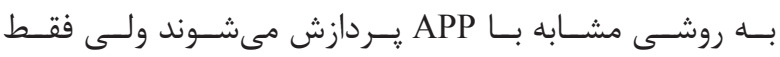

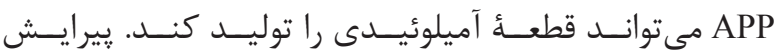

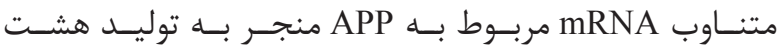

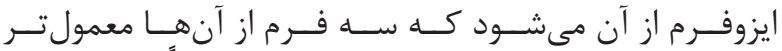

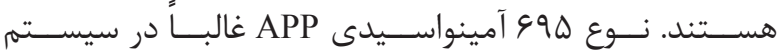

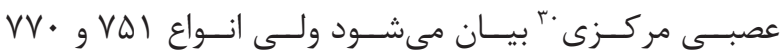

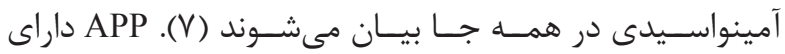

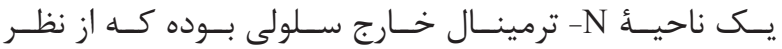

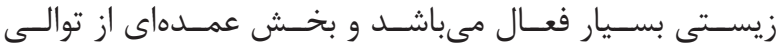

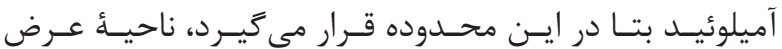

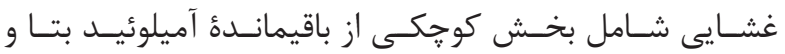

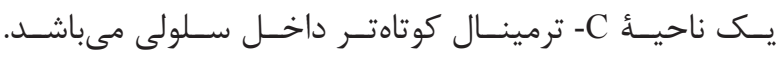

\footnotetext{
${ }^{21}$ Neocortex

${ }^{22}$ Familial Alzheimer's disease

${ }^{23}$ Sporadic Alzheimer's disease

${ }^{24}$ Presenilin

${ }^{25}$ Late-onset $\mathrm{AD}$
}

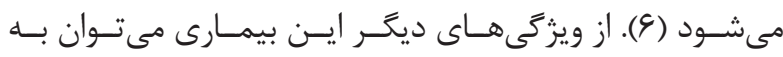

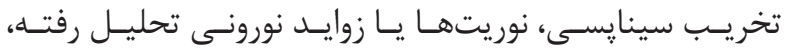

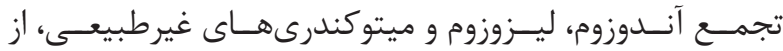

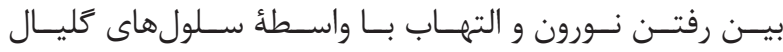

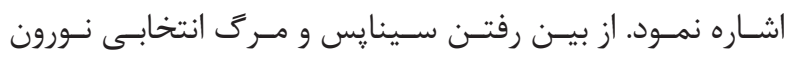

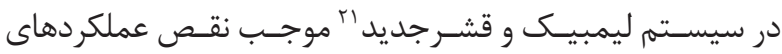

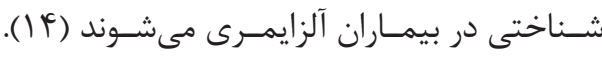

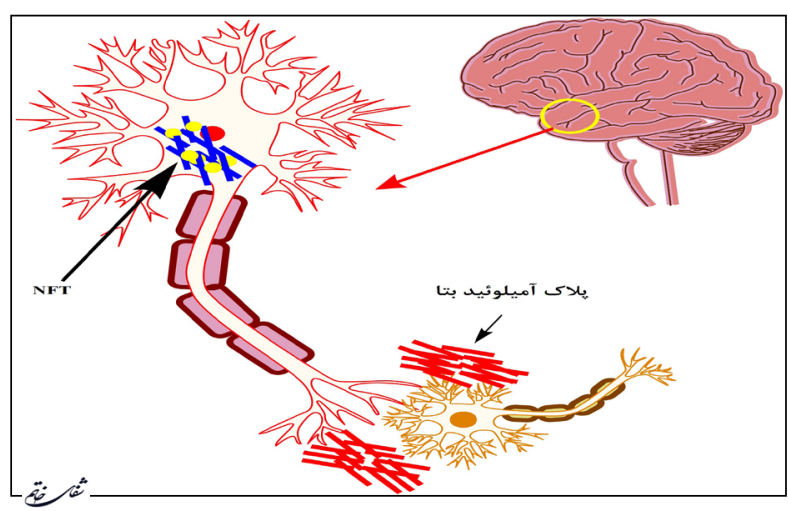

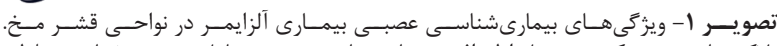

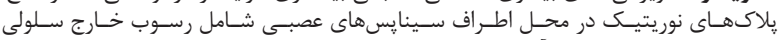

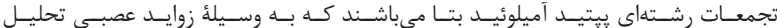

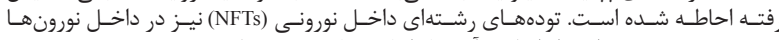

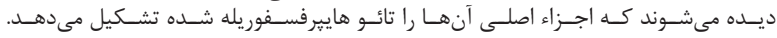

\section{انواع بيمارى آلزايمر و عوامل ايجاد آنها}

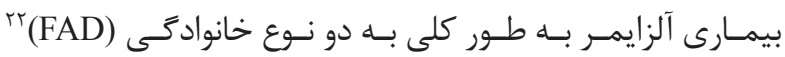

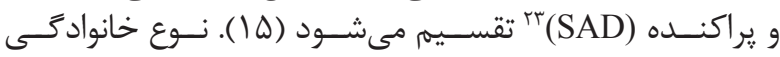

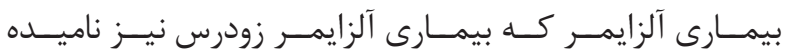

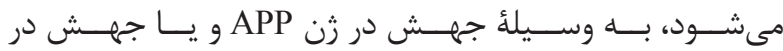

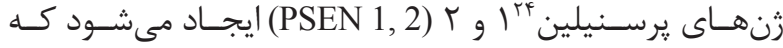

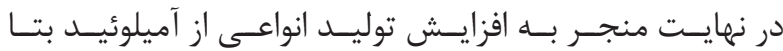

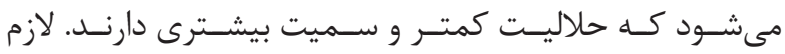

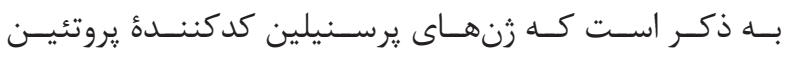

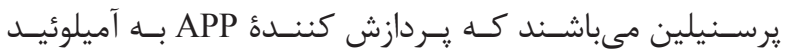

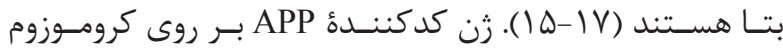

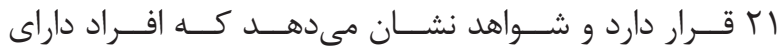

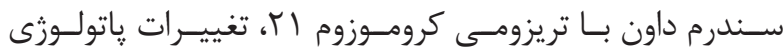

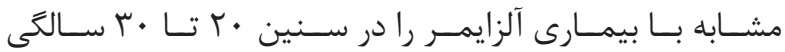

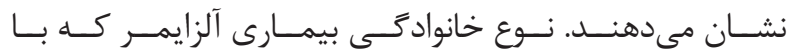

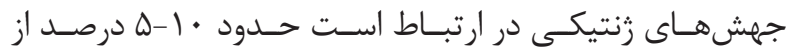

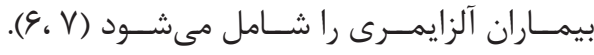

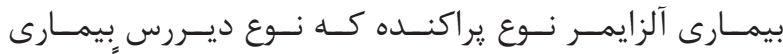

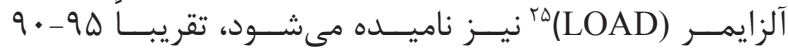

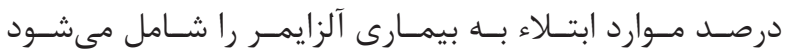

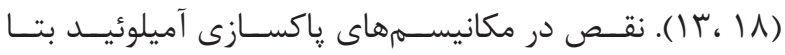

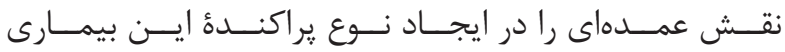

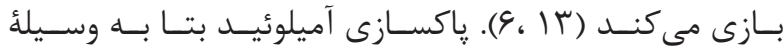

\footnotetext{
${ }^{26}$ Neprilysin

${ }^{27}$ Clusterin

${ }^{28}$ Apolipoprotein $\varepsilon 4$

${ }^{29}$ High density lipoprotein

${ }^{30}$ Central nervous system
} 
عملكردهاى فيزيولوزيك APP

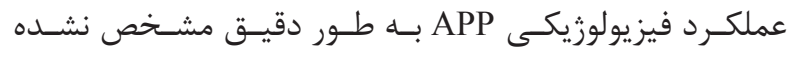

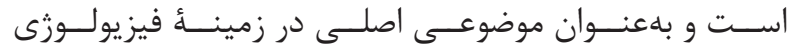

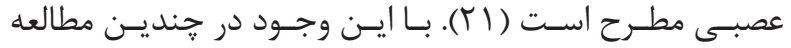

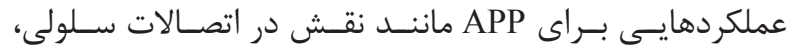

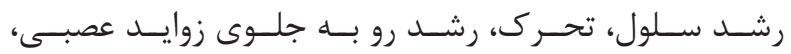

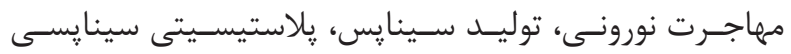

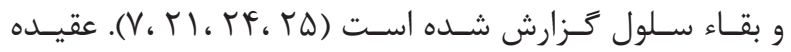

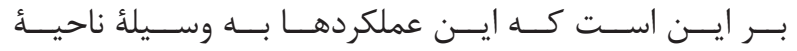

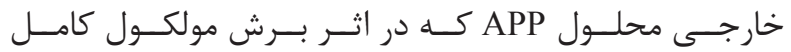

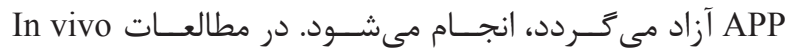

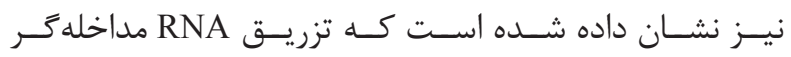

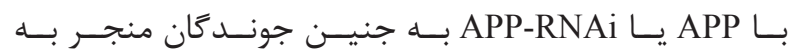

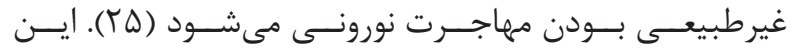

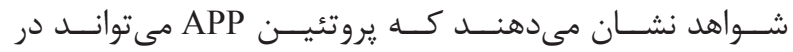

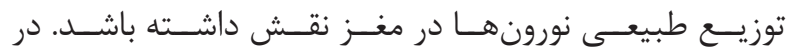

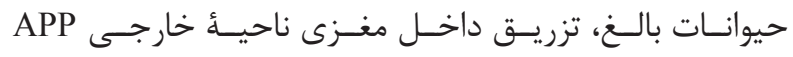

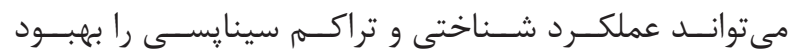

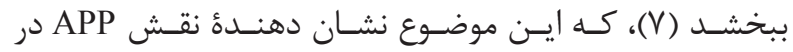

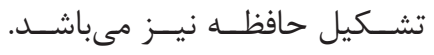

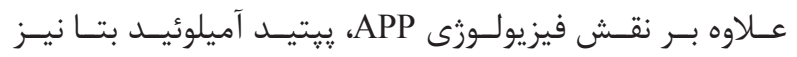

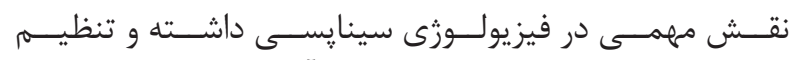

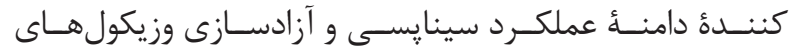

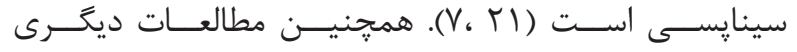

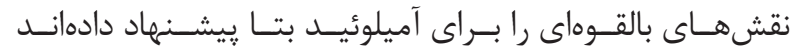

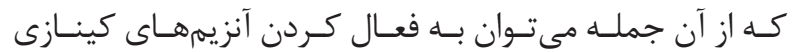
(YY، YV)

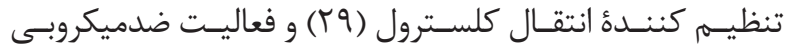

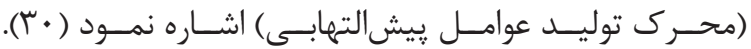

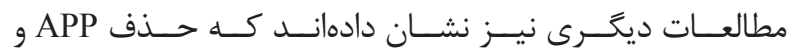

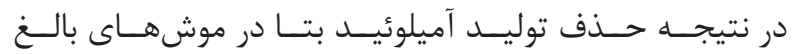

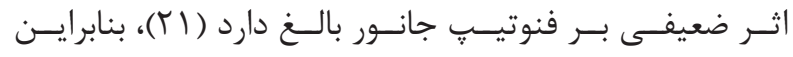

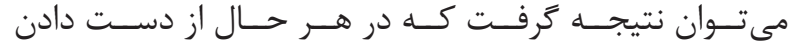

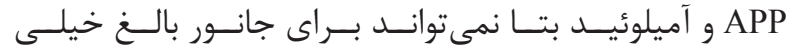

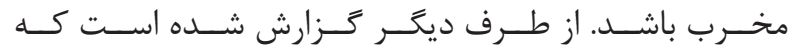

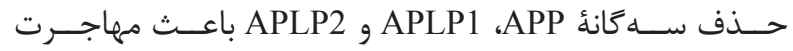

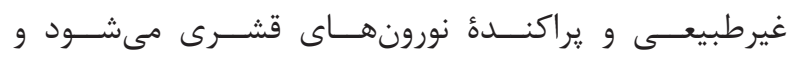

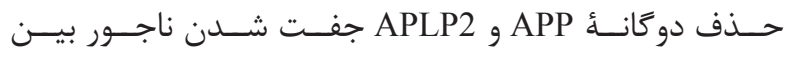

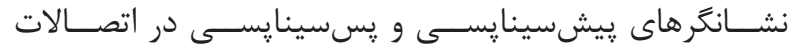

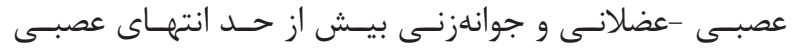

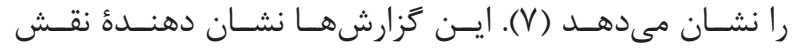

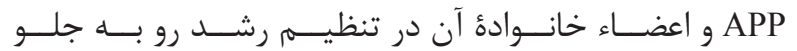

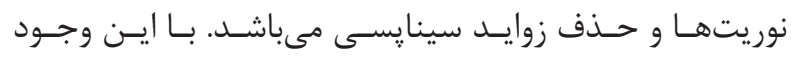

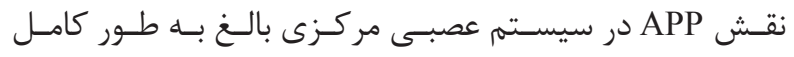

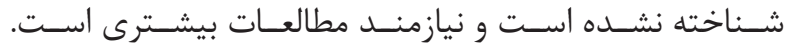

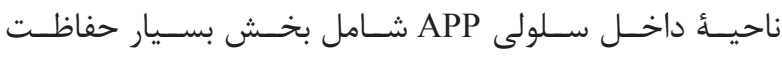

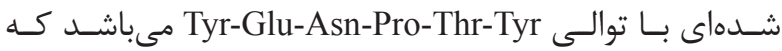

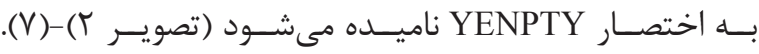

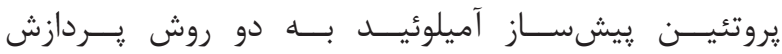

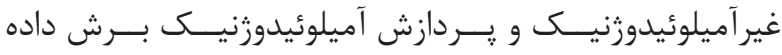

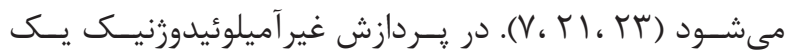

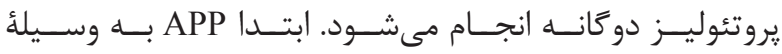

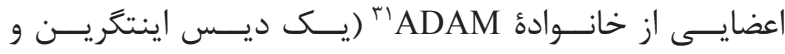

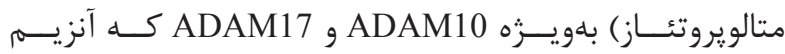

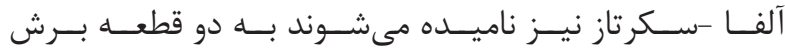

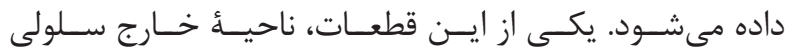

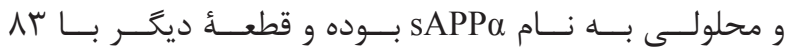

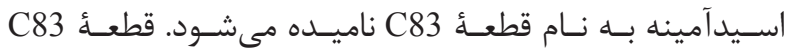

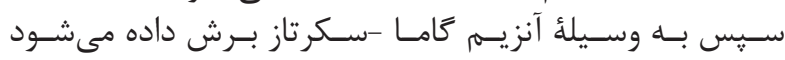

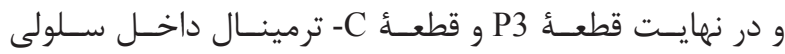

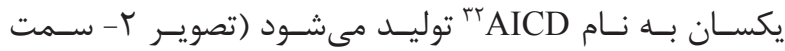

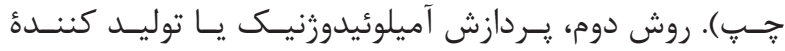

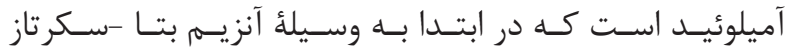

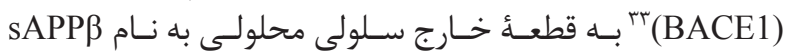

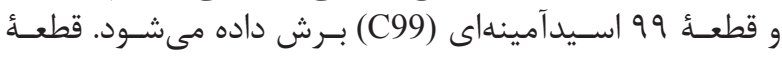

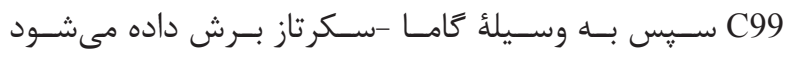

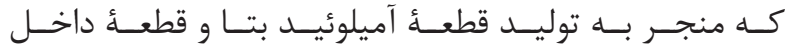

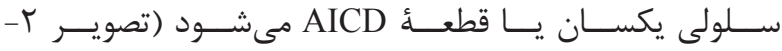

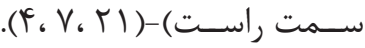

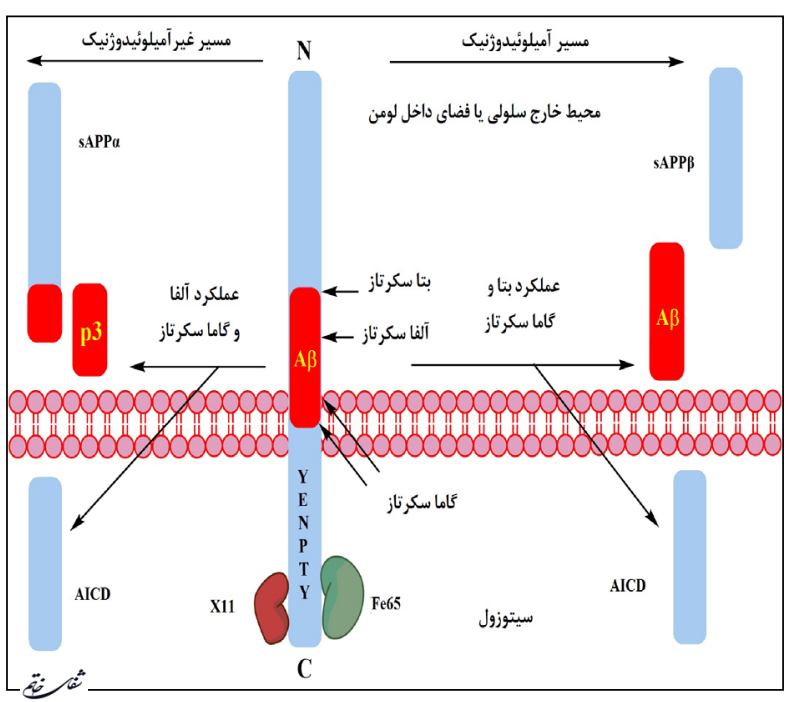

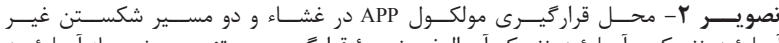

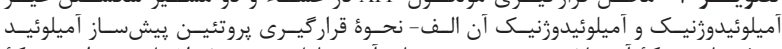

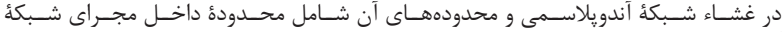

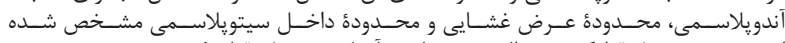

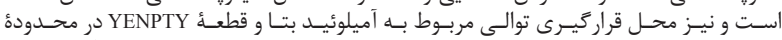

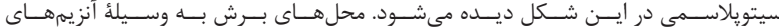

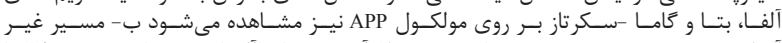

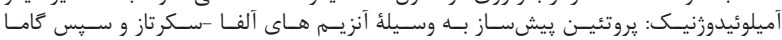

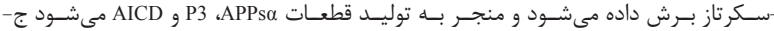

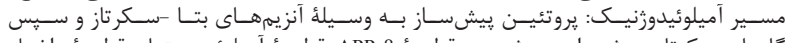

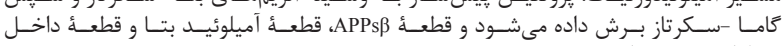

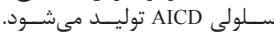

${ }^{31}$ A disintegrin and metalloproteinase

${ }^{32}$ Identical intracellular $\mathrm{C}$ - terminal domain

${ }^{33} \beta$-site amyloid precursor protein cleaving enzyme 


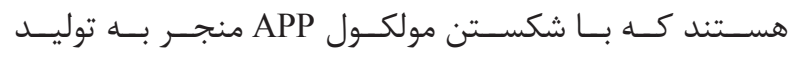

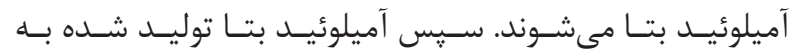

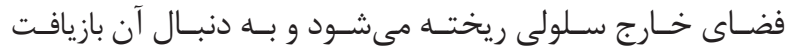

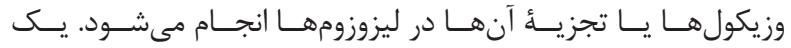

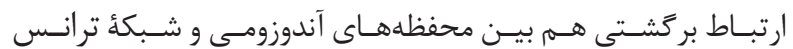

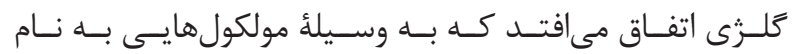

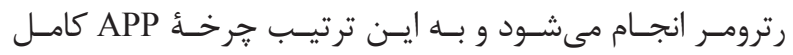

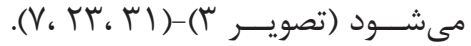

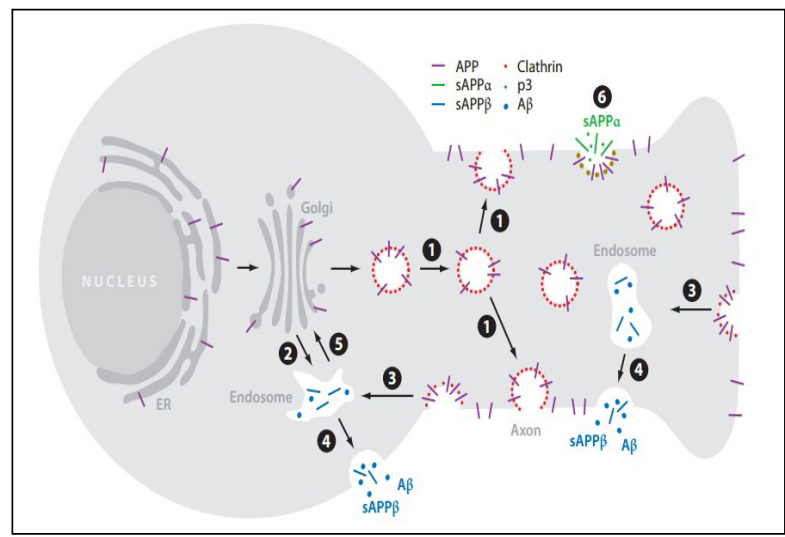

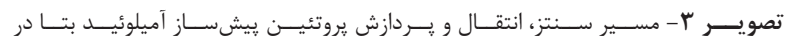

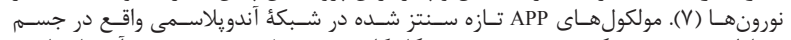

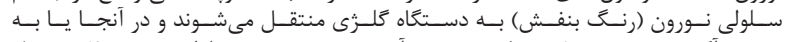

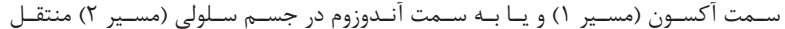

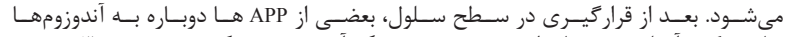

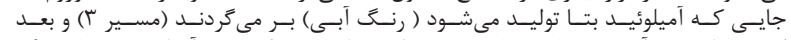

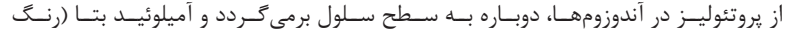

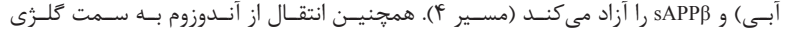

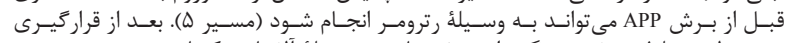

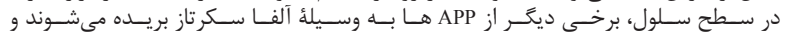

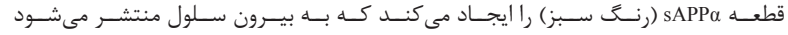

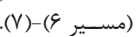

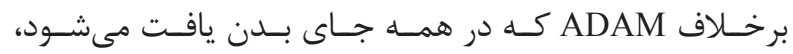

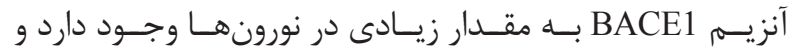

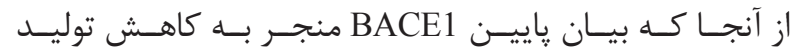

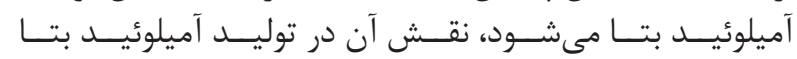

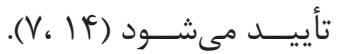

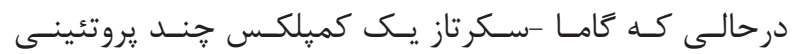

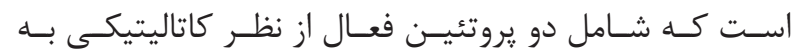

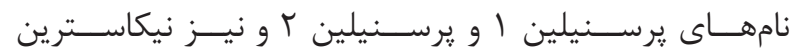

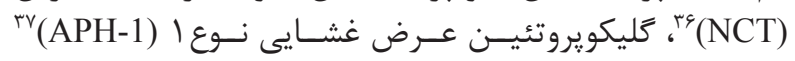

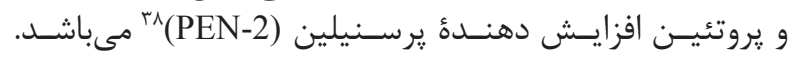

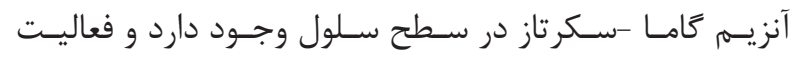

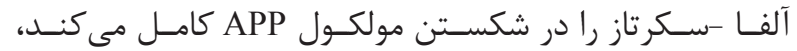

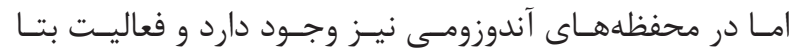

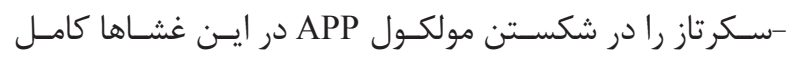

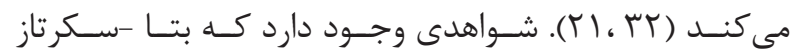

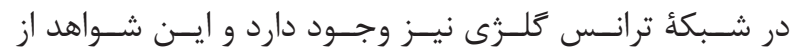

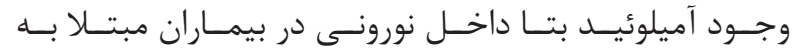

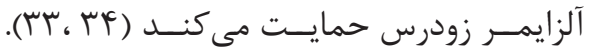

\footnotetext{
${ }^{34}$ Sorting protein- related receptor

${ }^{35}$ Trans-golgi network

${ }^{36}$ Nicastrin
}

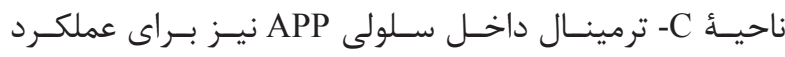

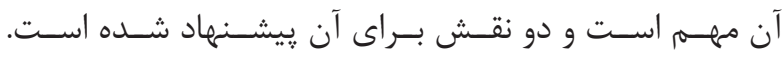

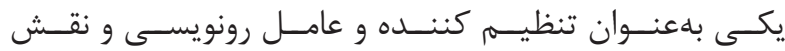

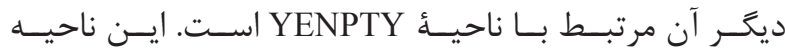

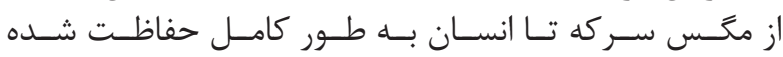

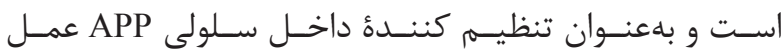

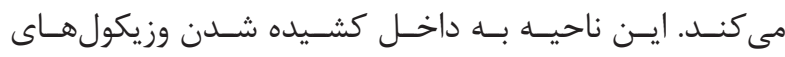

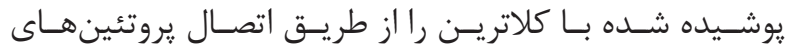

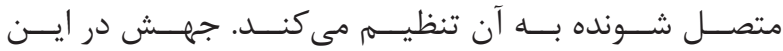

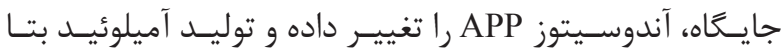

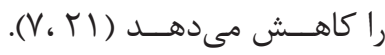

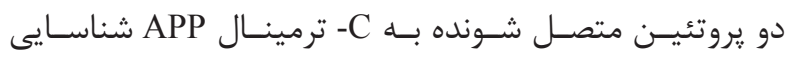

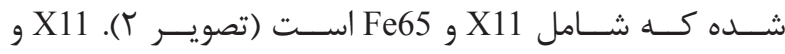

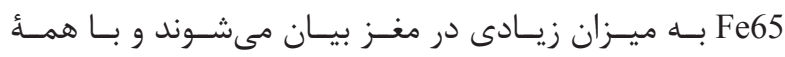

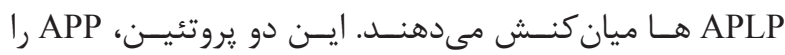

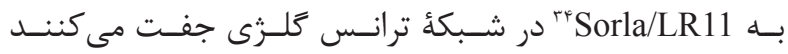

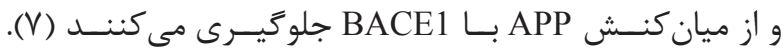
SORLA/LR11

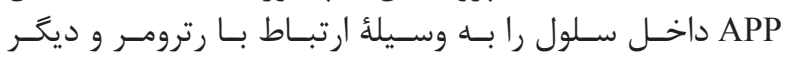

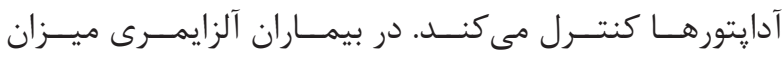

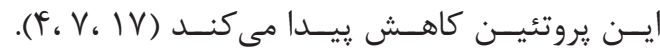

يردازش APP و توليد آميلوئيد بتا

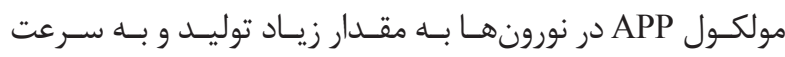

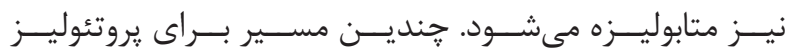

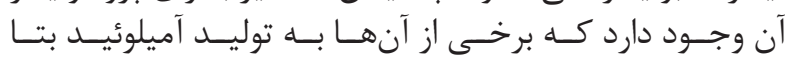

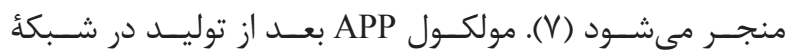

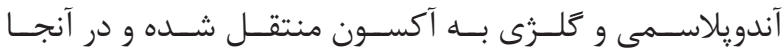

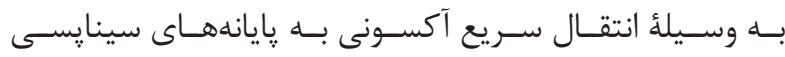

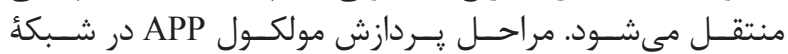

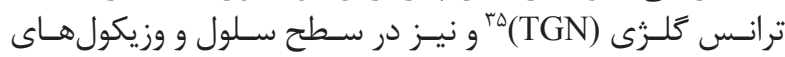

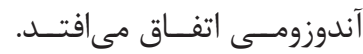

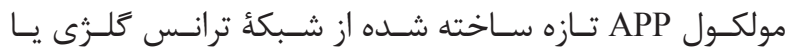

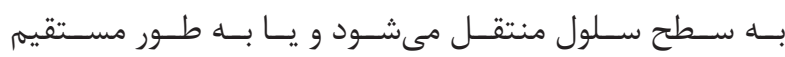

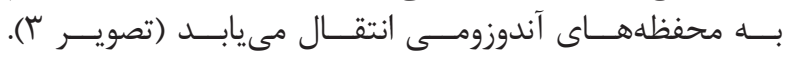

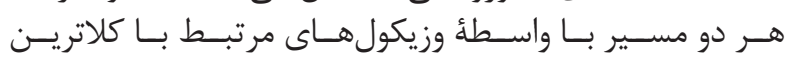

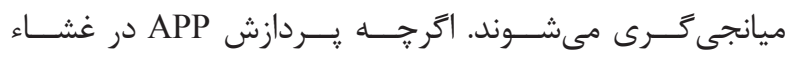

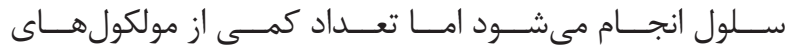

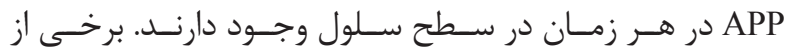

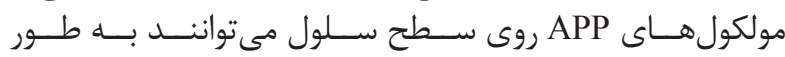

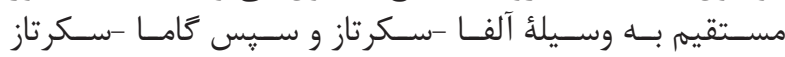

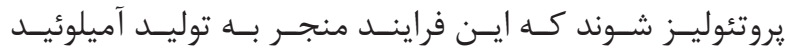

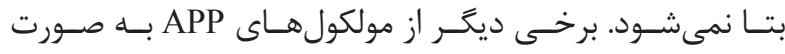

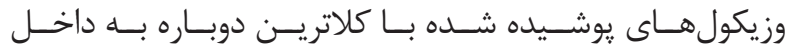

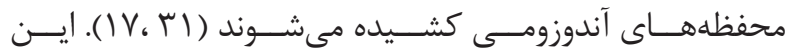

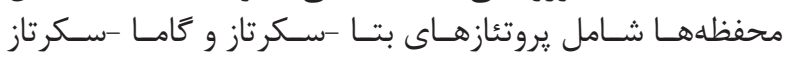

\footnotetext{
${ }^{37}$ Anterior pharynx defective 1

${ }^{38}$ Presenilin enhancer 2
} 
تغييرات يِيتيد آميلوئيد بتا، تجمع و سميت آن

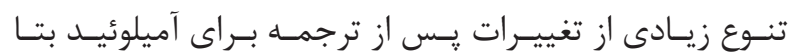

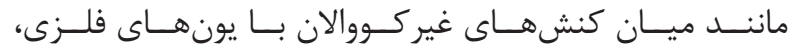

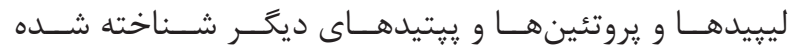

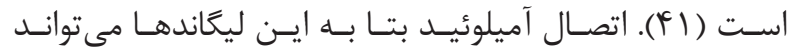

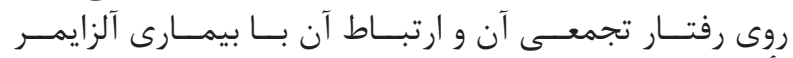

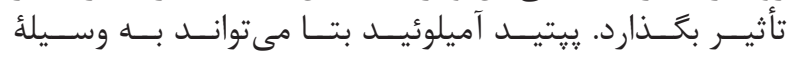

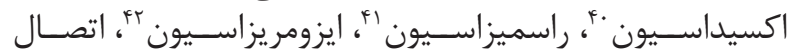

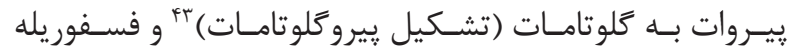

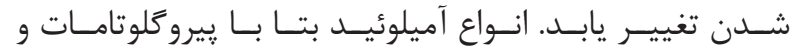

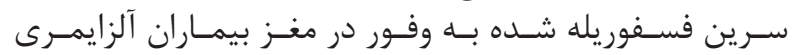

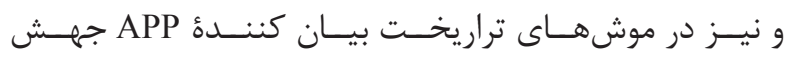

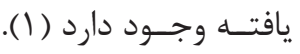

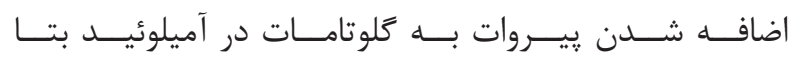

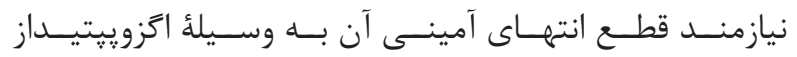

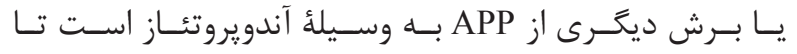

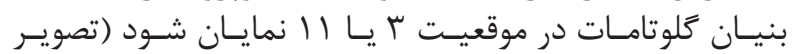

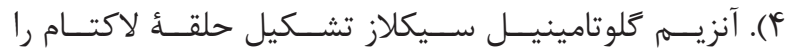

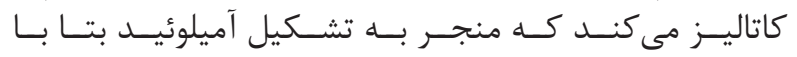

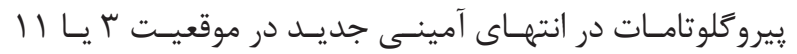

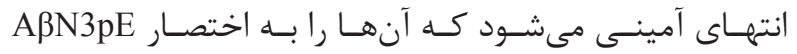

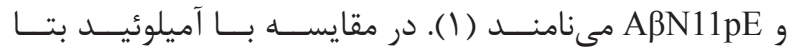

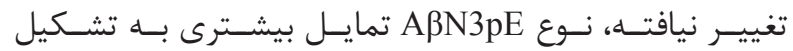

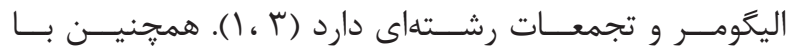

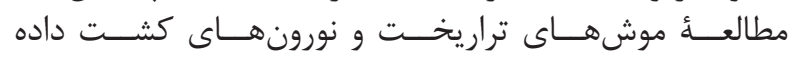

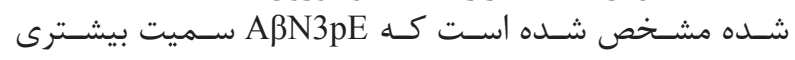

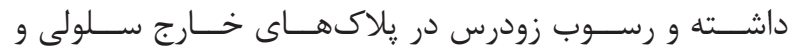

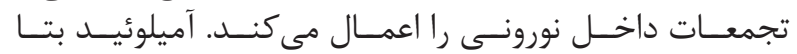

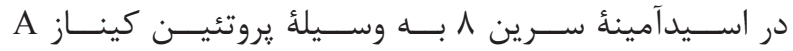

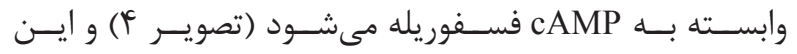

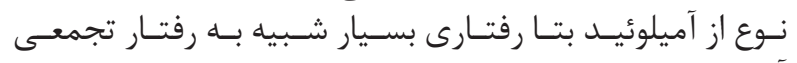

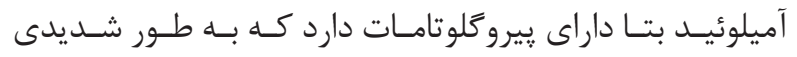

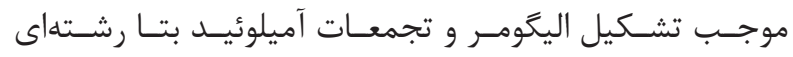

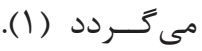

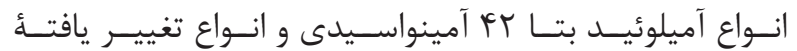

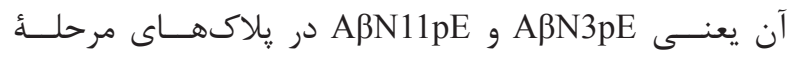

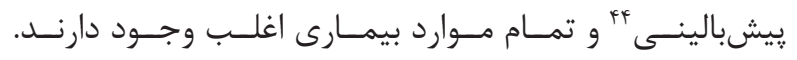

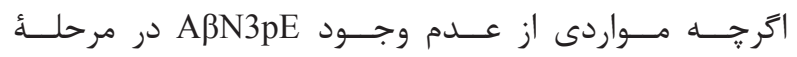

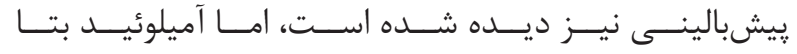

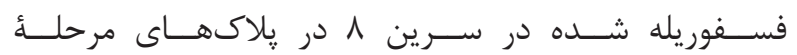

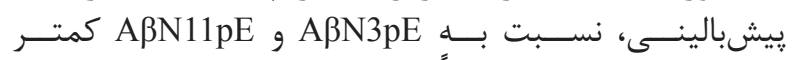

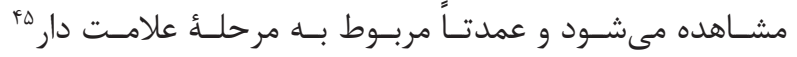

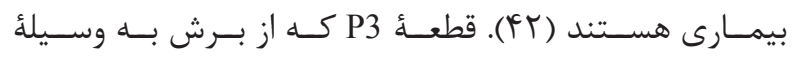

\footnotetext{
${ }^{39}$ Phosphorylation

${ }^{40}$ Oxidtion

${ }^{41}$ Racemization

${ }^{42}$ Isomerization
}

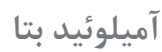

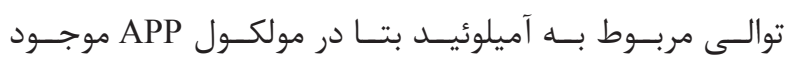

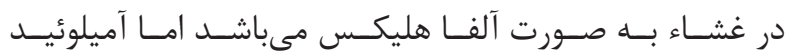

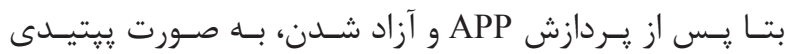

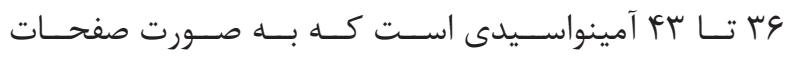

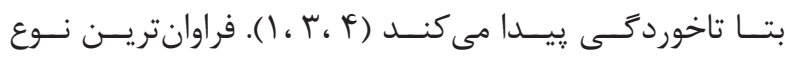

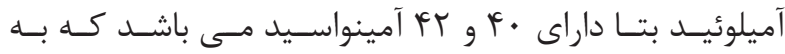

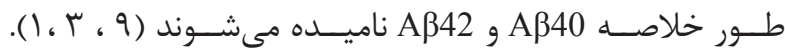

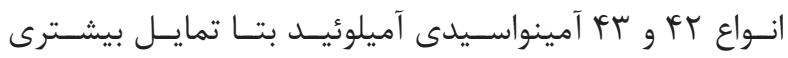

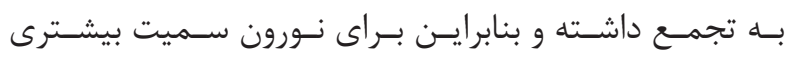

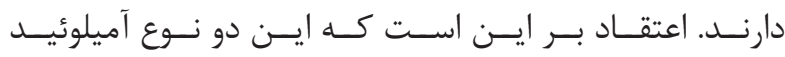

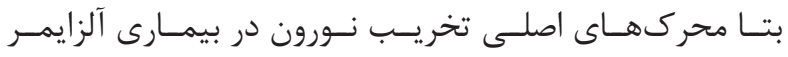

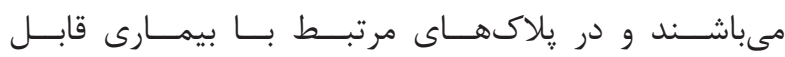

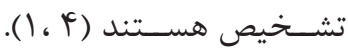

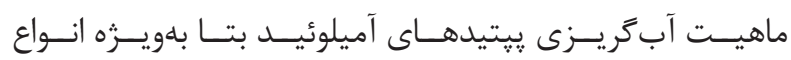

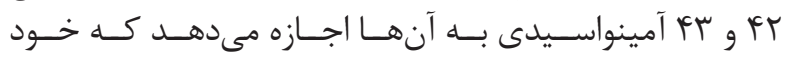

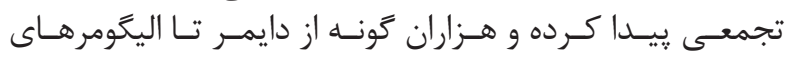

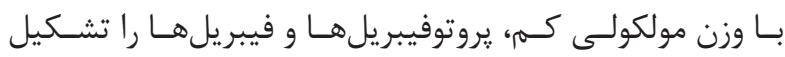

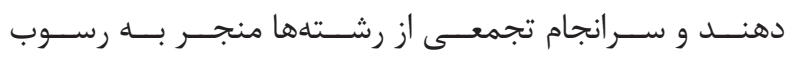

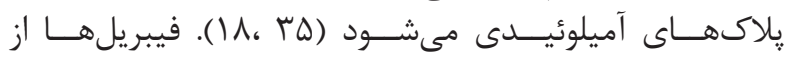

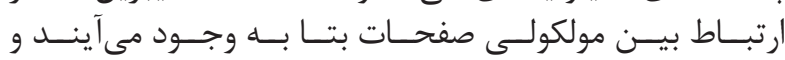

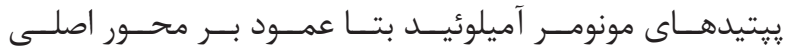

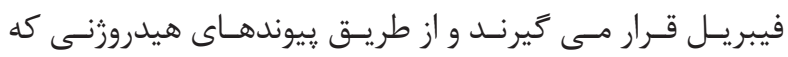

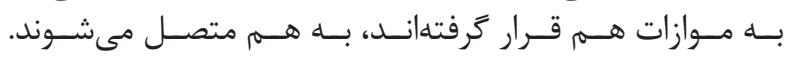

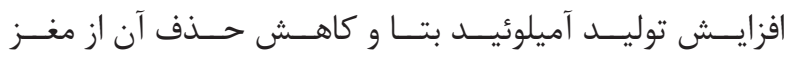

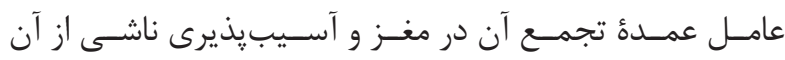

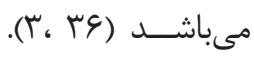

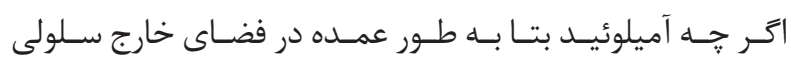

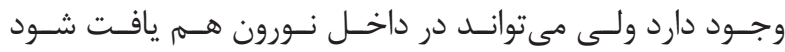

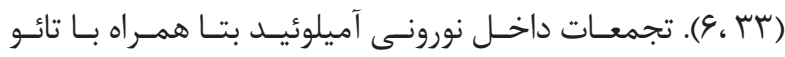

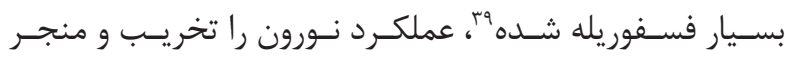

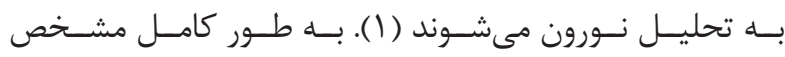

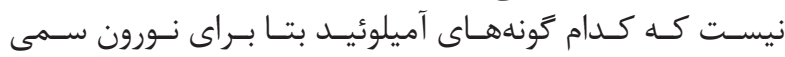

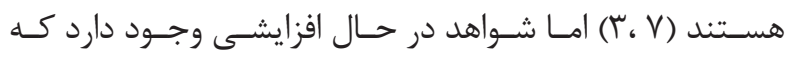

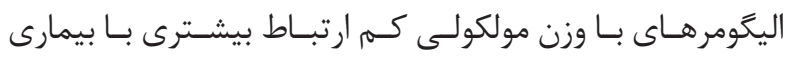

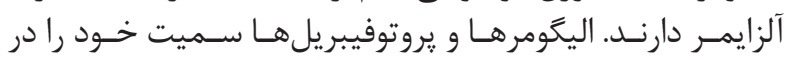

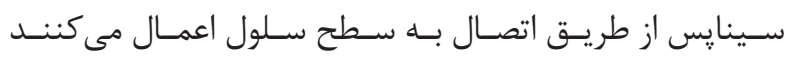

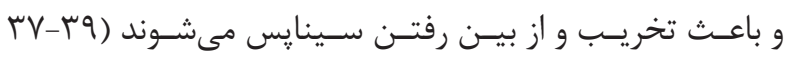

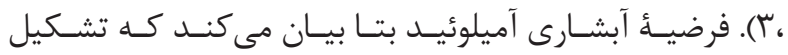

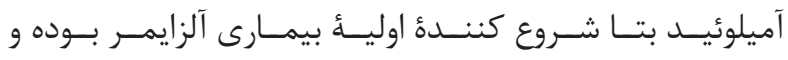

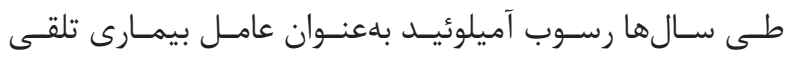

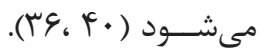

${ }^{43}$ Pyroglutamate formation

${ }^{44}$ P-pre AD

${ }^{45}$ Symptomatic 


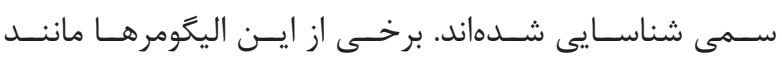

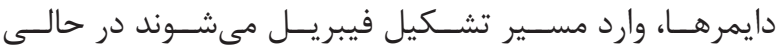

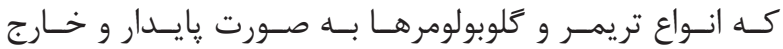

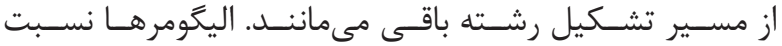

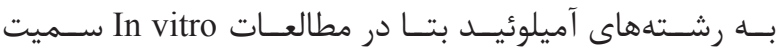

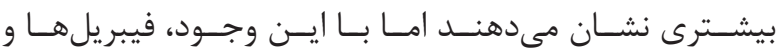

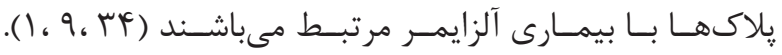

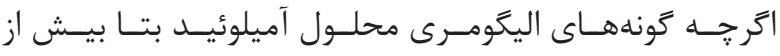

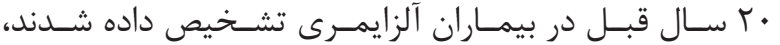

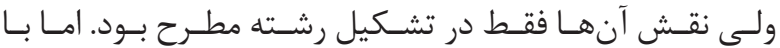

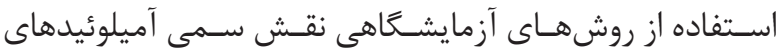

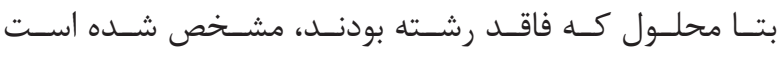

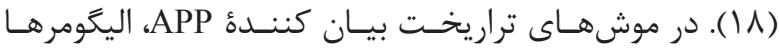

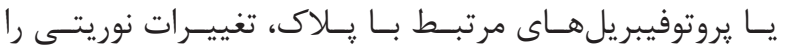

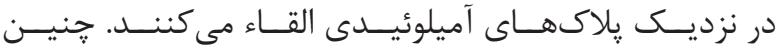

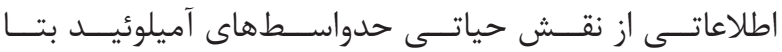

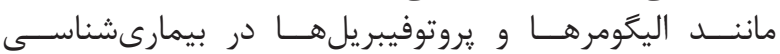

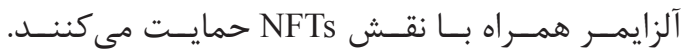

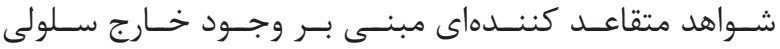

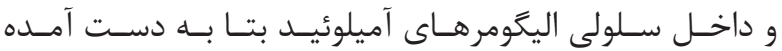

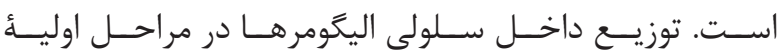

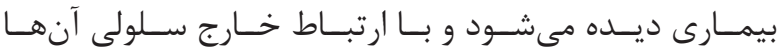

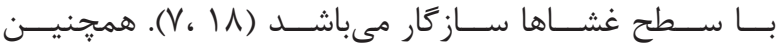

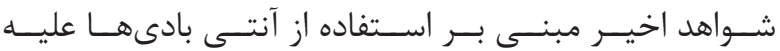

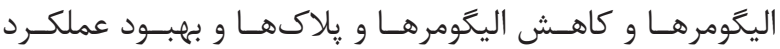

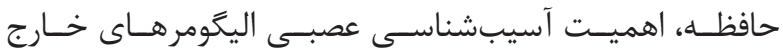

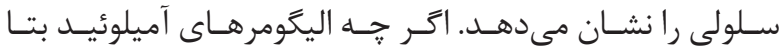

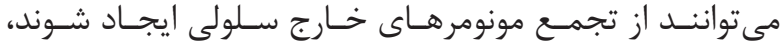

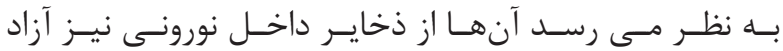

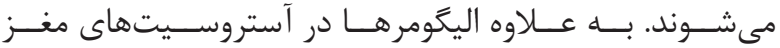

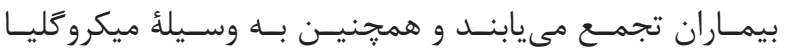

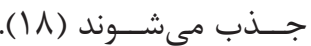

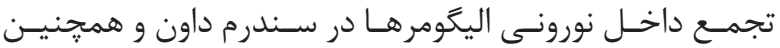

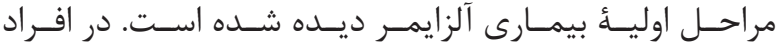

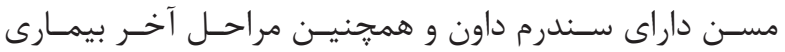

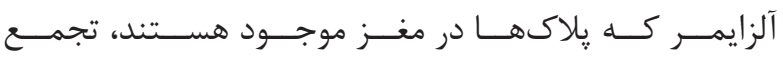

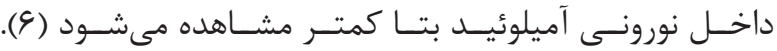

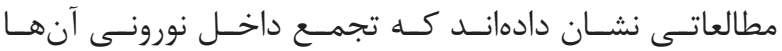

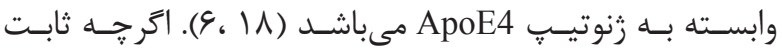

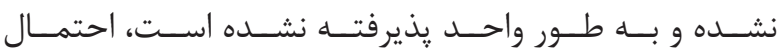

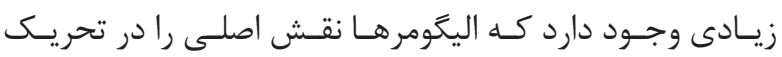

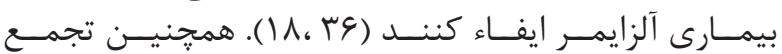

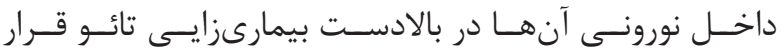

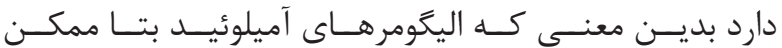

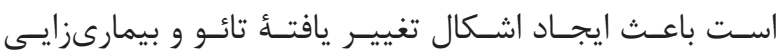

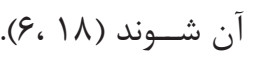

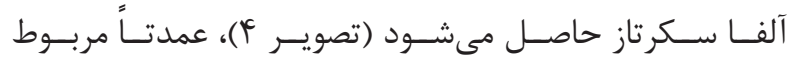

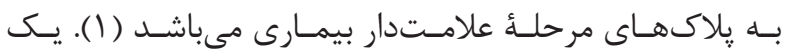

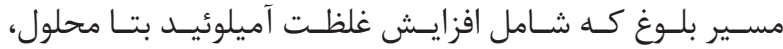

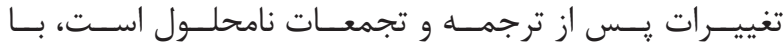

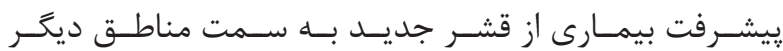

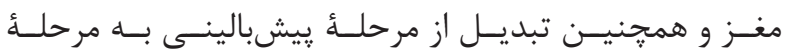

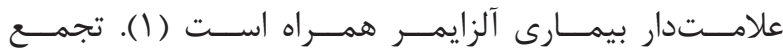

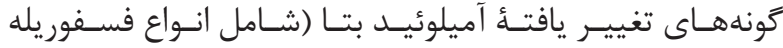

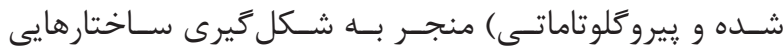

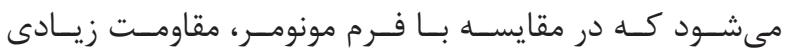

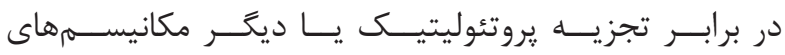

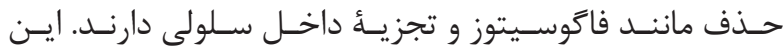

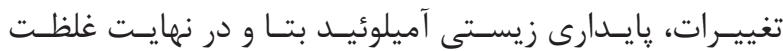

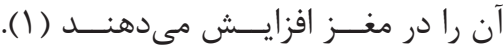

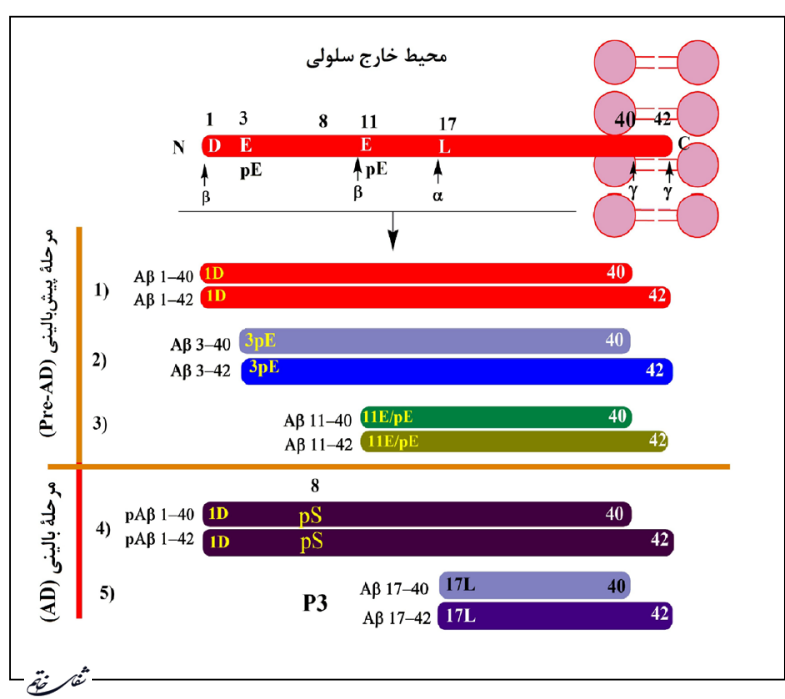

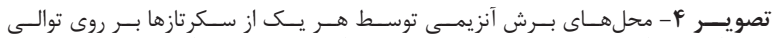

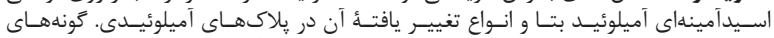

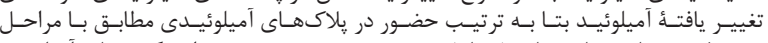

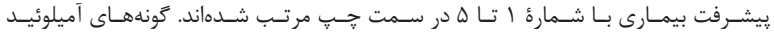

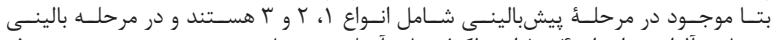

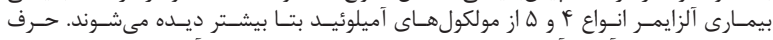

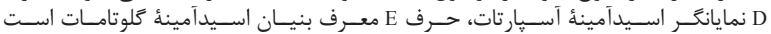

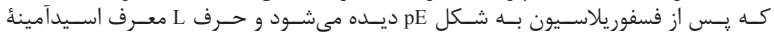

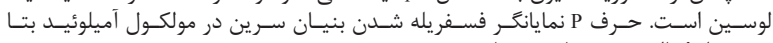

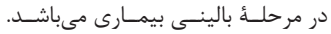

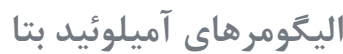

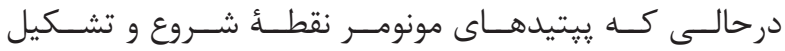

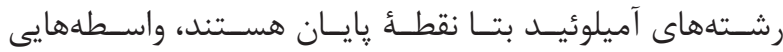

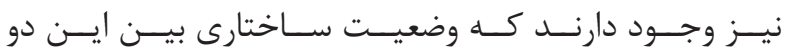

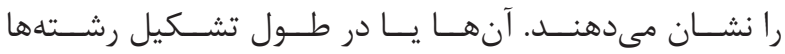

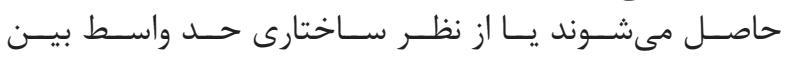

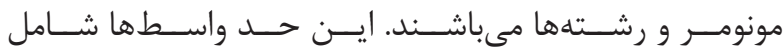

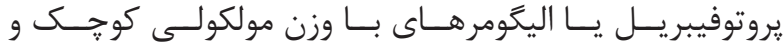

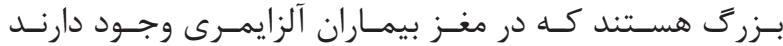

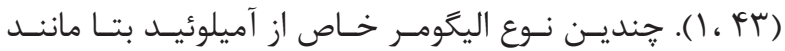

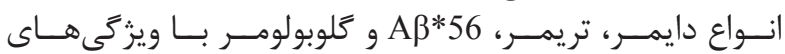




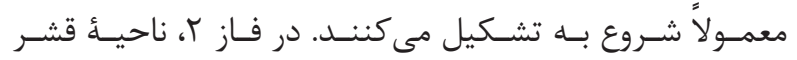

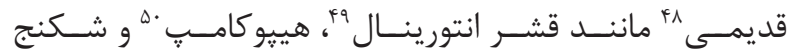

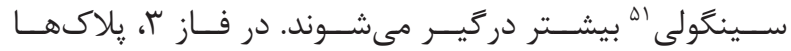

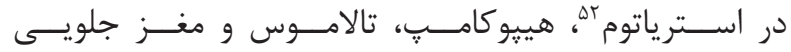

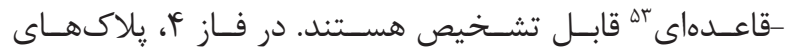

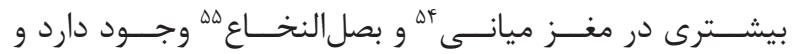

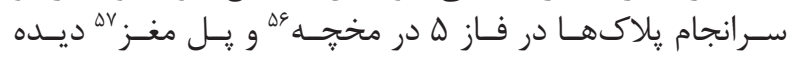

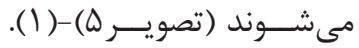

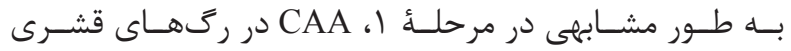

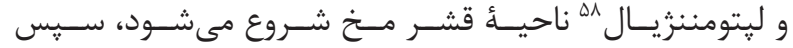

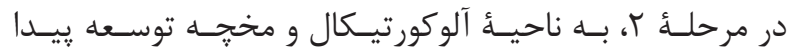

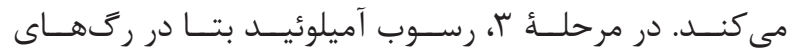

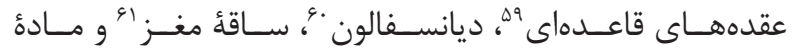

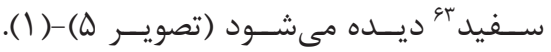

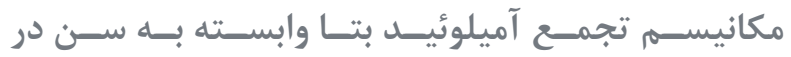
مغـز مـز

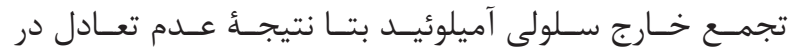

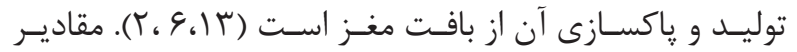

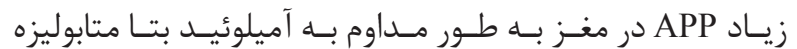

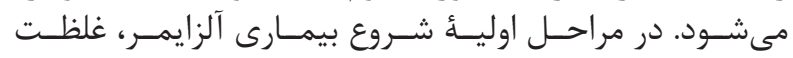

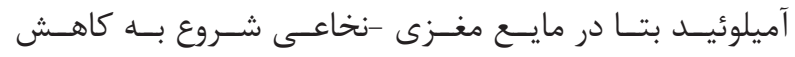

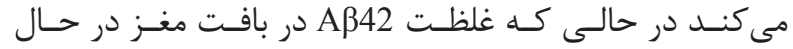

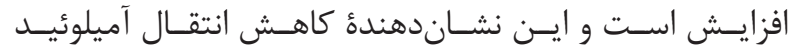

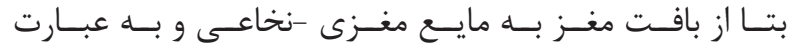

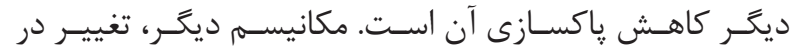

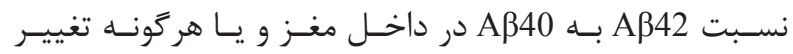

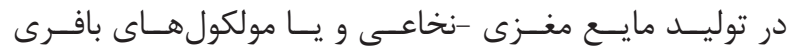

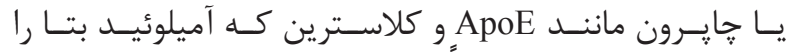

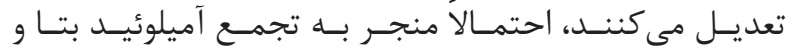

يلاكهاى آميلوئيد بتا

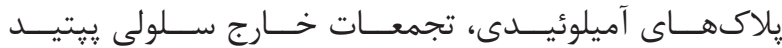

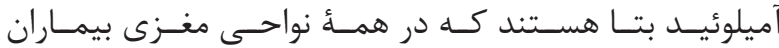

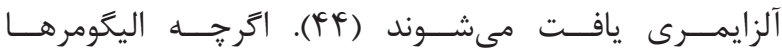

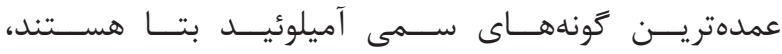

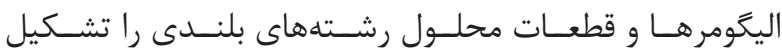

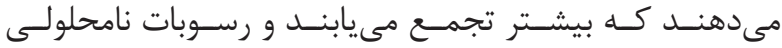

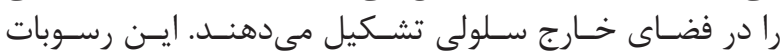

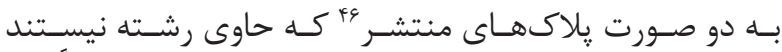

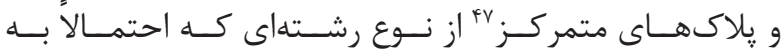

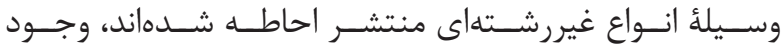

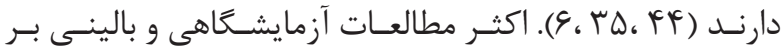

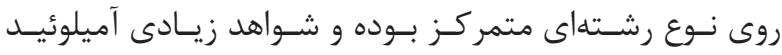

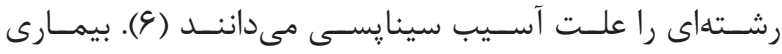

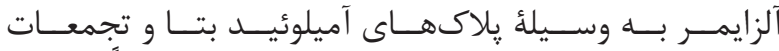

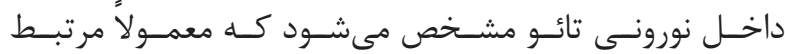

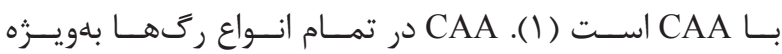

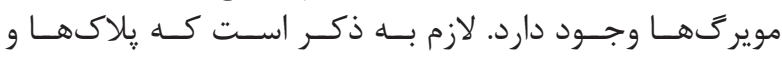

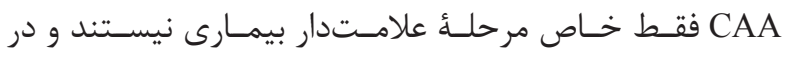

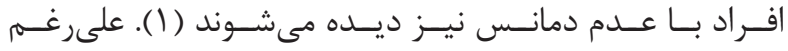

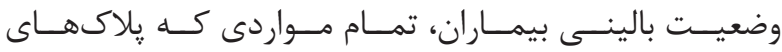

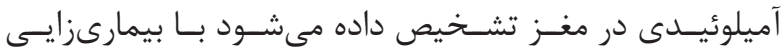

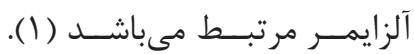

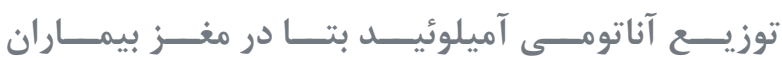

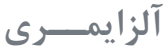

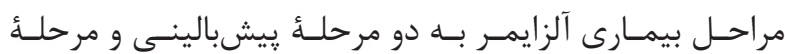

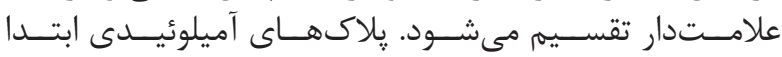

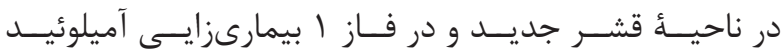

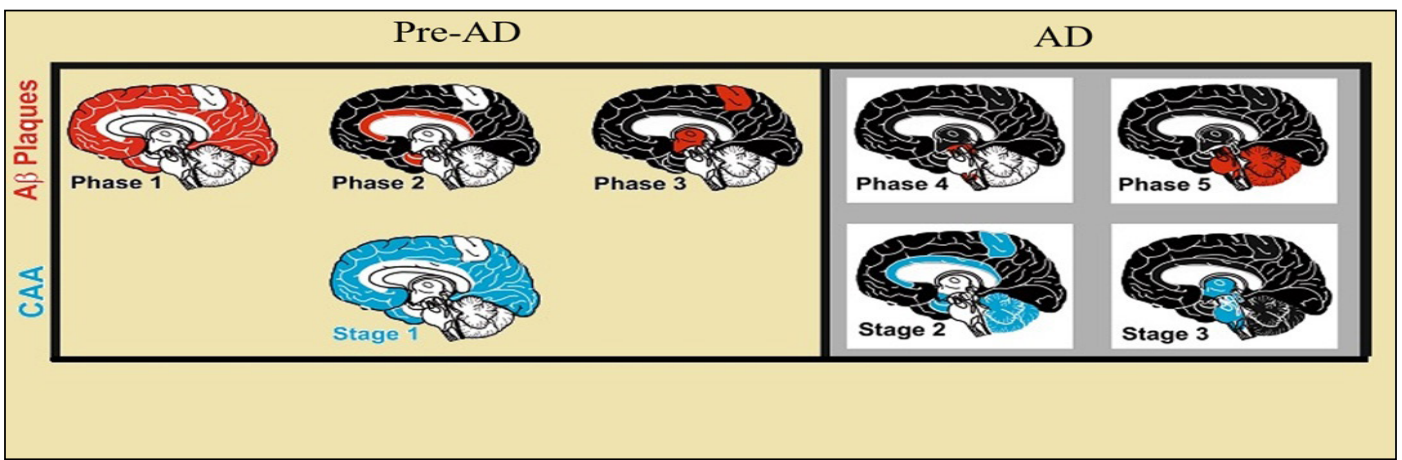

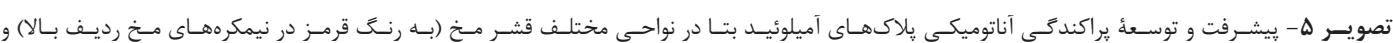

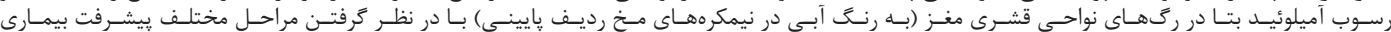

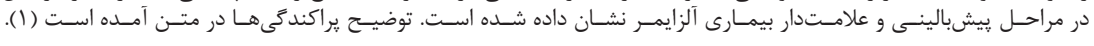

${ }^{46}$ diffuse plaques

${ }^{47}$ cored plaques

${ }^{48}$ Allocortical

${ }^{49}$ Entorhinal cortex

${ }^{50}$ Hipocompus

${ }^{51}$ Cingulate gyrus

${ }^{52}$ Striatum

${ }^{53}$ Basal forebrain

${ }^{54}$ Midbrain

\author{
${ }^{55}$ Medulla oblongata \\ ${ }^{56}$ Cerebellum \\ ${ }^{57}$ Pons \\ ${ }^{58}$ Cortical and leptomeningeal vessels \\ ${ }^{59}$ Basal ganglia \\ ${ }^{60}$ diencephalon \\ ${ }^{61}$ Brain stem \\ ${ }^{62}$ White matter
}




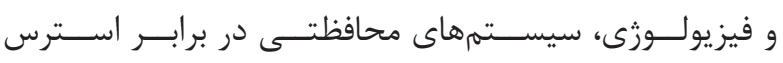

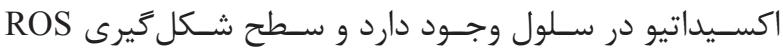

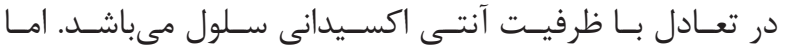

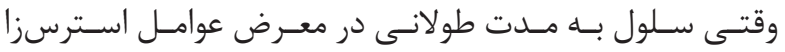

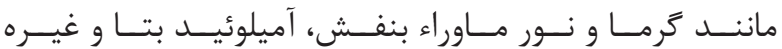

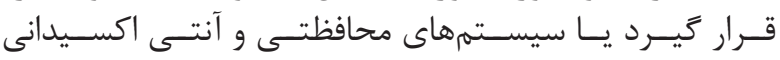

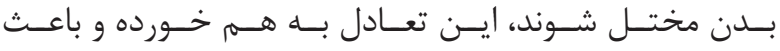

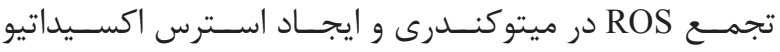

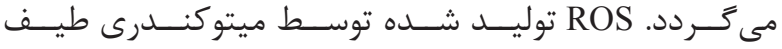

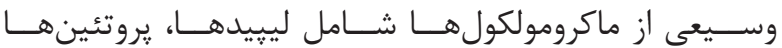

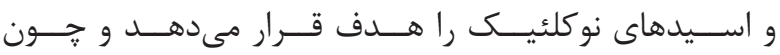

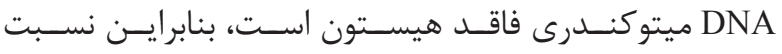

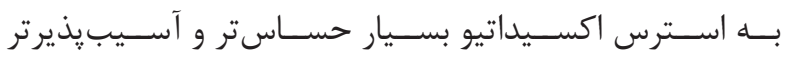

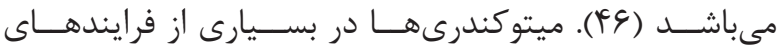

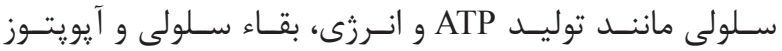

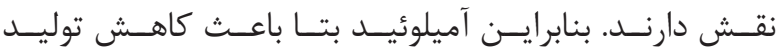

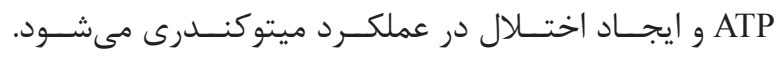

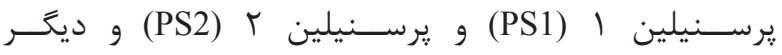

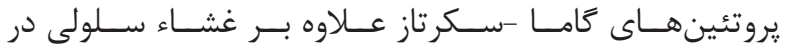

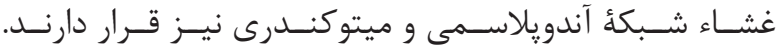

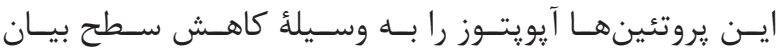

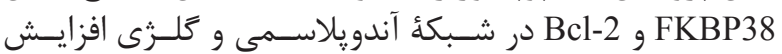

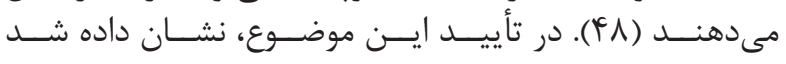

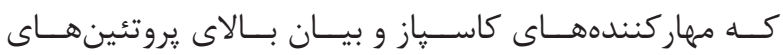

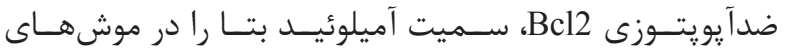

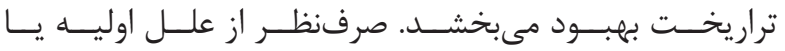

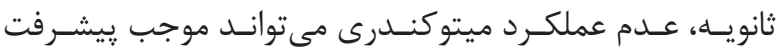

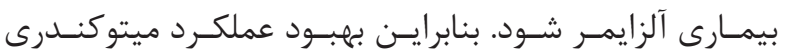

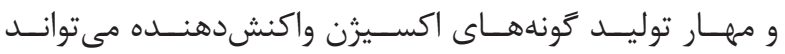

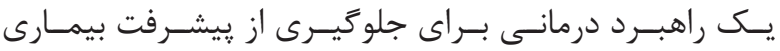

آلزايمــر باشـــ (

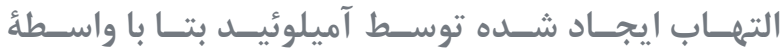

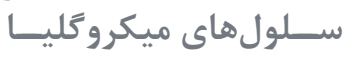

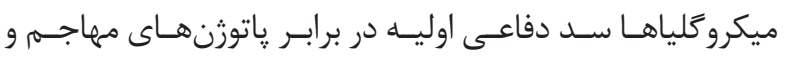

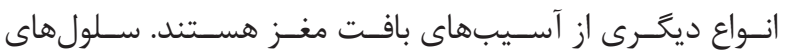

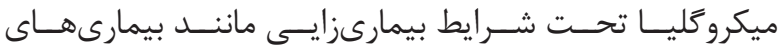

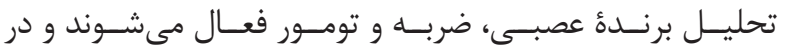

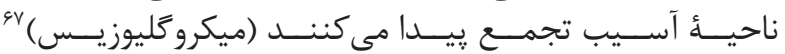

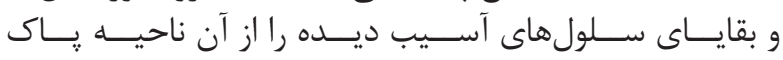

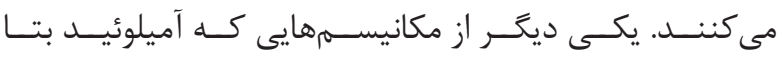

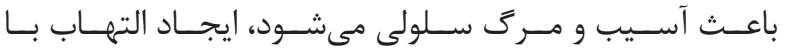

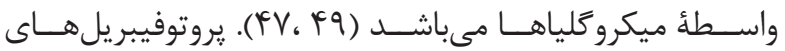

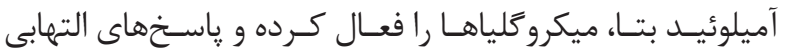

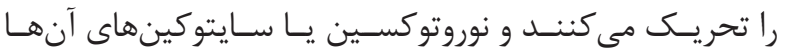

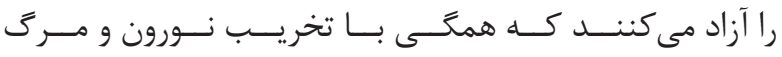

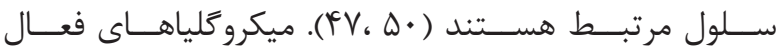

\footnotetext{
${ }^{63}$ Polyfunctional endothelial transporter proteins P- glycoprotein

${ }^{64}$ Receptor for advanced glycation endoproducts

${ }^{65}$ Low density lipoprotein- like Receptor
}

كاهـش رِاكسـازى آن در مايـع مغـزى -نخاعى مىشـود (V).

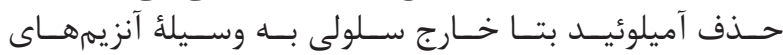

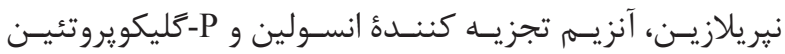

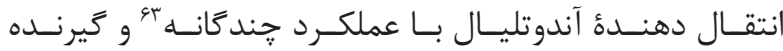

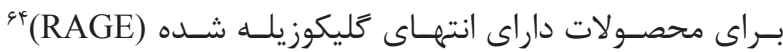

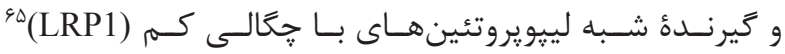

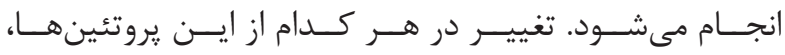

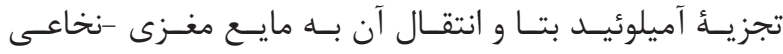

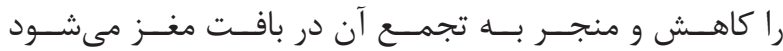

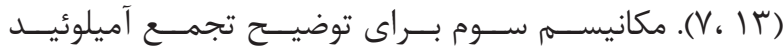

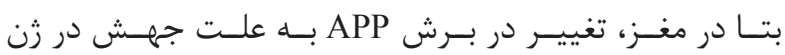

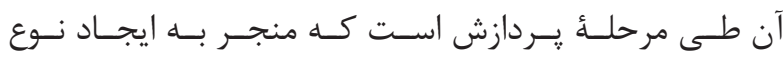

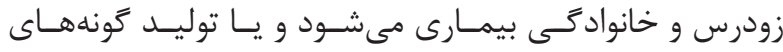

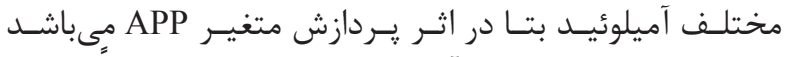

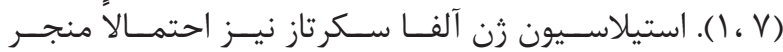

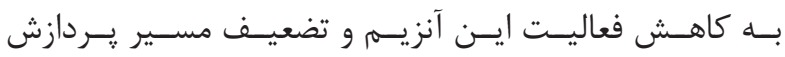

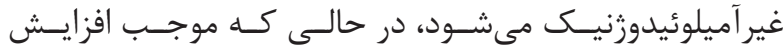

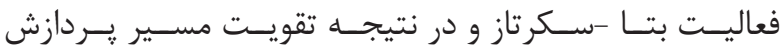

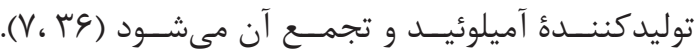

$$
\text { مكانيسم سميت آميلوئيد بتا }
$$

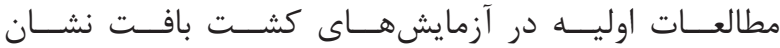

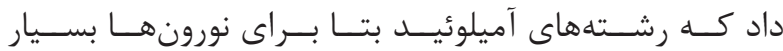

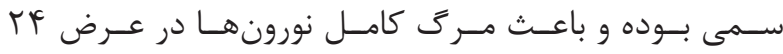

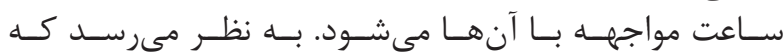

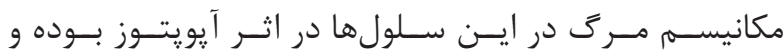

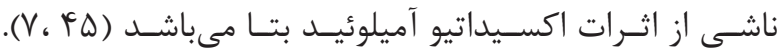

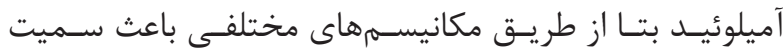

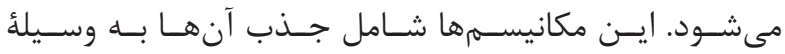

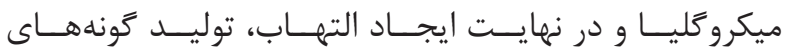

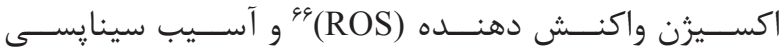

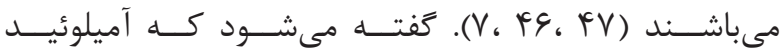

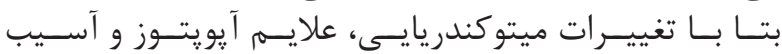

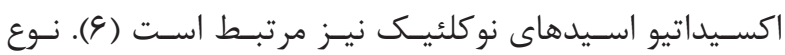

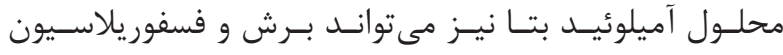

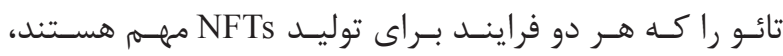

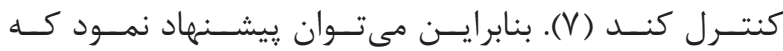

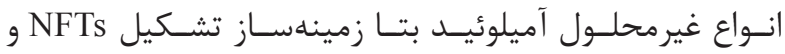

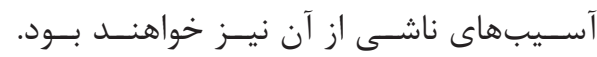

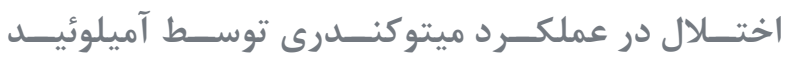
بتـا

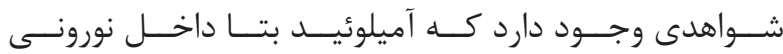

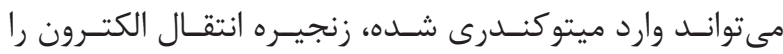

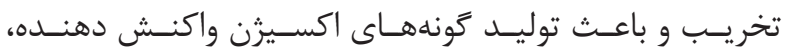

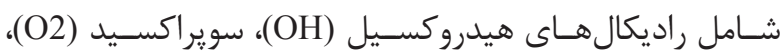

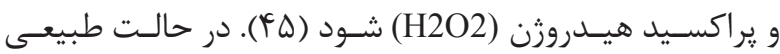

${ }^{66}$ Reactive Oxygen Species

${ }^{67}$ Microglyosis 


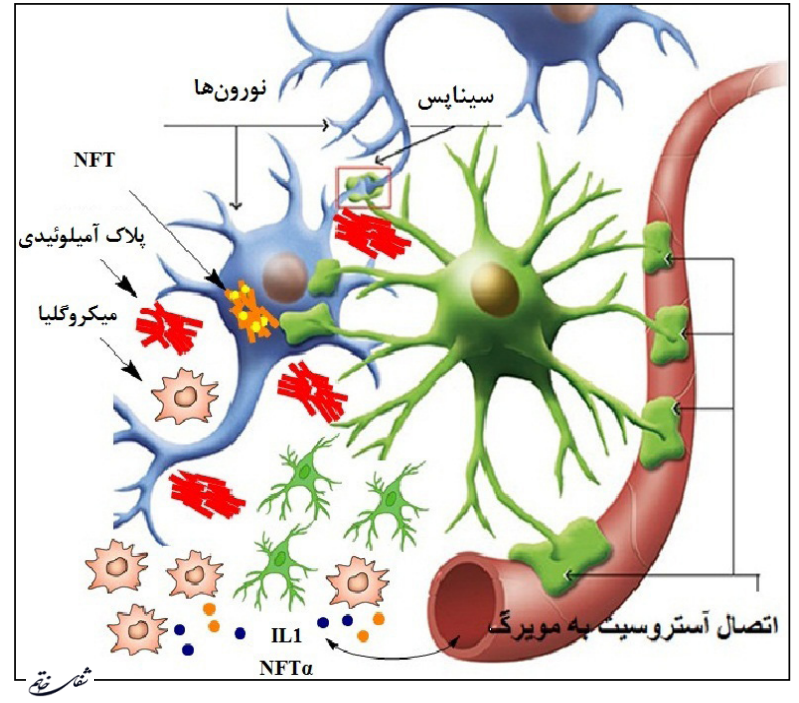

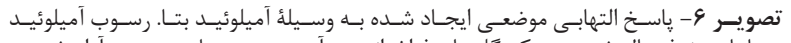

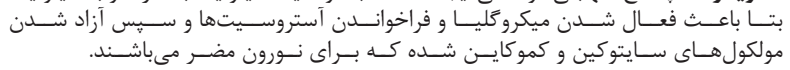

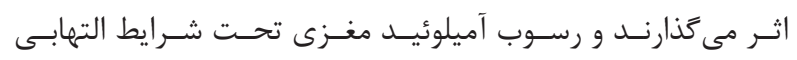

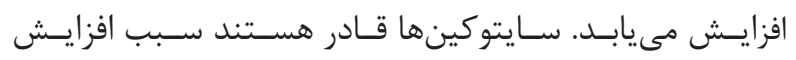

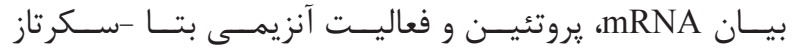

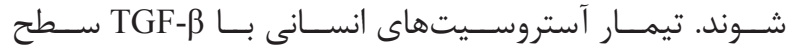

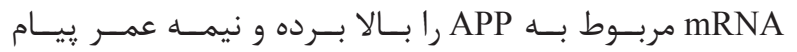

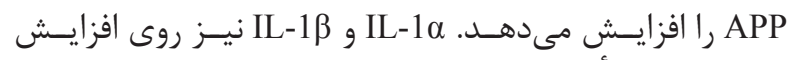

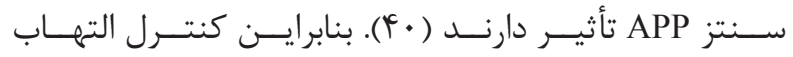

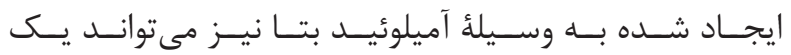

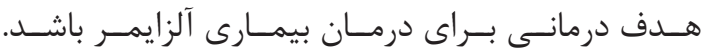

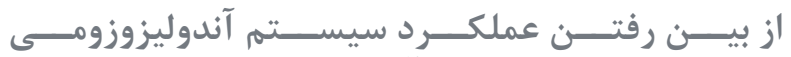

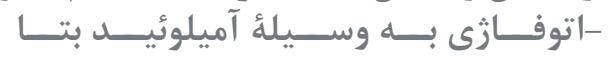

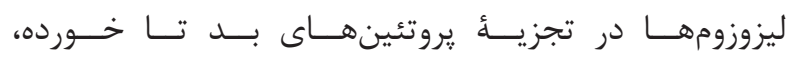

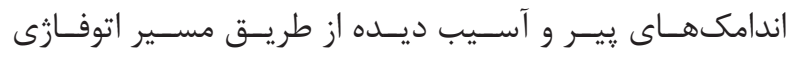

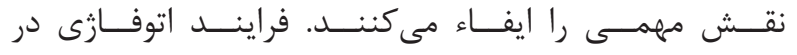

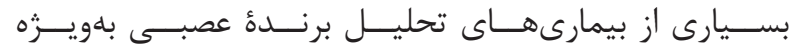

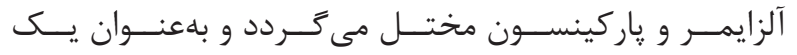

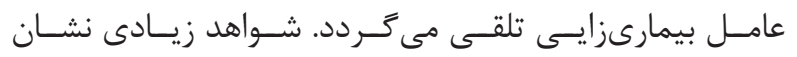

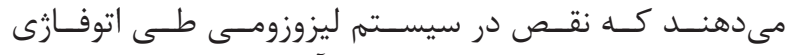

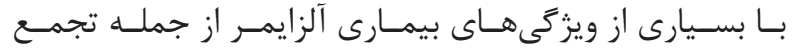

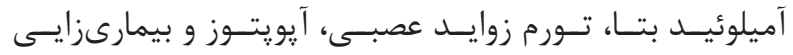

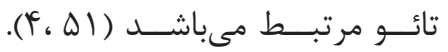

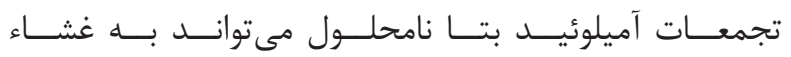

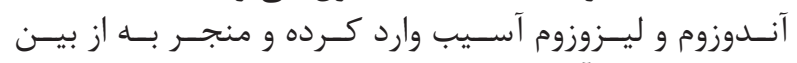

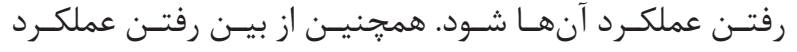

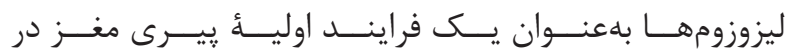

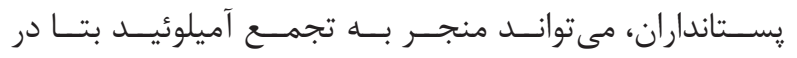

\footnotetext{
${ }^{68}$ Major Histocompatibility Complex

${ }^{69}$ Extracellular signal-regulated kinase

${ }^{70}$ Brain- derived neurotrophic factor
}

${ }^{71}$ Excitotoxicity

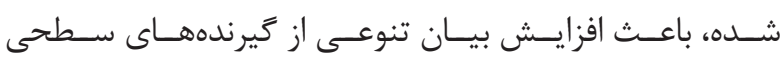

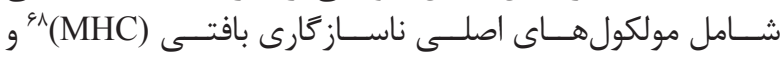

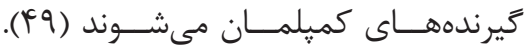

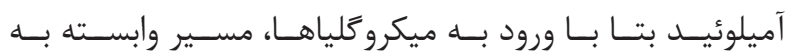

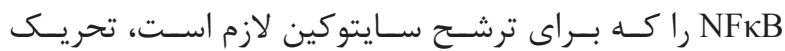

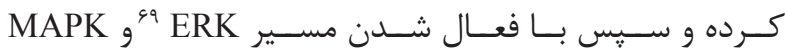

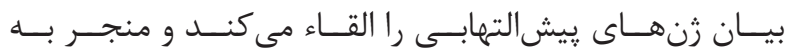

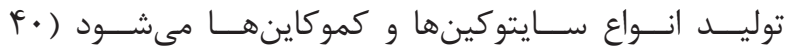

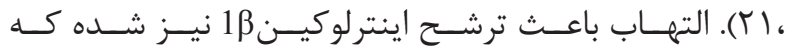

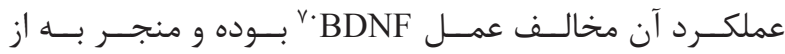

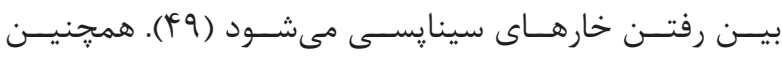
مترشـا TNFa

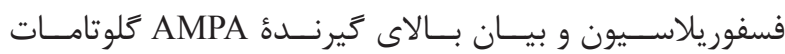

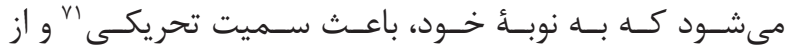

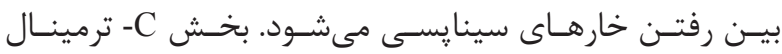

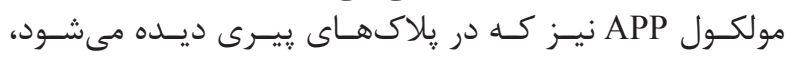

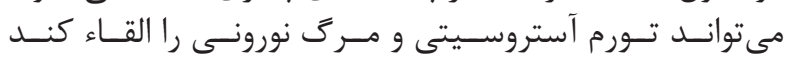

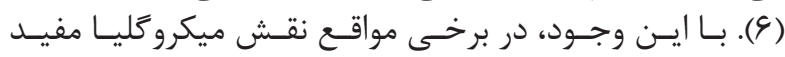

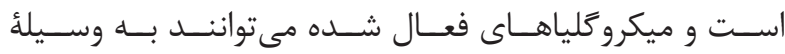

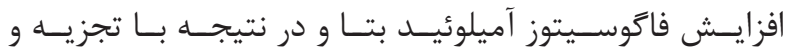

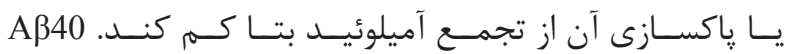

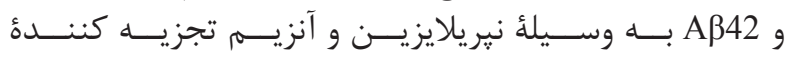

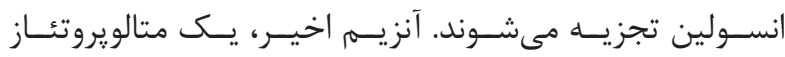

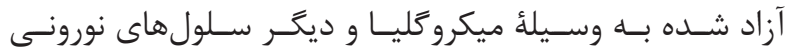

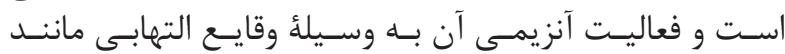

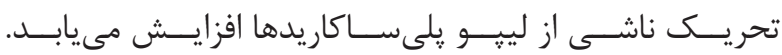

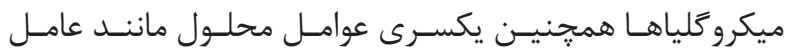

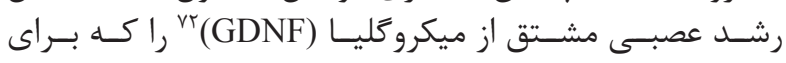

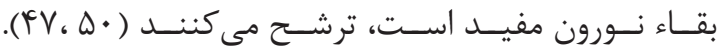

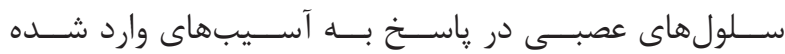

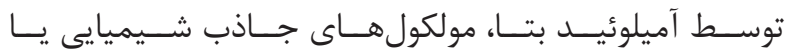

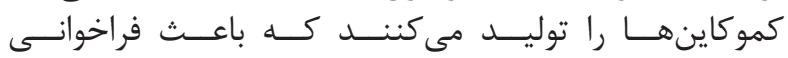

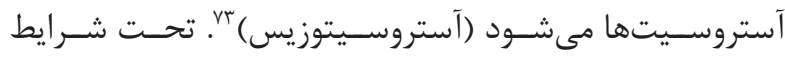

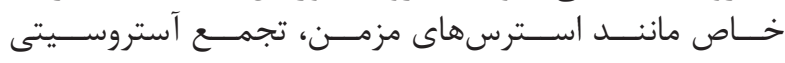

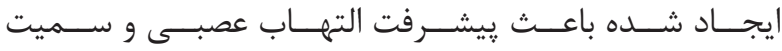

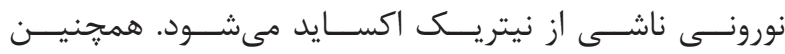

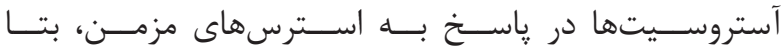

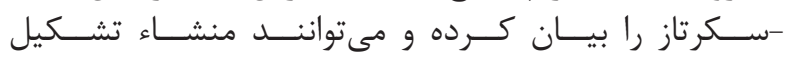

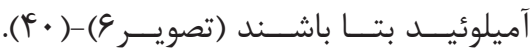

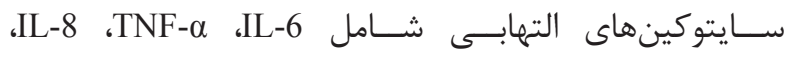
TGF- $\beta$

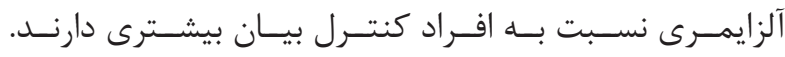

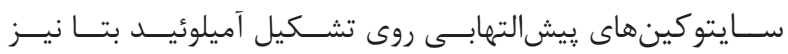

\footnotetext{
${ }^{72}$ Glial-derived neurotrophic factor

${ }^{73}$ Astrocytosis

${ }^{74}$ Macrophage inflammatory protein- $1 \alpha$ (MIP- $1 \alpha$ )
} 


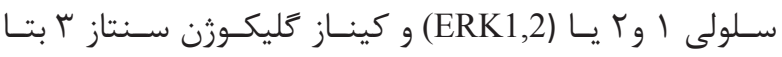

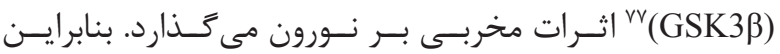

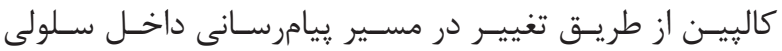

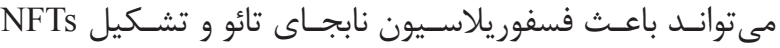

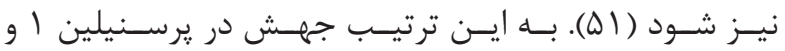

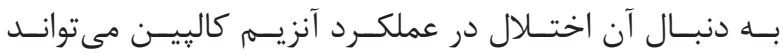

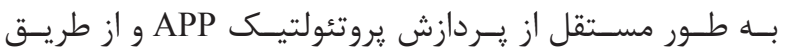

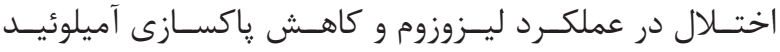

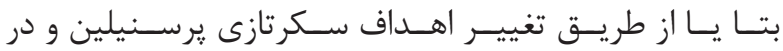

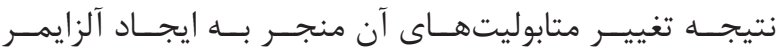

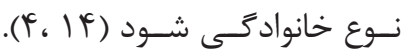
يروتئين تائو و نقش آن در بيمارى آلزايمر

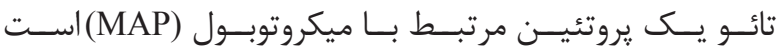

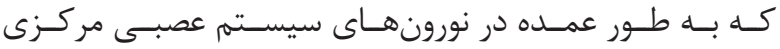

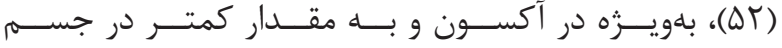

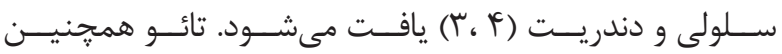

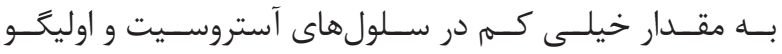

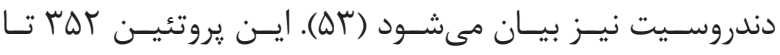

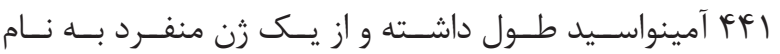

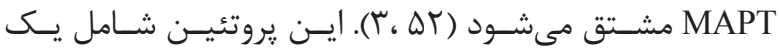

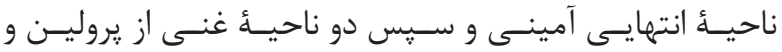

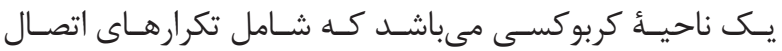

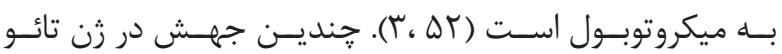

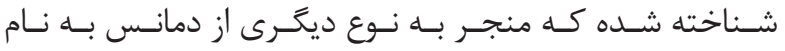

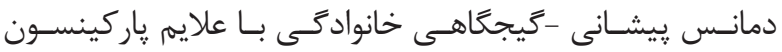

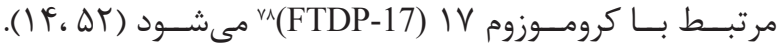

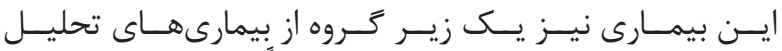

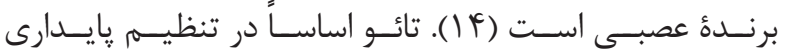

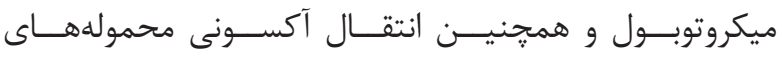

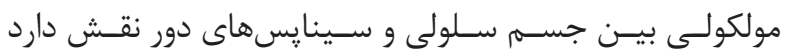

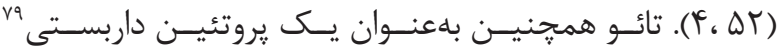

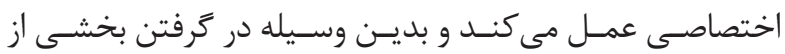

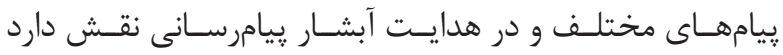

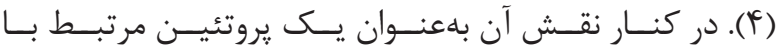

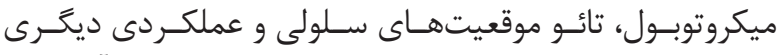

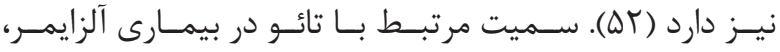

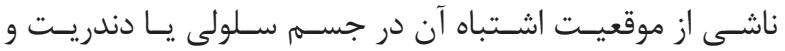

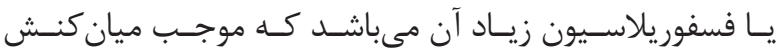

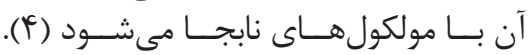

$$
\text { فسفوريلاسيون تائو }
$$

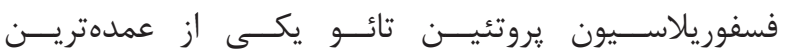

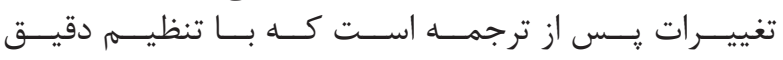

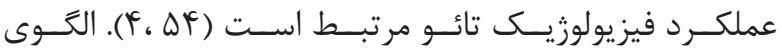

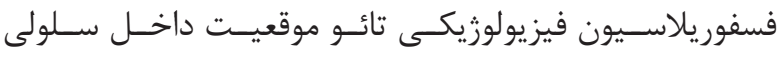

${ }^{75}$ Calpain

${ }^{76}$ Cycline depenedent kinase 5

${ }^{77}$ Glycogen synthase kinase- 3 beta

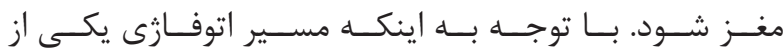

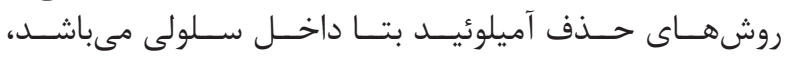

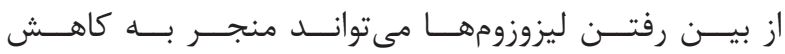

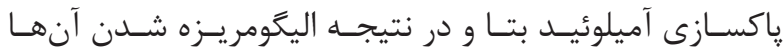

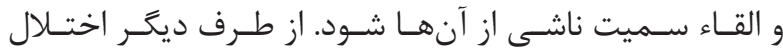

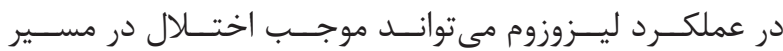

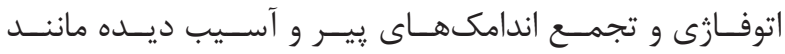

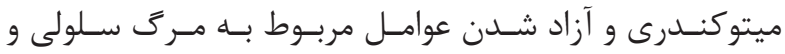

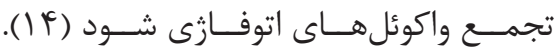

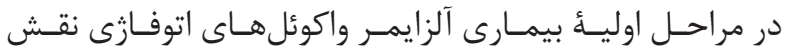

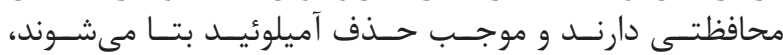

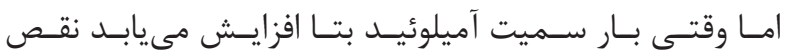

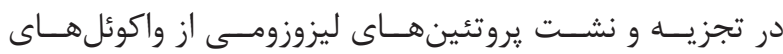

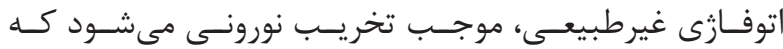

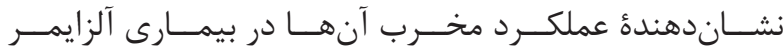

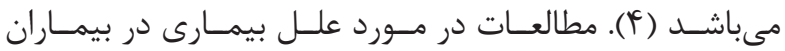

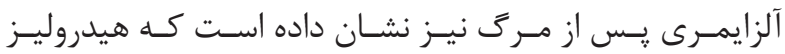

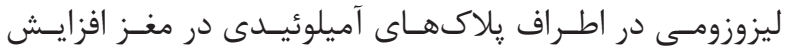

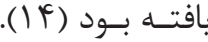

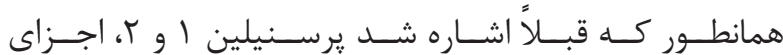

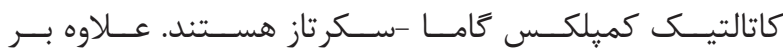

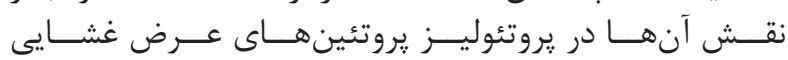

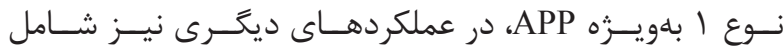

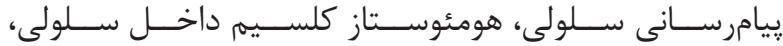

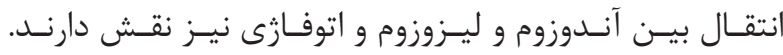

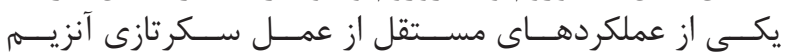

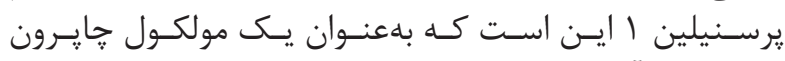

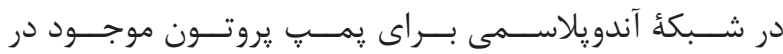

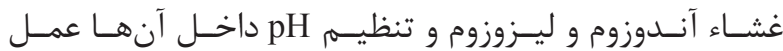

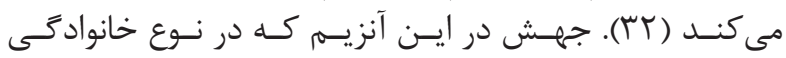

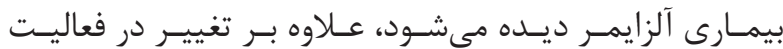

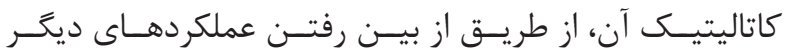

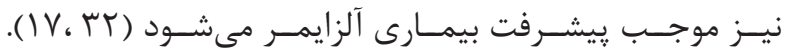

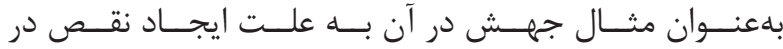

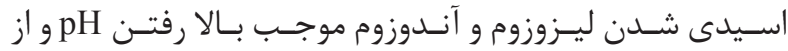

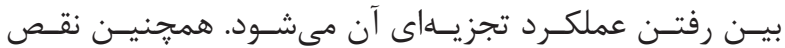

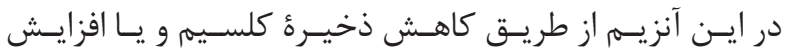

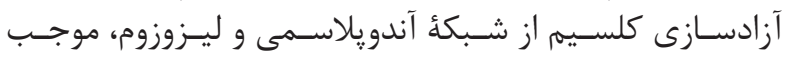

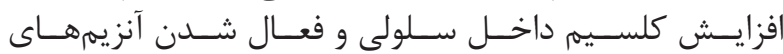

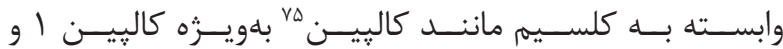

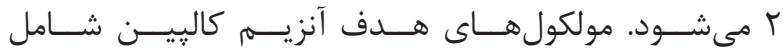

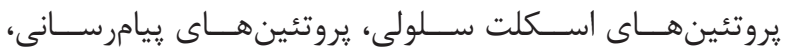

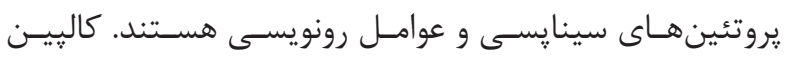

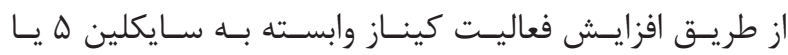
CDK5

${ }^{78}$ Frontotemporal dementia with parkinsonism linked to chromosome 17

${ }^{79}$ Scaffold protein 


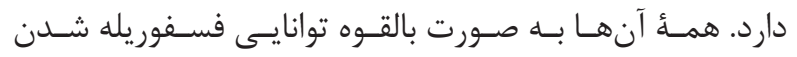

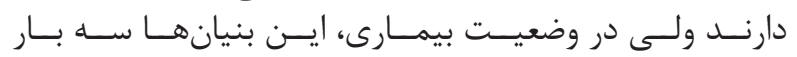

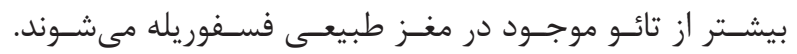

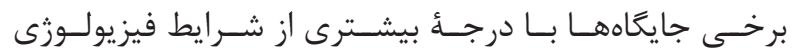

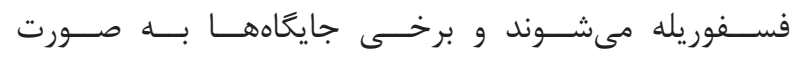

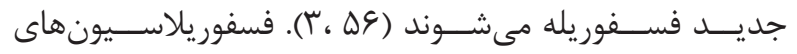

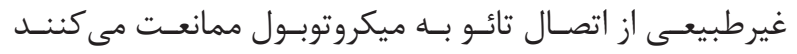

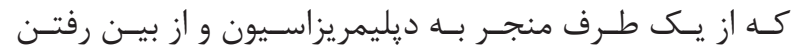

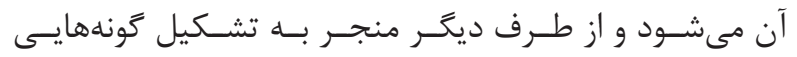

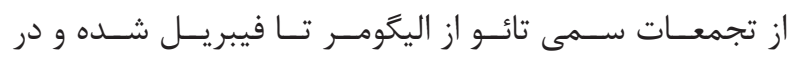

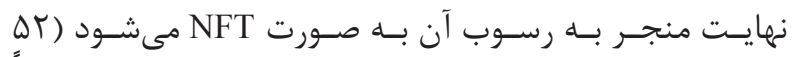

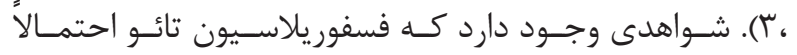

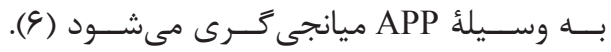

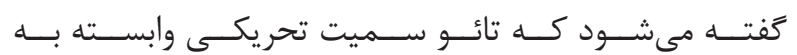

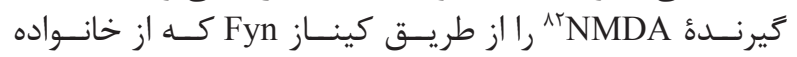

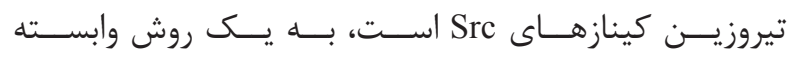

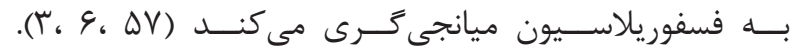

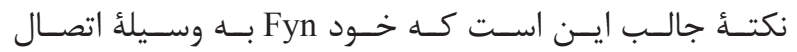

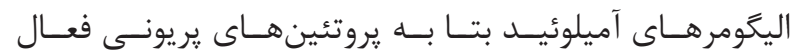

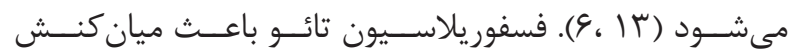

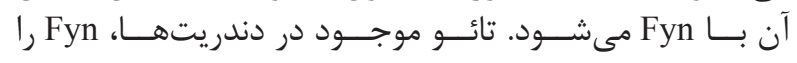

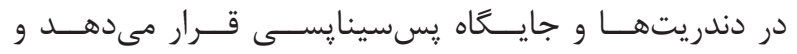

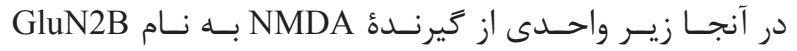

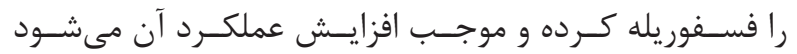

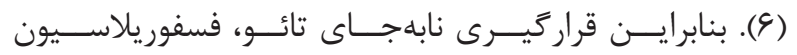

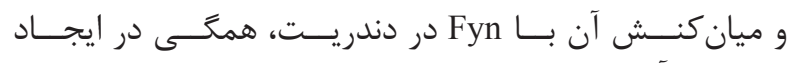

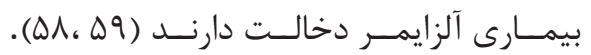

$$
\text { مكانيسمهاى هاييرفسفوريلاسيون بروتئين تائو }
$$

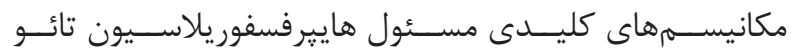

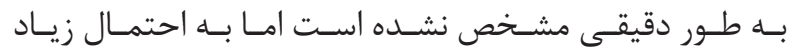

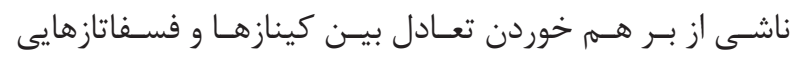

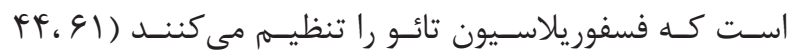

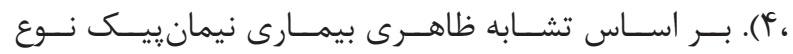

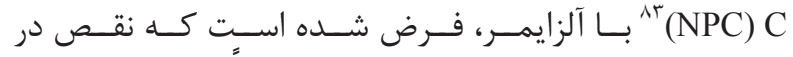

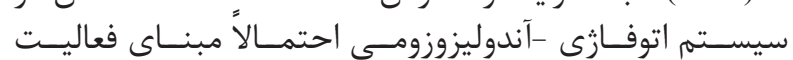

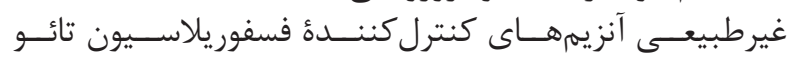

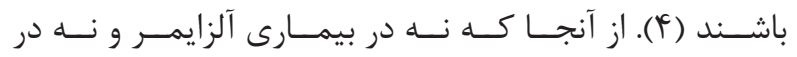

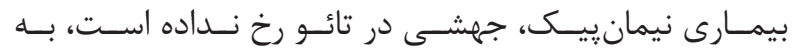

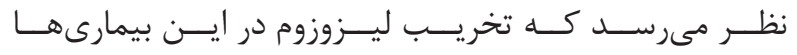

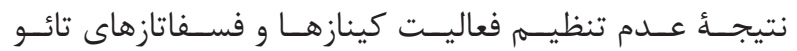

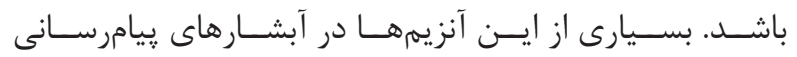

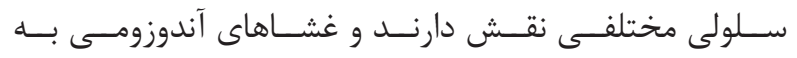

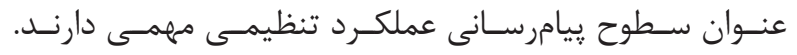

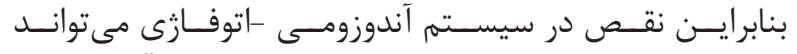

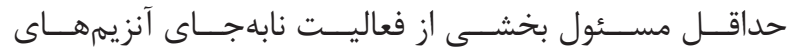

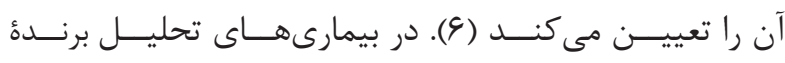

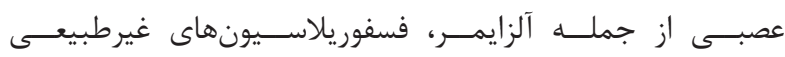

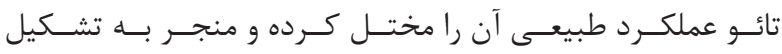

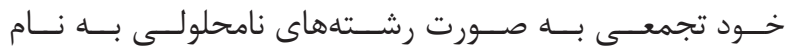

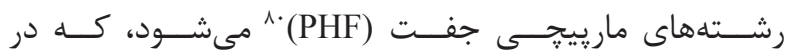

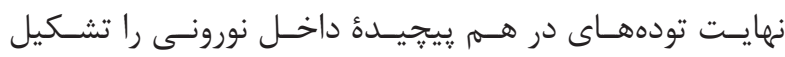

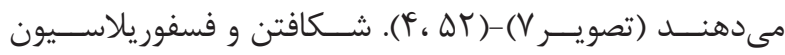

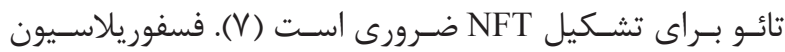

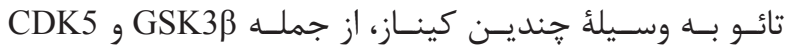

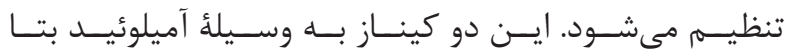

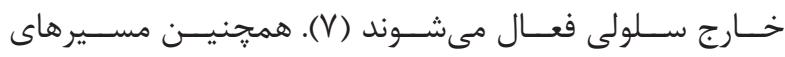

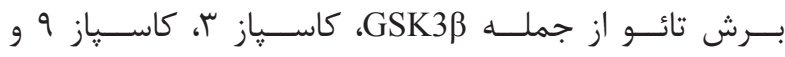

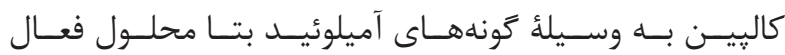

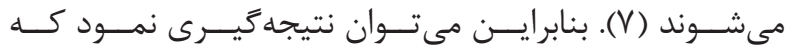

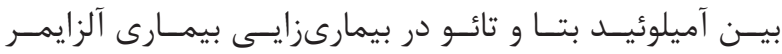

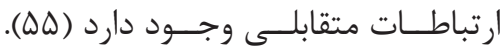

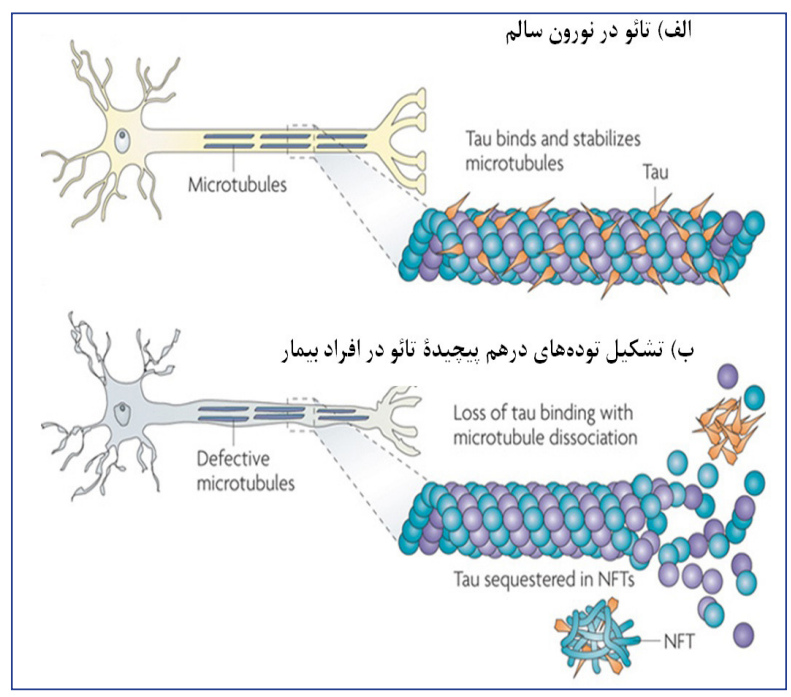

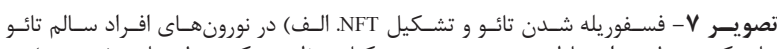

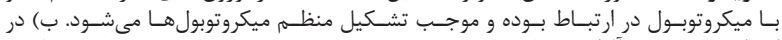

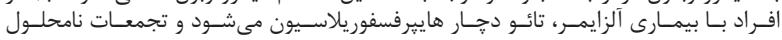

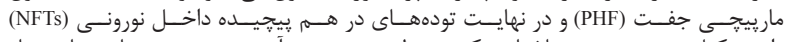

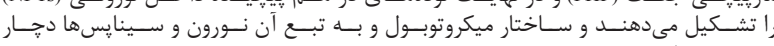

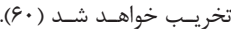

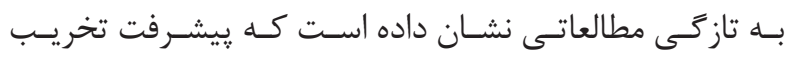

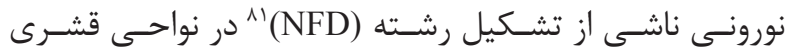

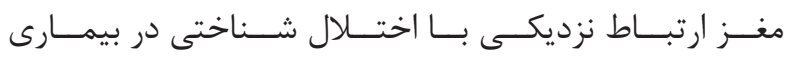

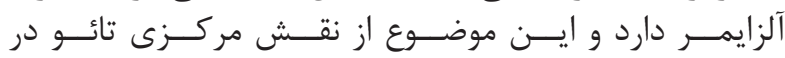

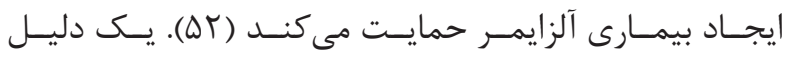

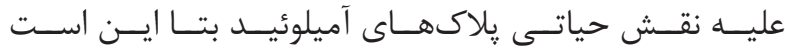

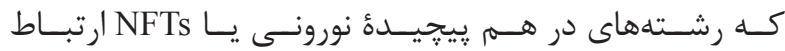

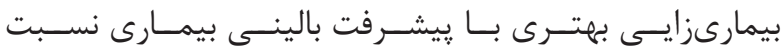

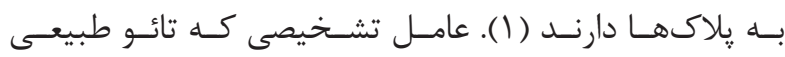

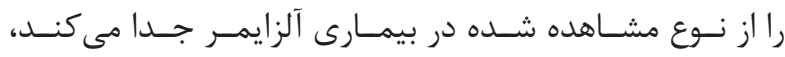

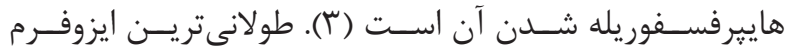

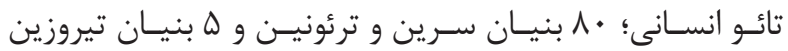

\footnotetext{
${ }^{82} \mathrm{~N}$-methyl D-aspartate receptor

${ }^{83}$ Niemann picks disease type-C
} 


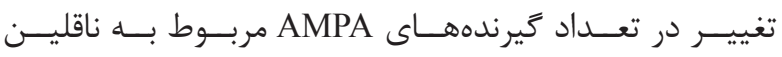

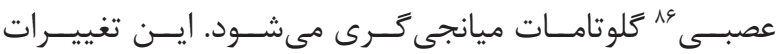

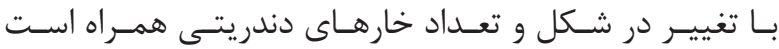

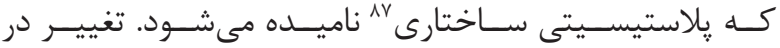

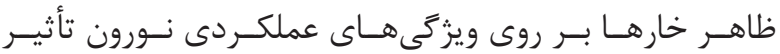

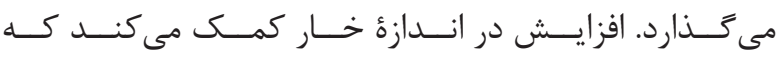

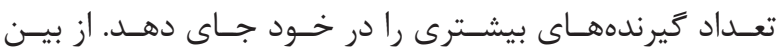

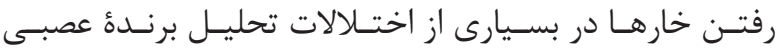

ديسـده مىشـــون (9).

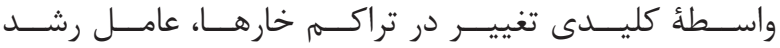

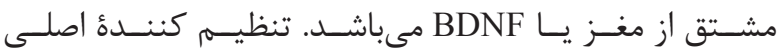

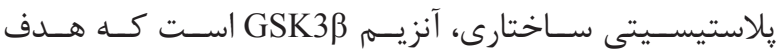

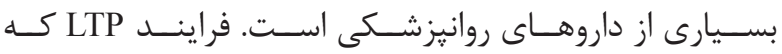

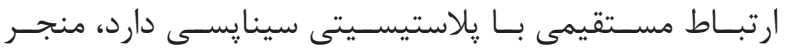

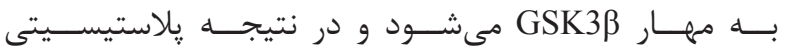

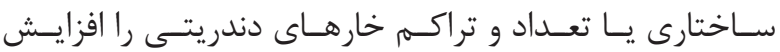

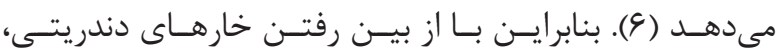

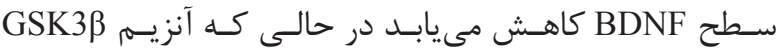

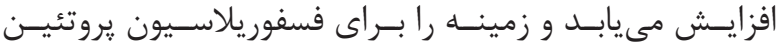

$$
\text { تائـو نيـز مهيــا مى كنــد. }
$$

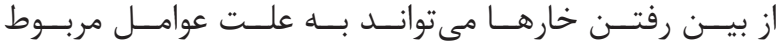

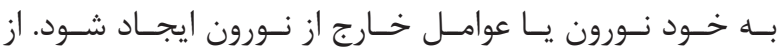

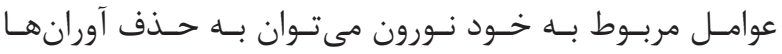

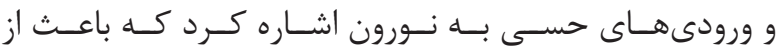

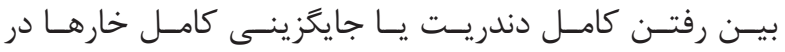

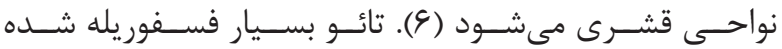

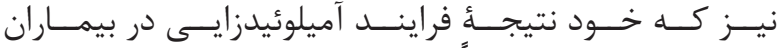

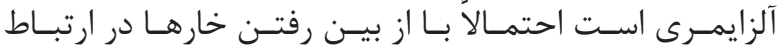

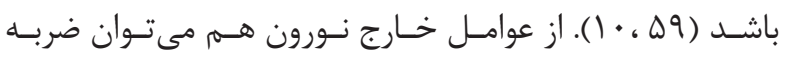

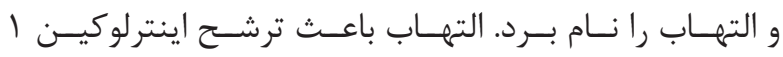

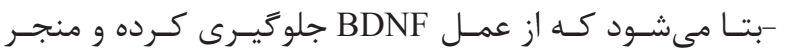

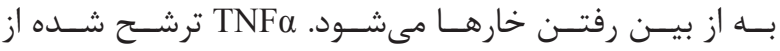

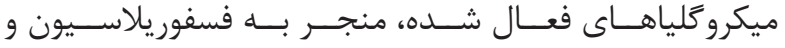

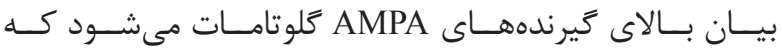

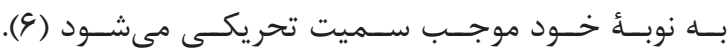

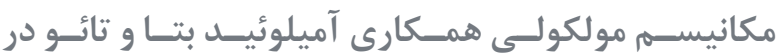
بيمــارى آلزايمر

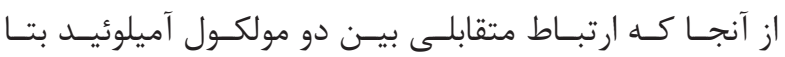

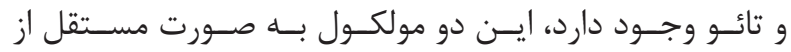

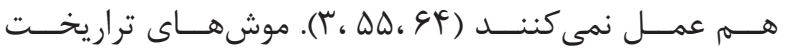

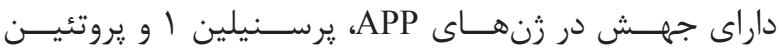

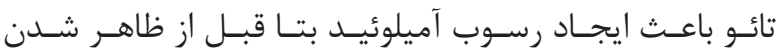

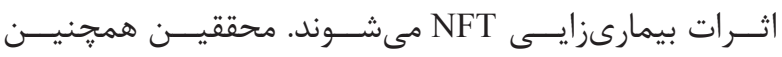

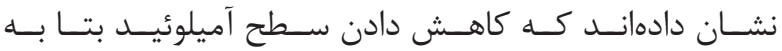

${ }^{84}$ Temporal lobe amnesias

${ }^{85}$ Bilateral hippocampal damage
كنترل كنــــــ فسفوريلاسـيون تائـو باشــد (AF).

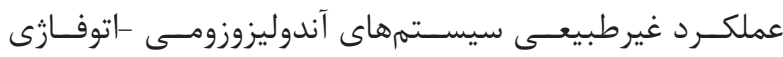

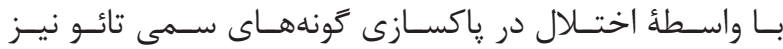

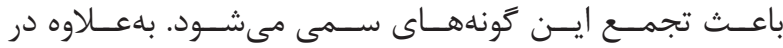

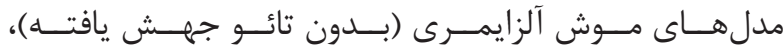

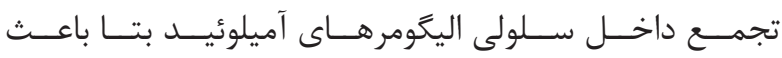

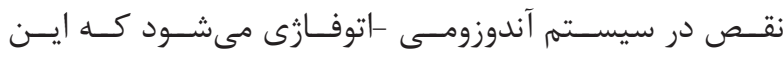

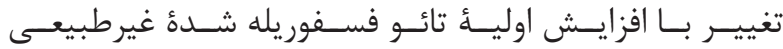

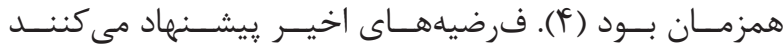

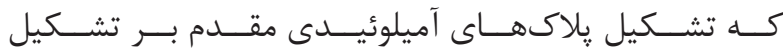

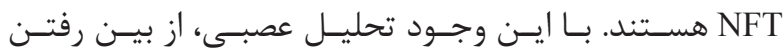

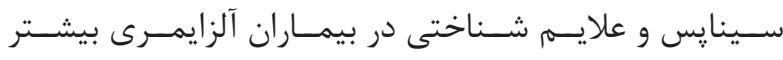

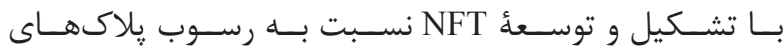

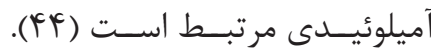

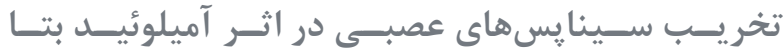
و تائسو

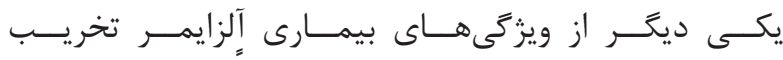

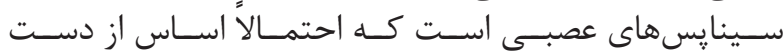

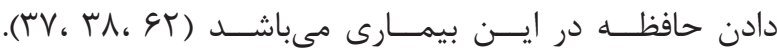

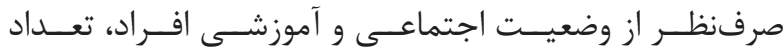

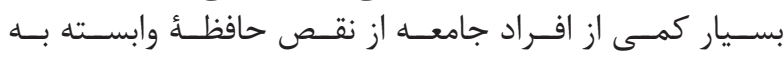

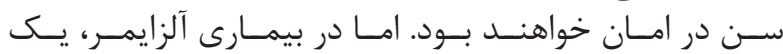

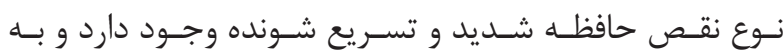

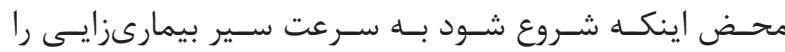

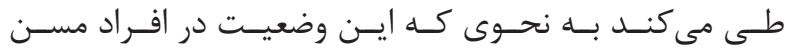

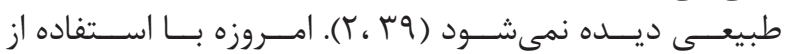

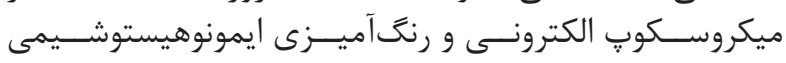

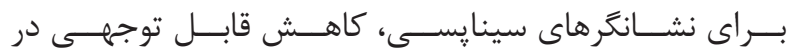

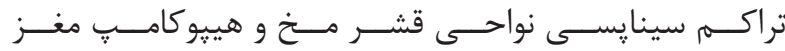

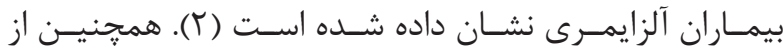

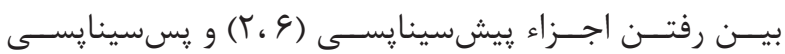

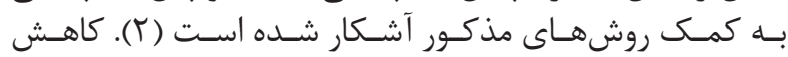

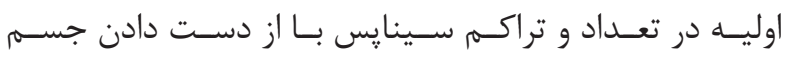

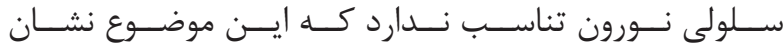

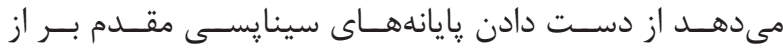

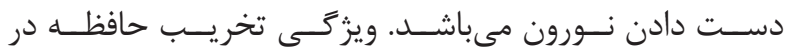

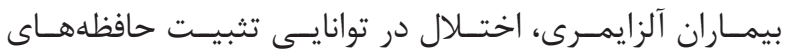

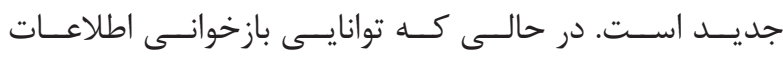

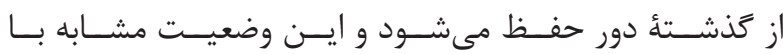

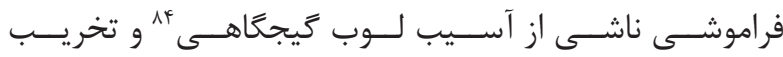

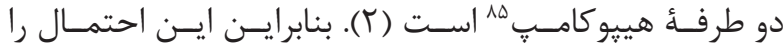

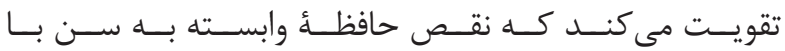

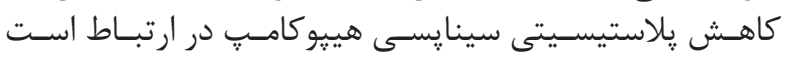

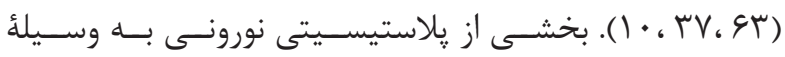

\footnotetext{
${ }^{86}$ Neurotransmitter

${ }^{87}$ Structural plastisity
} 


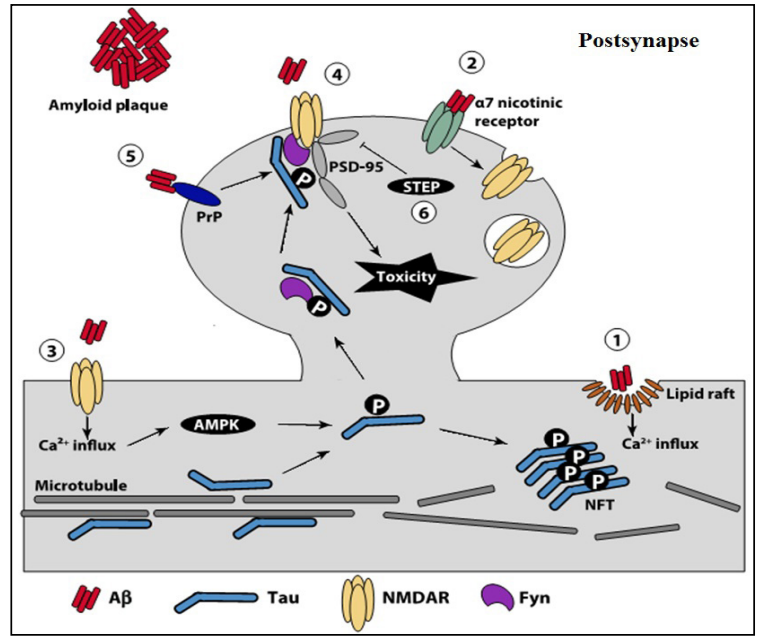

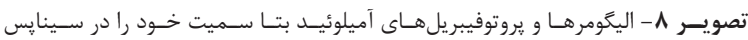

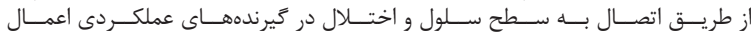

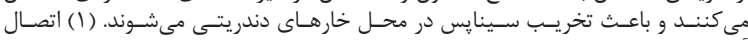

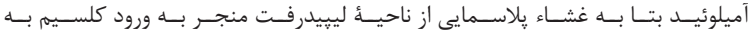

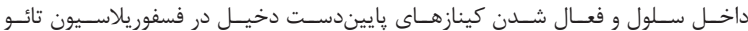

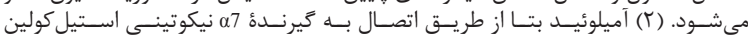

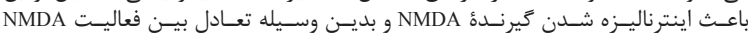

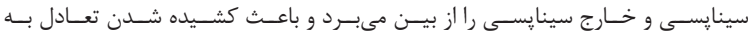

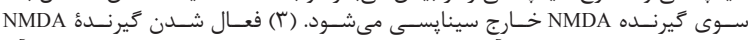

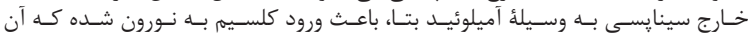

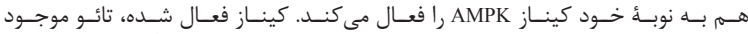

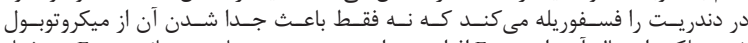

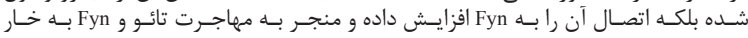

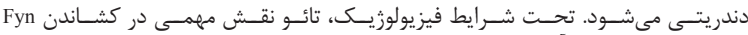

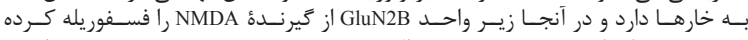

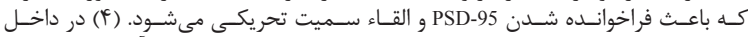

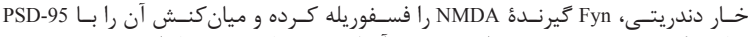

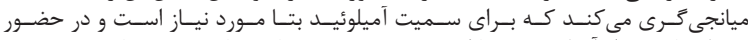

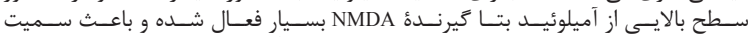

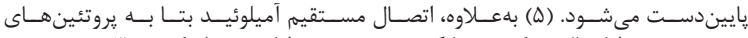

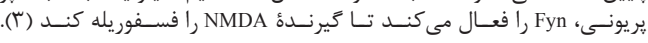

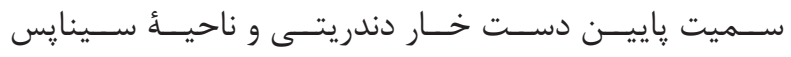

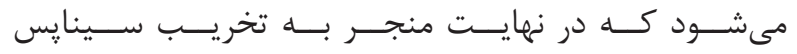

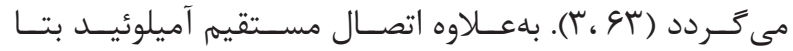

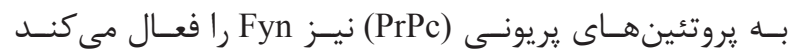

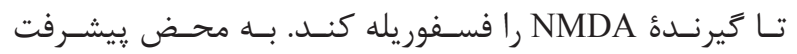

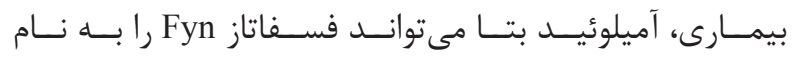

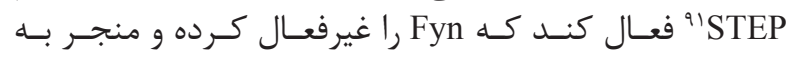

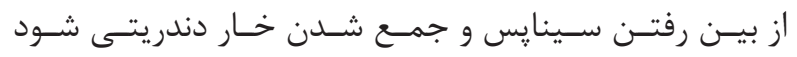

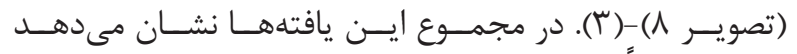

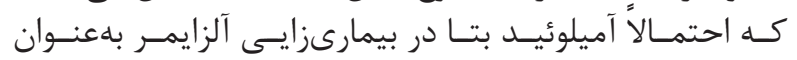

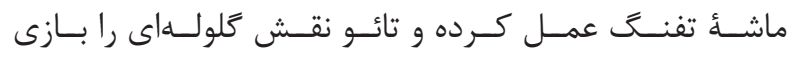

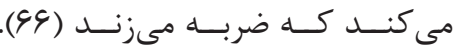

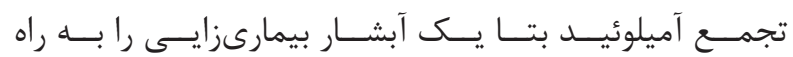

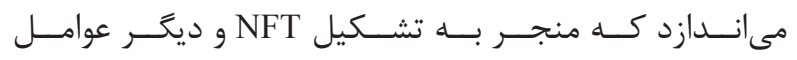

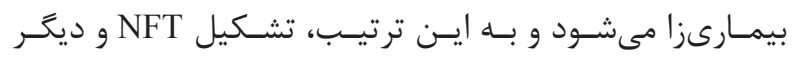

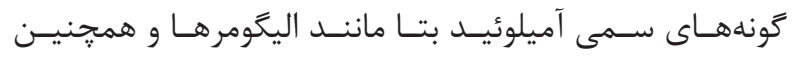

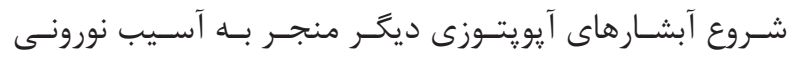

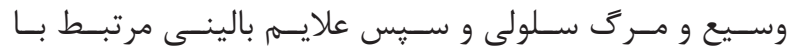

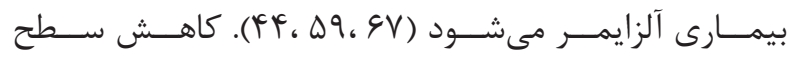

${ }^{88}$ Lipid raft

${ }^{89}$ Adenosine monophosphate-activated protein kinase

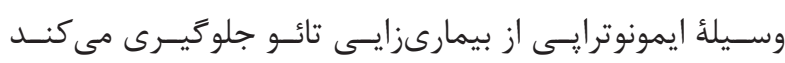

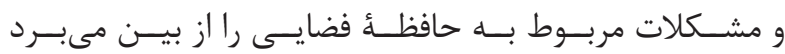

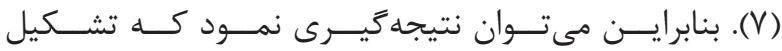

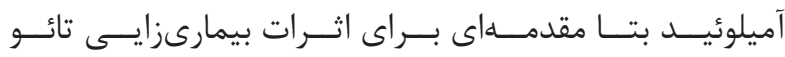

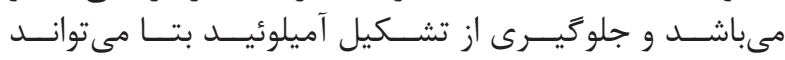

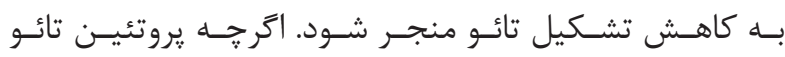

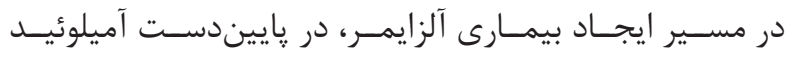

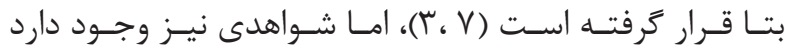

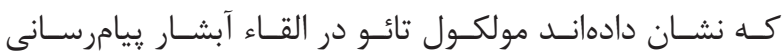

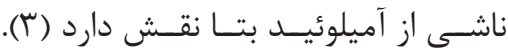

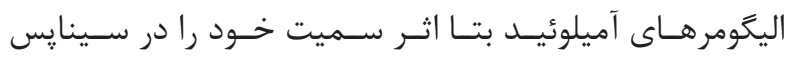

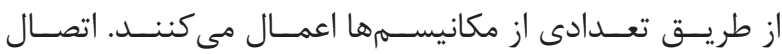

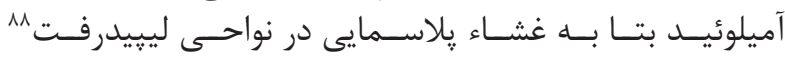

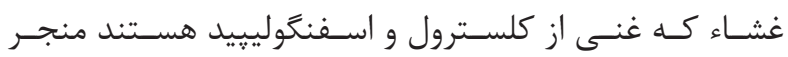

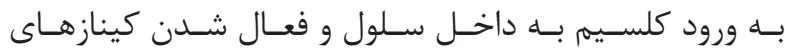

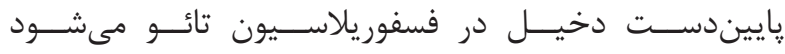

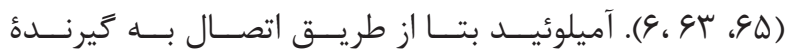

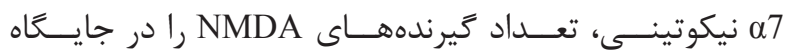

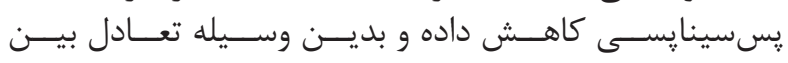

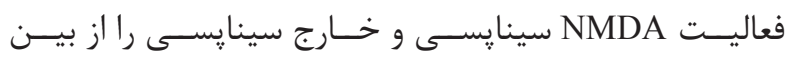

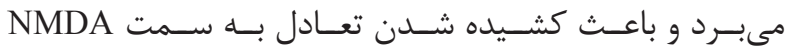

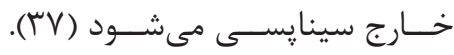

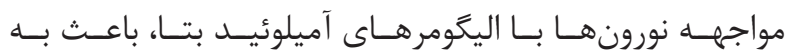

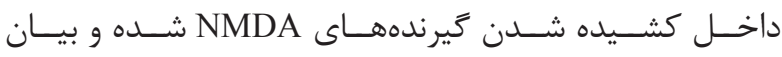

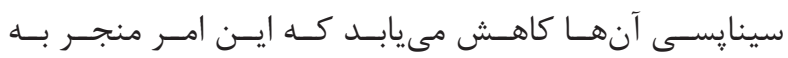

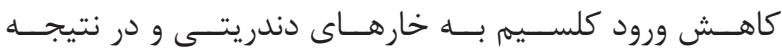

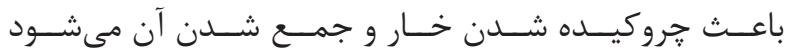

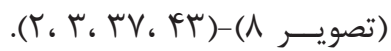

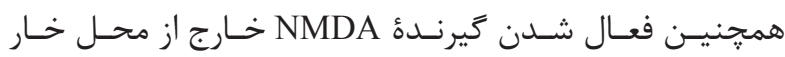

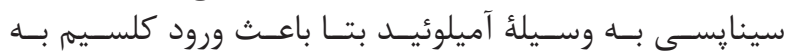

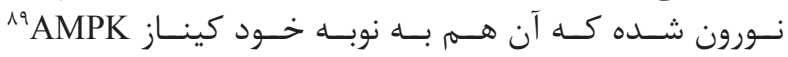

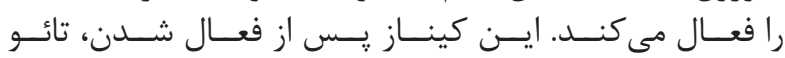

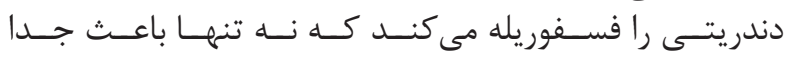

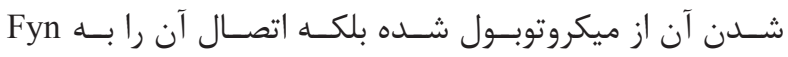

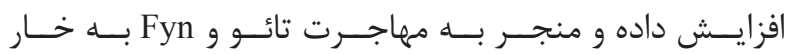

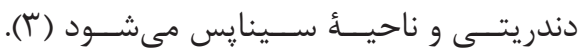

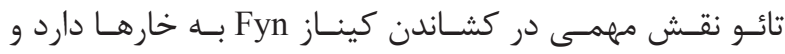

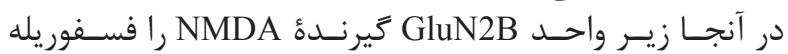

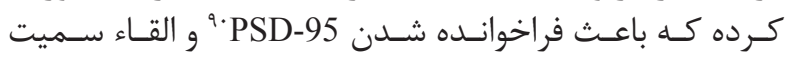

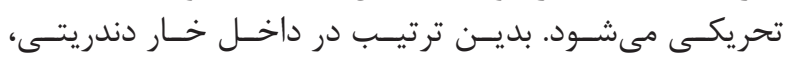

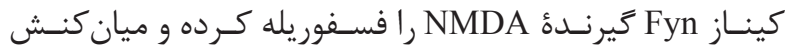

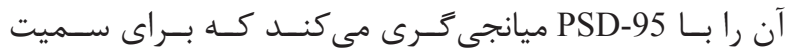

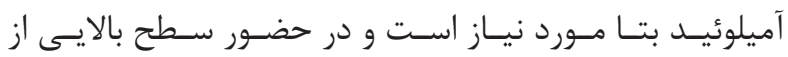

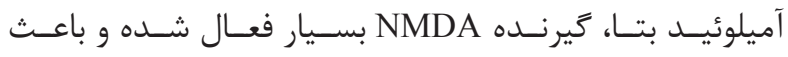

${ }^{90}$ Post-synaptic density-95

${ }^{91}$ Striatal enriched phosphatase 


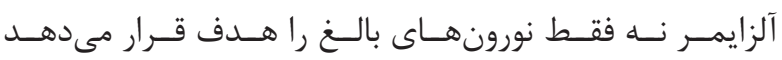

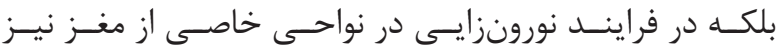

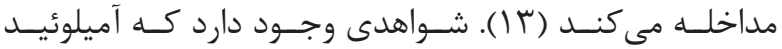

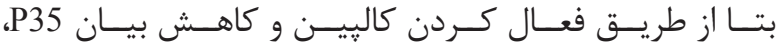

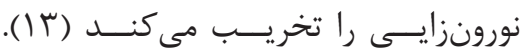
علايم بالينى و تشخيص بيمارى آلزايمر

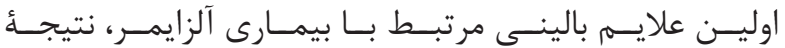

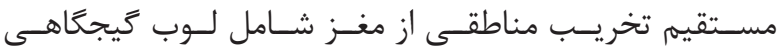

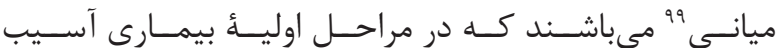

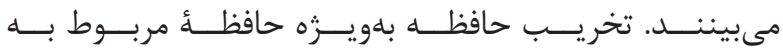

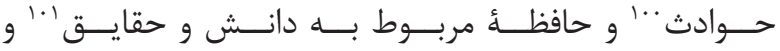

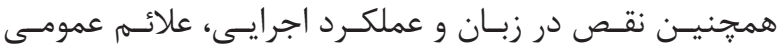

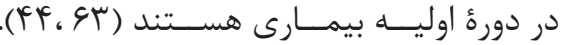

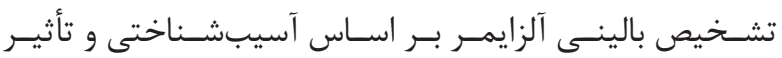

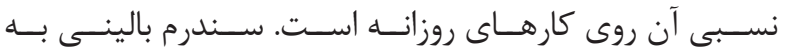

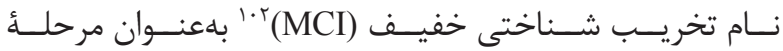

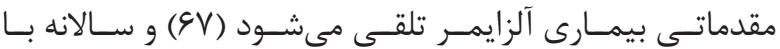

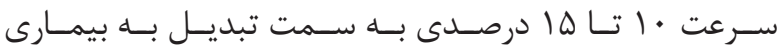

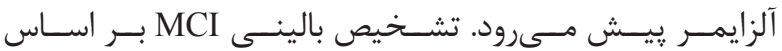

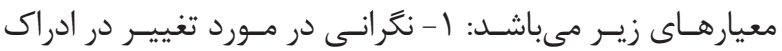

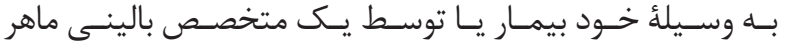

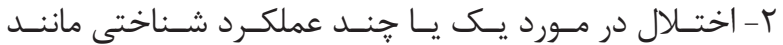

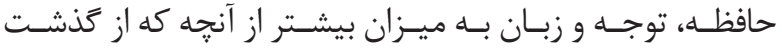

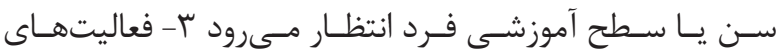

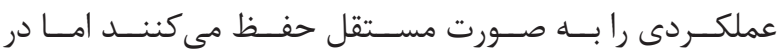

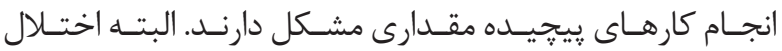

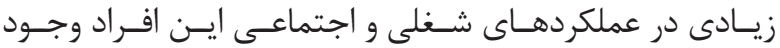

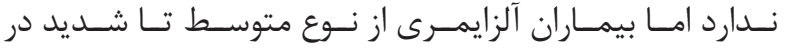

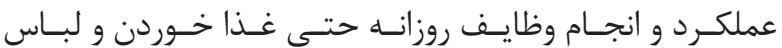

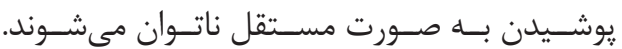

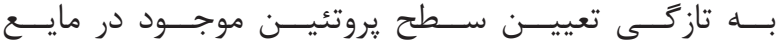

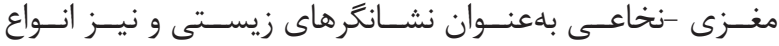

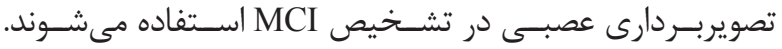

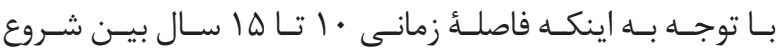

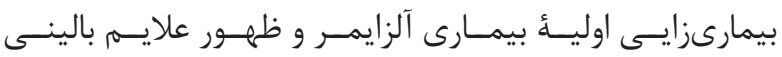

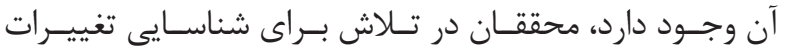

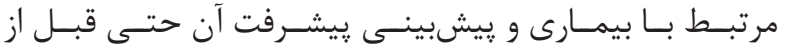

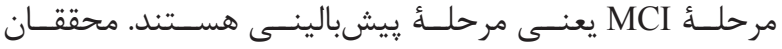

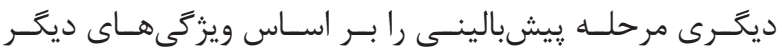

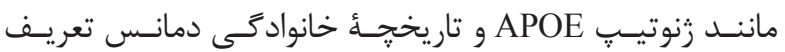

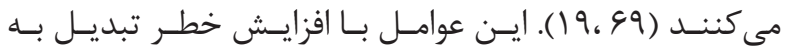

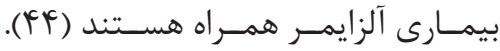

\footnotetext{
${ }^{92}$ Olfactory bulbs

${ }^{93}$ Sub-ventricular zone

${ }^{94}$ Hippocampal dentate gyrus

${ }^{95}$ Nestin

${ }^{96}$ Synapsin

${ }^{97}$ Axonal growth cone
}

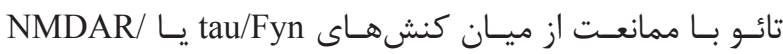

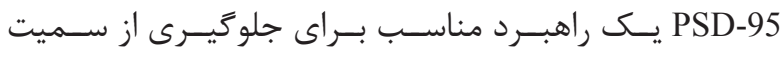

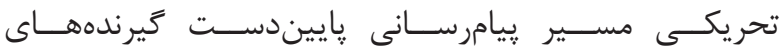
NMDA

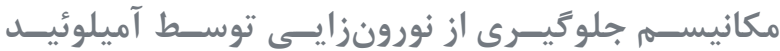

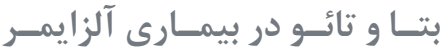

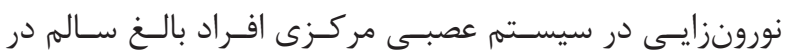

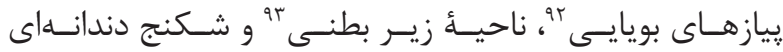

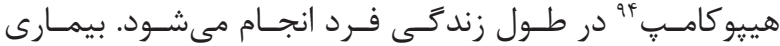

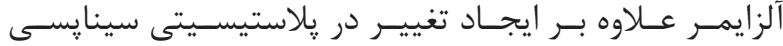

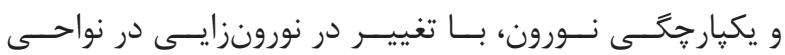

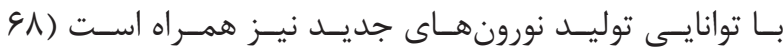

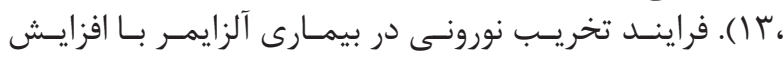

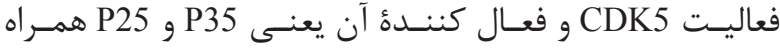

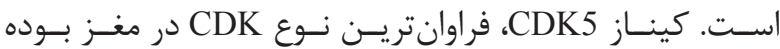

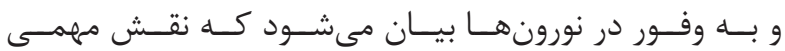

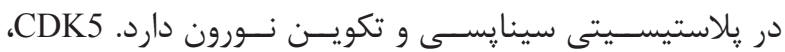

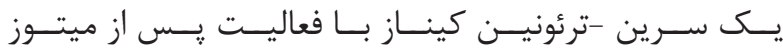

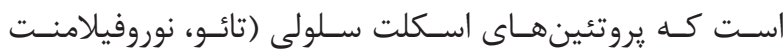

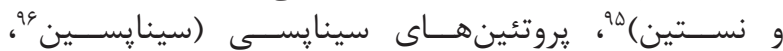

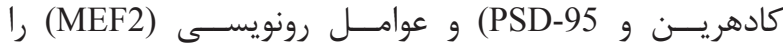

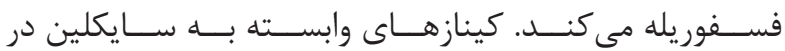

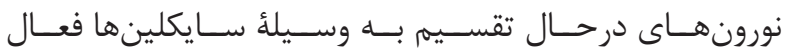

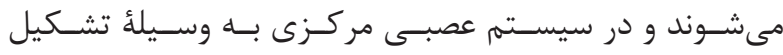

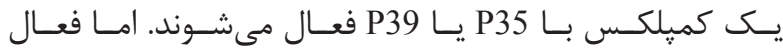

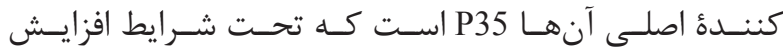

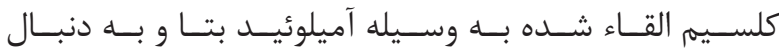

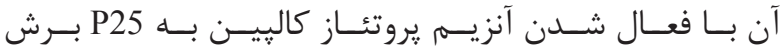

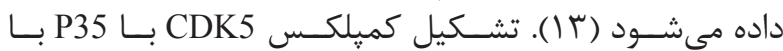

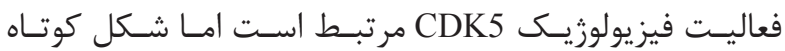

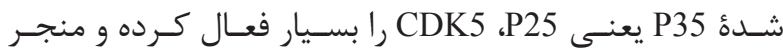

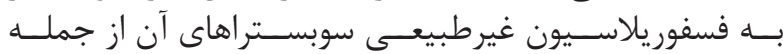

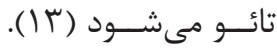

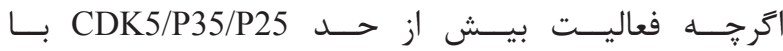

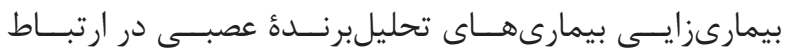

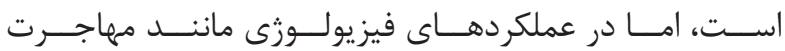

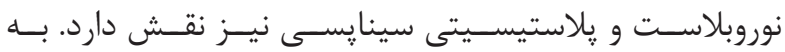

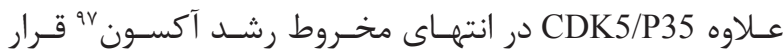

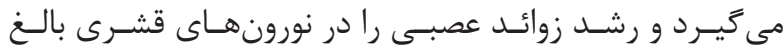

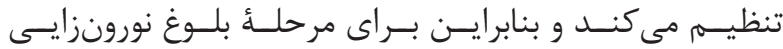

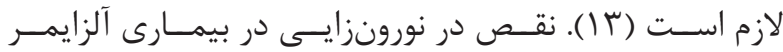

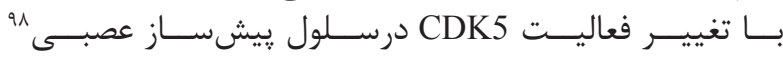

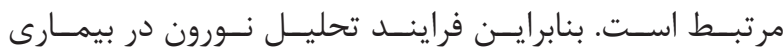

\footnotetext{
${ }^{98}$ Neural progenitor cell

${ }^{99}$ Medial temporal lobe

${ }^{100}$ Episodic memory

${ }^{101}$ Semantic memory

${ }^{102}$ Mild cognitive impairment
} 


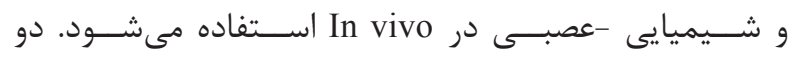

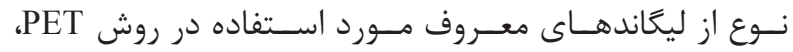

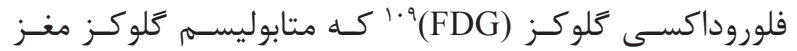

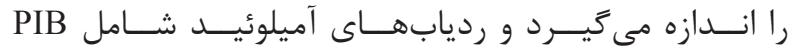

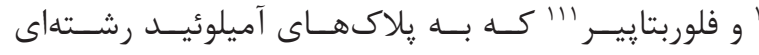

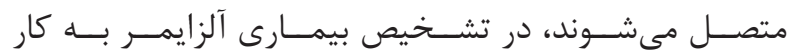

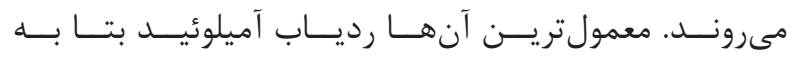

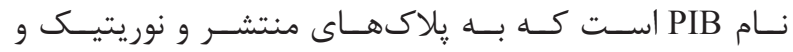

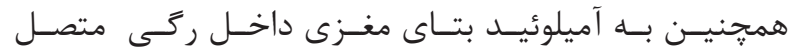

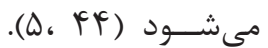

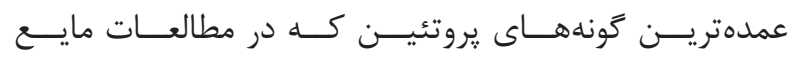

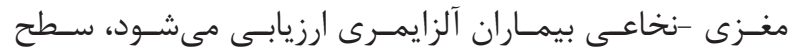

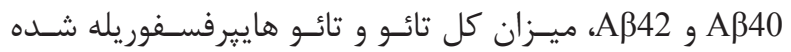

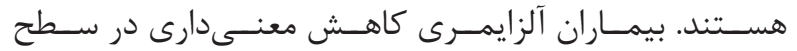

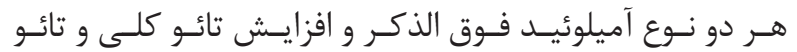

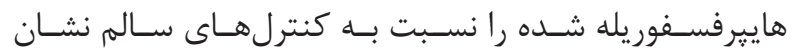

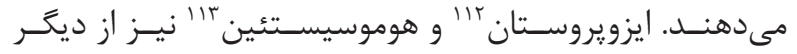

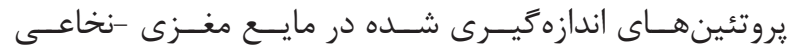

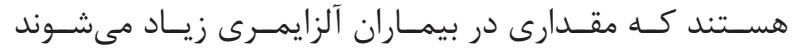

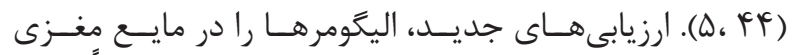

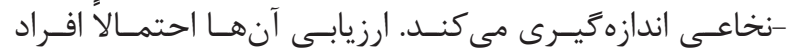

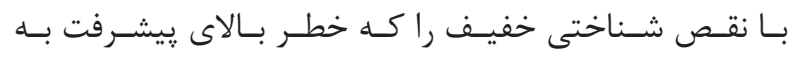

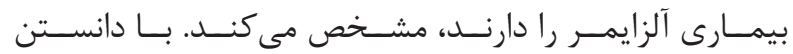

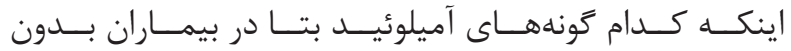

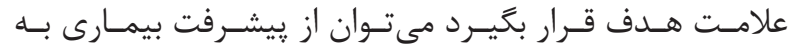

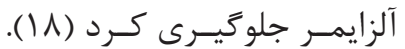

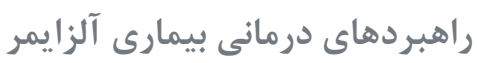

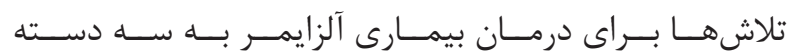

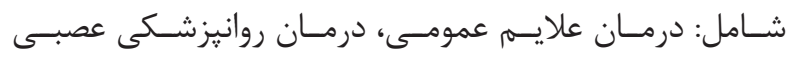

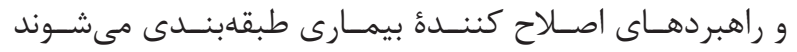

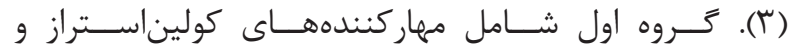

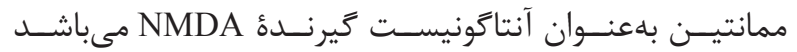

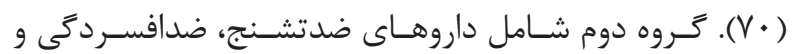

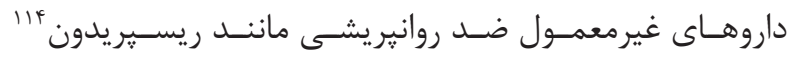

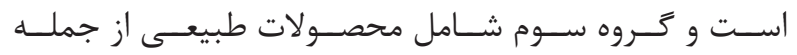

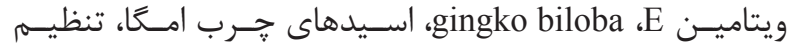

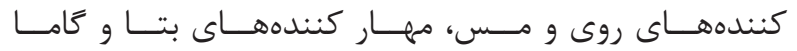

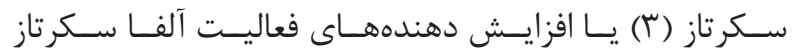

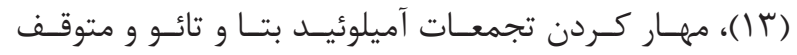

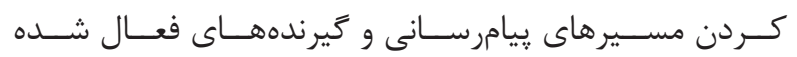

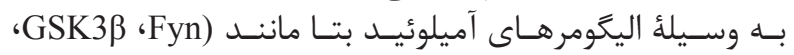

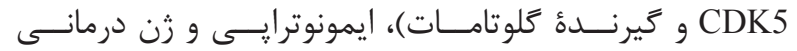

مىباشـــ (بآ).

${ }^{103}$ Mini mental state examination

${ }^{104}$ Magnetic resonance imaging

${ }^{105}$ Positron emission tomography

${ }^{106}$ Biomarkers

${ }^{107}$ Magnetic resonance spectroscopy

${ }^{108}$ Functional MRI
نشانكَر هاى زيستى بيمارى آلزايمر

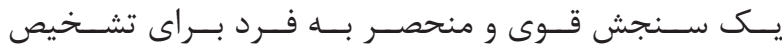

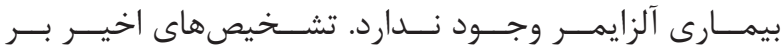

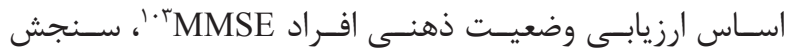

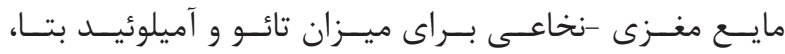

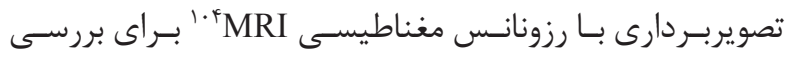

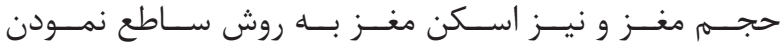

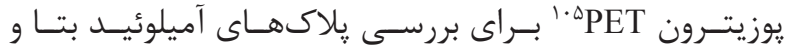

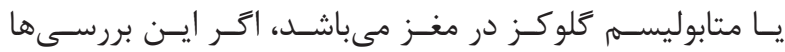

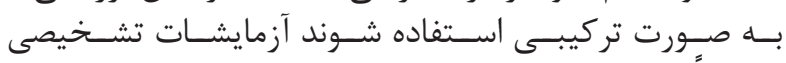

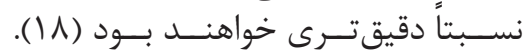

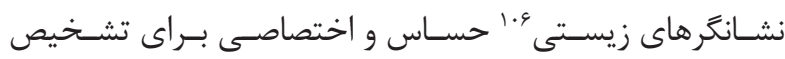

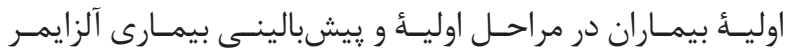

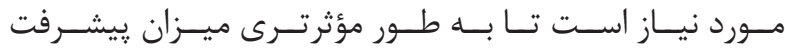

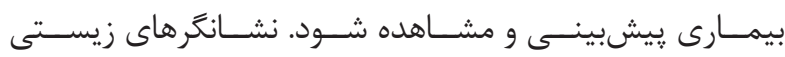

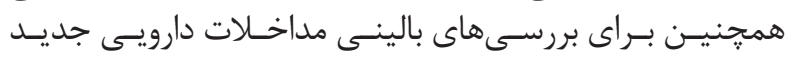

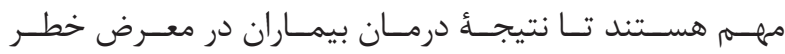

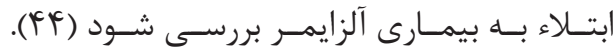

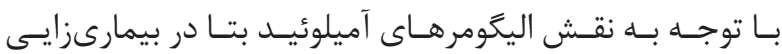

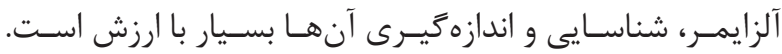

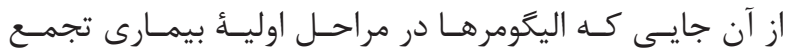

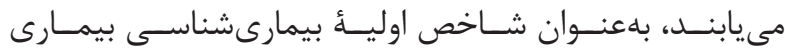

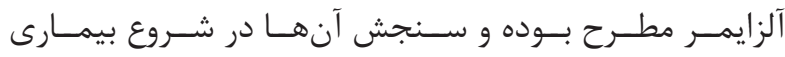

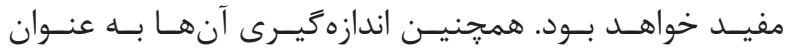

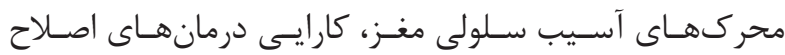

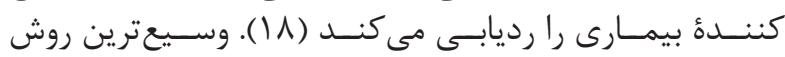

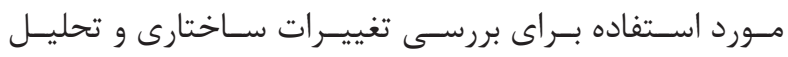

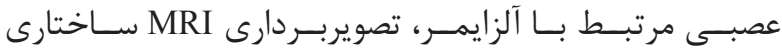

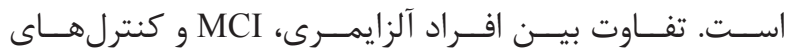

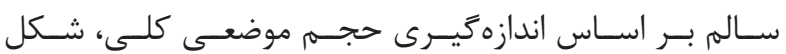

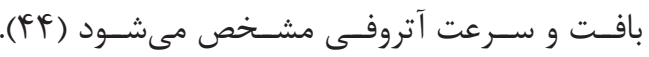

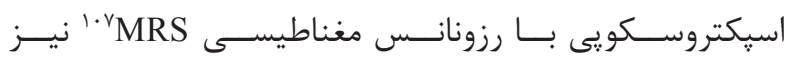

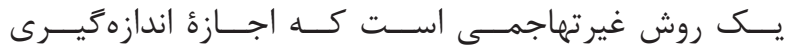

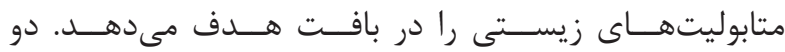

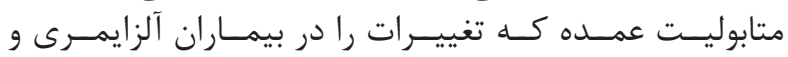

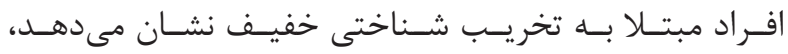
MRI - N

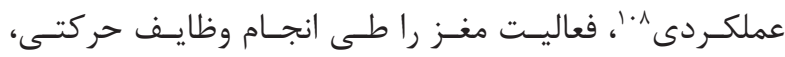

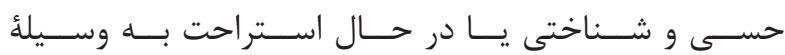

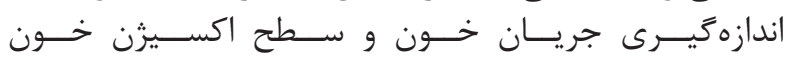

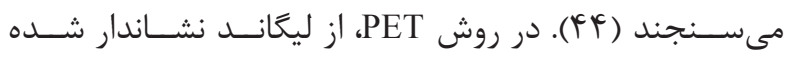

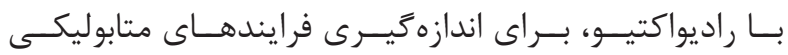

\footnotetext{
${ }^{109}$ Florodeoxyglucose

${ }^{110}$ Pittsburgh compound B

${ }^{111}$ Flobetapir

${ }^{112}$ Isoprostane

${ }^{113}$ Homocysteine

${ }^{114}$ Risperidone
} 


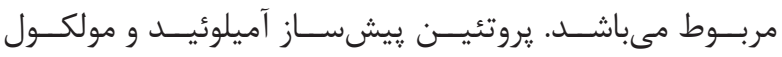

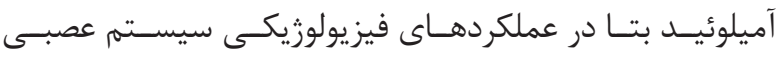

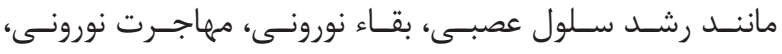

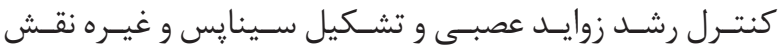

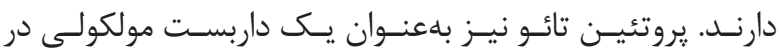

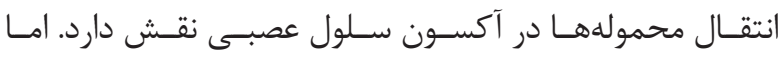

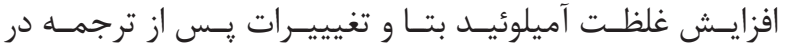

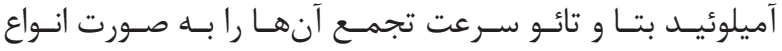

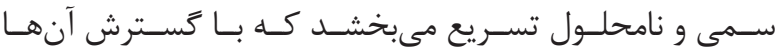

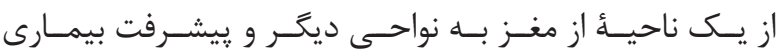

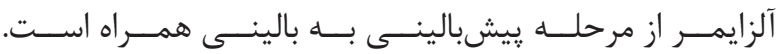

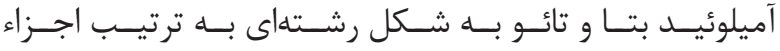

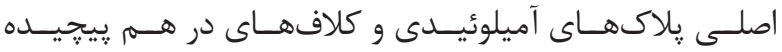

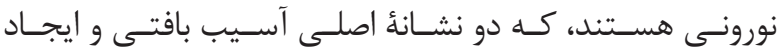

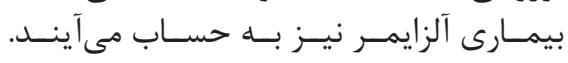

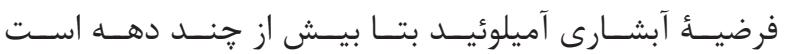

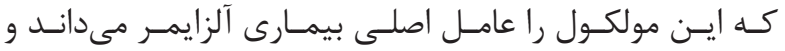

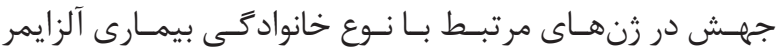

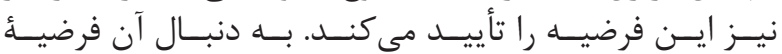

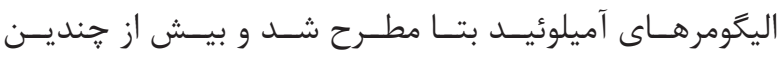

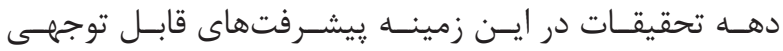

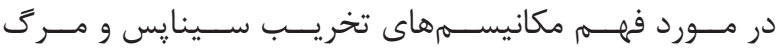

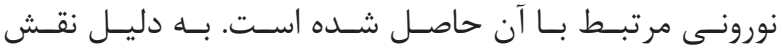

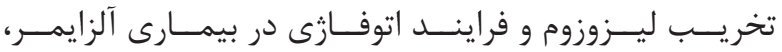

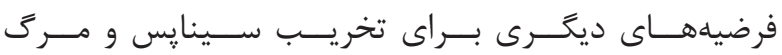

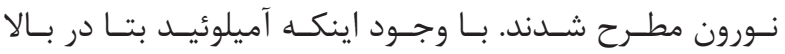

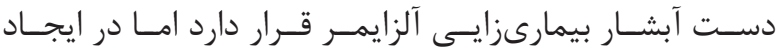

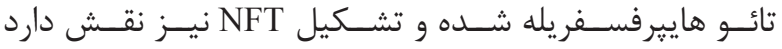

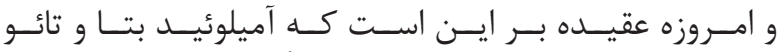

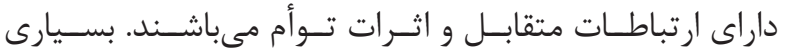

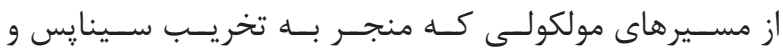

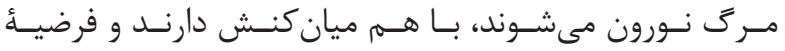

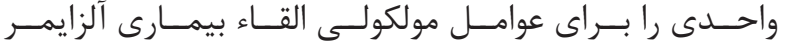

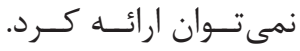

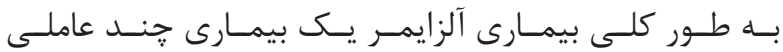

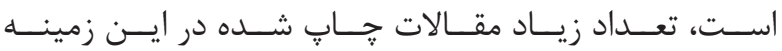

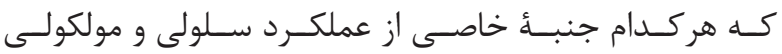

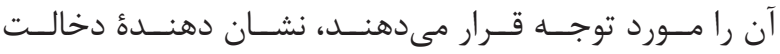

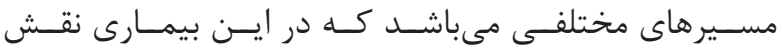

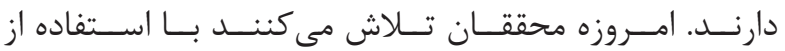

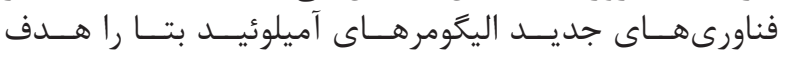

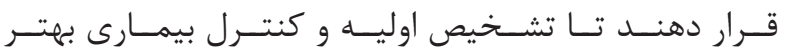

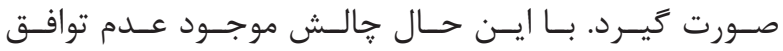

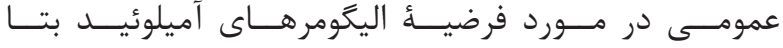

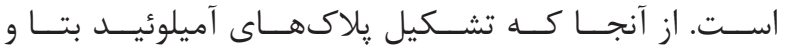

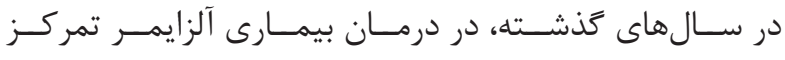

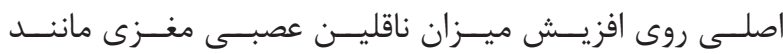

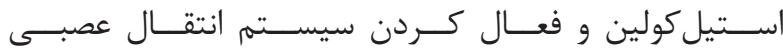

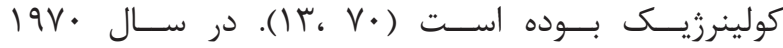

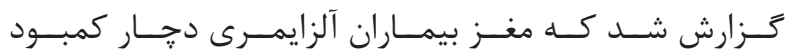

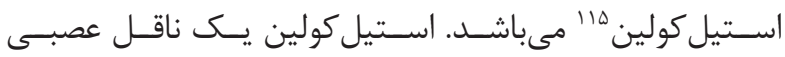

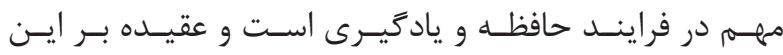

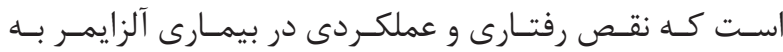

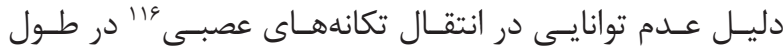

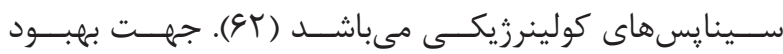

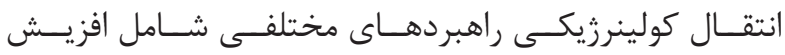

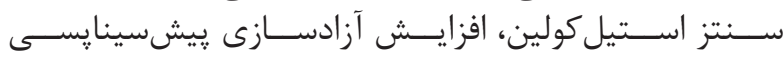

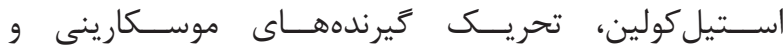

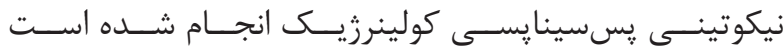

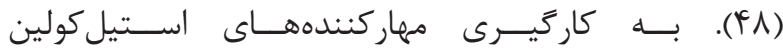

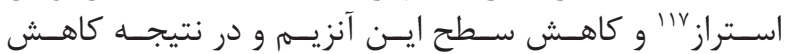

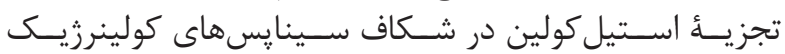

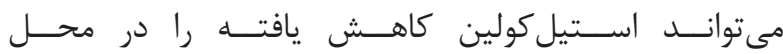

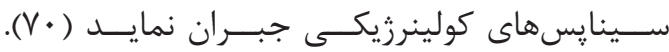

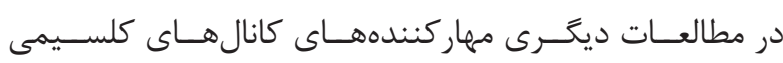

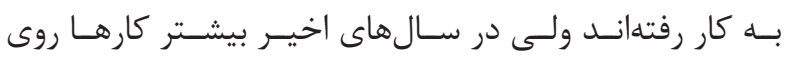

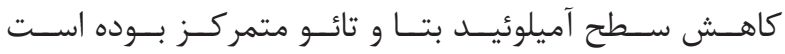

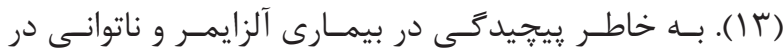

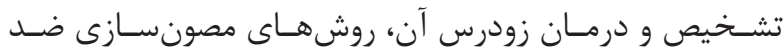

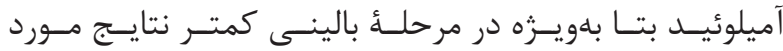

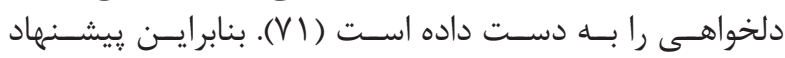

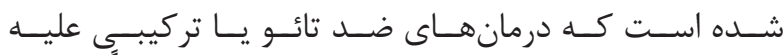

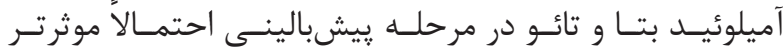

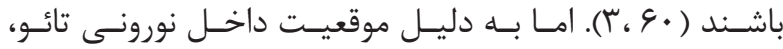

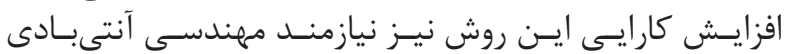

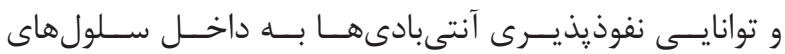

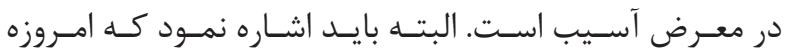

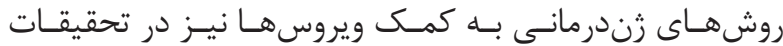

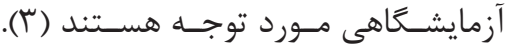

نتيجه كيرى

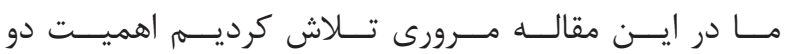

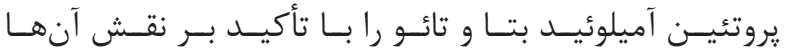

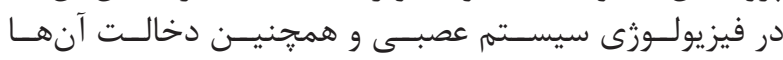

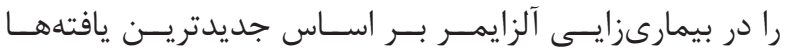
بررسـى و مسرور نمائيـهم.

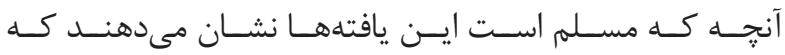

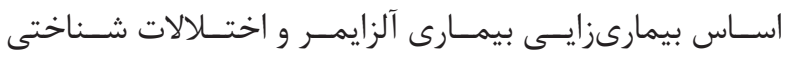

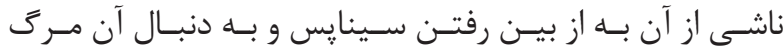

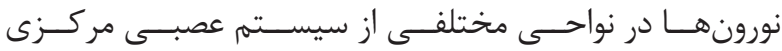




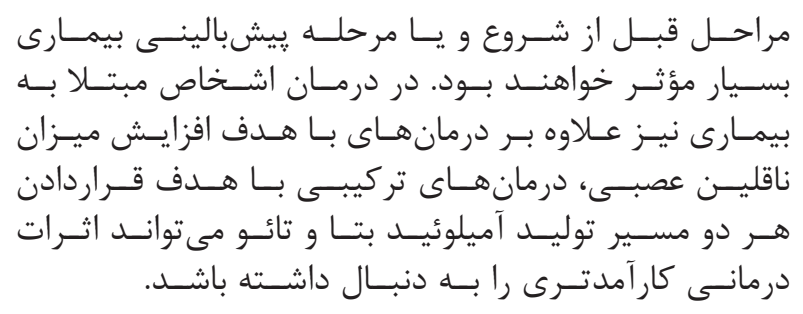

1. Thal DR, Walter J, Saido TC, Fandrich M. Neuropathology and biochemistry of $A \beta$ and its aggregates in Alzheimer's disease. Acta Neuropathol. 2015; 129: 167-82.

2. Shankar GM, Walsh DM. Alzheimer's disease: synaptic dysfunction and Abeta. Mol Neurodegener. 2009; 4: 48. doi: 10.1186/1750-1326-4-48.

3. Nisbet RM, Polanco JC, Ittner LM, Gotz J. Tau aggregation and its interplay with amyloid- $\beta$. Acta Neuropathol. 2015; 129(2): 207-20.

4. Peric A, Annaert W. Early etiology of Alzheimer's disease: tipping the balance toward autophagy or endosomal dysfunction? Acta Neuropathol. 2015; 129(3): 363-81.

5. Vinters HV. Emerging concepts in Alzheimer's disease. Annu Rev Pathol. 2015; 10: 291-319.

6. Dorostkar MM, Zou C, Blazquez-Llorca L, Herms J. Analyzing dendritic spine pathology in Alzheimer's disease: problems and opportunities. Acta Neuropathol. 2015; 130(1): 1-19.

7. O'Brien RJ, Wong PC. Amyloid precursor protein processing and Alzheimer's disease. Annu Rev Neurosci. 2011; 34: 185-204.

8. Glenner GG, Wong CW. Alzheimer's disease: initial report of the purification and characterization of a novel cerebrovascular amyloid protein. Biochem Biophys Res Commun. 1984; 120(3): 885-90.

9. Dumery L, Bourdel F, Soussan Y, Fialkowsky A, Viale $\mathrm{S}$, Nicolas $\mathrm{P}$, et al. beta-Amyloid protein aggregation: its implication in the physiopathology of Alzheimer's disease. Pathol Biol (Paris). 2001; 49(1): 72-85.

10. Abramov E, Dolev I, Fogel H, Ciccotosto GD, Ruff E, Slutsky I. Amyloid-beta as a positive endogenous regulator of release probability at hippocampal synapses. Nat Neurosci. 2009; 12(12): 1567-76.

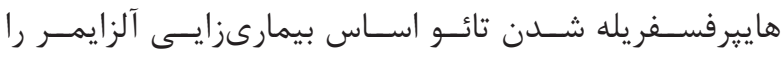

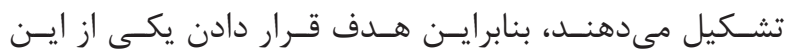

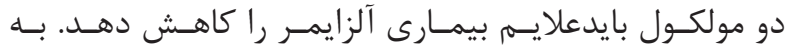

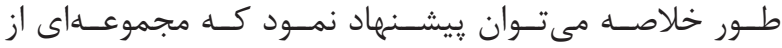

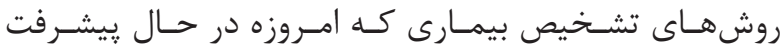

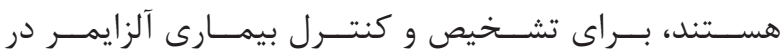

\section{منابع}

11. Kamenetz F, Tomita $T$, Hsieh H, Seabrook G, Borchelt D, Iwatsubo T, et al. APP processing and synaptic function. Neuron. 2003; 37(6): 925-37.

12. Zou K, Gong JS, Yanagisawa K, Michikawa M. A novel function of monomeric amyloid beta-protein serving as an antioxidant molecule against metalinduced oxidative damage. J Neurosci. 2002; 22(12): 4833-41.

13. Crews L, Masliah E. Molecular mechanisms of neurodegeneration in Alzheimer's disease. Hum Mol Genet. 2010; 19(R1): R12-20.

14. Bi X. Alzheimer disease: update on basic mechanisms. J Am Osteopath Assoc. 2010; 110(9): S3-9.

15. Bertram L, Lill CM, Tanzi RE. The genetics of Alzheimer disease: back to the future. Neuron. 2010; 68(2): 270-81.

16. Bettens K, Sleegers K, Van Broeckhoven C. Current status on Alzheimer disease molecular genetics: from past, to present, to future. Hum Mol Genet. 2010; 19(R1): R4-R11.

17. Rosenberg RN, Lambracht-Washington D, Yu G, Xia W. Genomics of Alzheimer disease: a review. JAMA Neurol. 2016; doi: 10.1001/jamaneurol. 2016.0301.

18. Viola KL, Klein WL. Amyloid $\beta$ oligomers in Alzheimer's disease pathogenesis, treatment, and diagnosis. Acta Neuropathol. 2015; 129(2): 183-206.

19. Yu JT, Tan L, Hardy J. Apolipoprotein E in Alzheimer's disease: an update. Annu Rev Neurosci. 2014; 37: 79-100.

20. Bayer TA, Cappai R, Masters CL, Beyreuther K, Multhaup G. It all sticks together--the APP-related family of proteins and Alzheimer's disease. Mol Psychiatry. 1999; 4(6): 524-8.

21. Jacobsen KT, Iverfeldt K. Amyloid precursor protein 
and its homologues: a family of proteolysis-dependent receptors. Cell Mol Life Sci. 2009; 66(14): 2299-318.

22. Zhang YW, Thompson R, Zhang H, Xu H. APP processing in Alzheimer's disease. Mol Brain. 2011; 4:3. doi: 10.1186/1756-6606-4-3.

23. Chen $M$. The maze of APP processing in Alzheimer's disease: where did we go wrong in reasoning? Front Cell Neurosci. 2015; 9:186. doi: 10.3389/fncel.2015.00186.

24. Cummings BJ, Su JH, Geddes JW, Van Nostrand WE, Wagner SL, Cunningham DD, et al. Aggregation of the amyloid precursor protein within degenerating neurons and dystrophic neurites in Alzheimer's disease. Neuroscience. 1992; 48(8): 763-77.

25. Young-Pearse TL, Bai J, Chang R, Zheng JB, LoTurco JJ, Selkoe DJ. A critical function for betaamyloid precursor protein in neuronal migration revealed by in utero RNA interference. J Neurosci. 2007; 27(52): 14459-69.

26. Bogoyevitch MA, Boehm I, Oakley A, Ketterman AJ, Barr RK. Targeting the JNK MAPK cascade for inhibition: basic science and therapeutic potential. Biochim Biophys Acta. 2004; 1697(1-2): 89-101.

27. Tabaton M, Zhu X, Perry G, Smith MA, Giliberto L. Signaling effect of amyloid-beta (42) on the processing of AbetaPP. Exp Neurol. 2010; 221(1): 18-25.

28. Baruch-Suchodolsky R, Fischer B. Abeta40, either soluble or aggregated, is a remarkably potent antioxidant in cell-free oxidative systems. Biochemistry. 2009; 48(20): 4354-70.

29. Yao ZX, Papadopoulos V. Function of beta-amyloid in cholesterol transport: a lead to neurotoxicity. FASEB J. 2002; 16(12): 1677-9.

30. Soscia SJ, Kirby JE, Washicosky KJ, Tucker SM, Ingelsson M, Hyman B, et al. The Alzheimer's diseaseassociated amyloid beta-protein is an antimicrobial peptide. PLoS One. 2010; 5(3): e9505. doi: 10.1371/ journal.pone.0009505.

31. Cirrito JR, Kang JE, Lee J, Stewart FR, Verges DK, Silverio LM, et al. Endocytosis is required for synaptic activity-dependent release of amyloid- $\beta$ in vivo. Neuron. 2008; 58(1): 42-51.

32. Bergmans BA, De Strooper B. Gamma-secretases: from cell biology to therapeutic strategies. Lancet Neurol. 2010; 9(2): 215-26.
33. Huse JT, Liu K, Pijak DS, Carlin D, Lee VM, Doms RW. Beta-secretase processing in the trans-Golgi network preferentially generates truncated amyloid species that accumulate in Alzheimer's disease brain. J Biol Chem. 2002; 277(18): 16278-84.

34. LaFerla FM, Green KN, Oddo S. Intracellular amyloid-beta in Alzheimer's disease. Nat Rev Neurosci. 2007; 8(7): 499-509.

35. Dimakopoulos AC. Protein aggregation in Alzheimer's disease and other neoropathological disorders. Curr Alzheimer Res. 2005; 2(1): 19-28.

36. Selkoe DJ, Hardy J. The amyloid hypothesis of Alzheimer's disease at 25 years. EMBO Mol Med. 2016; 8(6): 595-608.

37. Mota SI, Ferreira IL, Rego AC. Dysfunctional synapse in Alzheimer's disease - A focus on NMDA receptors. Neuropharmacology. 2014; 76 Pt A:16-26. doi: $\quad 10.1016 /$ j.neuropharm.2013.08.013.

38. Sheng M, Sabatini BL, Sudhof TC. Synapses and Alzheimer's disease. Cold Spring Harb Perspect Biol. 2012; 4(5): doi: 10.1101/cshperspect.a005777.

39. Viola KL, Velasco PT, Klein WL. Why Alzheimer's is a disease of memory: the attack on synapses by A beta oligomers (ADDLs). J Nutr Health Aging. 2008; 12(1): 51S-7S.

40. Sastre M, Klockgether T, Heneka MT. Contribution of inflammatory processes to Alzheimer's disease: molecular mechanisms. Int J Dev Neurosci. 2006; 24(23): 167-76.

41. Duce JA, Bush AI. Biological metals and Alzheimer's disease: implications for therapeutics and diagnostics. Prog Neurobiol. 2010; 92(1): 1-18.

42. Saido TC, Iwatsubo T, Mann DM, Shimada H, Ihara Y, Kawashima S. Dominant and differential deposition of distinct beta-amyloid peptide species, A beta N3(pE), in senile plaques. Neuron. 1995; 14(2): 457-66.

43. Palop JJ, Mucke L. Amyloid-beta-induced neuronal dysfunction in Alzheimer's disease: from synapses toward neural networks. Nat Neurosci. 2010; 13(7): 812-8.

44. Risacher SL, Saykin AJ. Neuroimaging and other biomarkers for Alzheimer's disease: the changing landscape of early detection. Annu Rev Clin Psychol. 2013; 9: 621-48.

45. Huang WJ, Zhang X, Chen WW. Role of oxidative 
stress in Alzheimer's disease. Biomed Rep. 2016; 4(5): 519-22.

46. Miranda S, Opazo C, Larrondo LF, Munoz FJ, Ruiz F, Leighton F, et al. The role of oxidative stress in the toxicity induced by amyloid beta-peptide in Alzheimer's disease. Prog Neurobiol. 2000; 62(6): 633-48.

47. Wes PD, Sayed FA, Bard F, Gan L. Targeting microglia for the treatment of Alzheimer's Disease. Glia. 2016; doi: 10.1002/glia.22988.

48. Babaei Abraki S, Chavoshi-Nezhad S. Mitochondrial defects and oxidative stress in Alzheimer disease. Shefaye Khatam. 2014. 2(1): 85-94.

49. Hong S, Beja-Glasser VF, Nfonoyim BM, Frouin A, Li S, Ramakrishnan S, et al. Complement and microglia mediate early synapse loss in Alzheimer mouse models. Science. 2016; 352(6286): 712-6.

50. McGeer PL, McGeer EG. Targeting microglia for the treatment of Alzheimer's disease. Expert Opin Ther Targets. 2015; 19(4): 497-506.

51. McBrayer M, Nixon RA. Lysosome and calcium dysregulation in Alzheimer's disease: partners in crime. Biochem Soc Trans. 2013; 41(6): 1495-502.

52. Derisbourg M, Leghay C, Chiappetta G, FernandezGomez FJ, Laurent C, Demeyer D, et al. Role of the Tau N-terminal region in microtubule stabilization revealed by new endogenous truncated forms. Sci Rep. 2015; 5: 9659-69.

53. Kim DH, Yeo SH, Park JM, Choi JY, Lee TH, Park SY, et al. Genetic markers for diagnosis and pathogenesis of Alzheimer's disease. Gene. 2014; 545(2): 185-93.

54. Rodriguez-Martin T, Cuchillo-Ibanez I, Noble W, Nyenya F, Anderton BH, Hanger DP. Tau phosphorylation affects its axonal transport and degradation. Neurobiol Aging. 2013; 34(9): 2146-57.

55. Han P, Shi J. A theoretical analysis of the synergy of amyloid and Tau in Alzheimer's disease. J Alzheimers Dis. 2016; 52(4): 1461-70.

56. Beharry C, Cohen LS, Di J, Ibrahim K, Briffa-Mirabella S, Alonso Adel C. Tau-induced neurodegeneration: mechanisms and targets. Neurosci Bull. 2014; 30(2): 346-58.

57. Noble W, Hanger DP, Miller CC, Lovestone S. The importance of tau phosphorylation for neurodegenerative diseases. Front Neurol. 2013; 4: 83. doi: $10.3389 /$ fneur.2013.00083.

58. Chiang K, Koo EH. Emerging therapeutics for Alzheimer's disease. Annu Rev Pharmacol Toxicol. 2014; 54: 381-405.

59. Pooler AM, Noble W, Hanger DP. A role for tau at the synapse in Alzheimer's disease pathogenesis. Neuropharmacology. 2014; 76 Pt A: 1-8.

60. Brunden KR, Trojanowski JQ, Lee VM. Advances in tau-focused drug discovery for Alzheimer's disease and related tauopathies. Nat Rev Drug Discov. 2009; 8(10): 783-93.

61. Simic G, Babic Leko M, Wray S, Harrington C, Delalle I, Jovanov-Milosevic N, et al. Tau Protein hyperphosphorylation and aggregation in Alzheimer's disease and other tauopathies, and possible neuroprotective strategies. Biomolecules. 2016; 6(1): 6 . doi: $\quad$ 10.3390/biom6010006.

62. Tiraboschi P, Hansen LA, Alford M, Masliah E, Thal LJ, Corey-Bloom J. The decline in synapses and cholinergic activity is asynchronous in Alzheimer's disease. Neurology. 2000; 55(9): 1278-83.

63. Tampellini D, Gouras GK. Synapses, synaptic activity and intraneuronal abeta in Alzheimer's disease. Front Aging Neurosci. 2010; 2. doi: 10.3389/ fnagi.2010.00013.

64. Spires-Jones TL, Hyman BT. The intersection of amyloid beta and tau at synapses in Alzheimer's disease. Neuron. 2014; 82(4): 756-71.

65. Ehehalt R, Keller P, Haass C, Thiele C, Simons $\mathrm{K}$. Amyloidogenic processing of the Alzheimer betaamyloid precursor protein depends on lipid rafts. J Cell Biol. 2003; 160(1): 113-23.

66. Bloom GS. Amyloid-beta and tau: the trigger and bullet in Alzheimer disease pathogenesis. JAMA Neurol. 2014; 71(4): 505-8.

67. Liao D, Miller EC, Teravskis PJ. Tau acts as a mediator for Alzheimer's disease-related synaptic deficits. Eur J Neurosci. 2014; 39(7): 1202-13.

68. Lippa CF, Hamos JE, Pulaski-Salo D, DeGennaro LJ, Drachman DA. Alzheimer's disease and aging: effects on perforant pathway perikarya and synapses. Neurobiol Aging. 1992; 13(3): 405-11.

69. Wang C, Yu JT, Wang HF, Jiang T, Tan CC, Meng XF, 
et al. Meta-analysis of peripheral blood apolipoprotein E levels in Alzheimer's disease. PLoS One. 2014; 9(2): e89041. doi: 10.1371/journal.pone.0089041.

70. Nalivaeva NN, Turner AJ. AChE and the amyloid precursor protein (APP) - Cross-talk in Alzheimer's disease. Chem Biol Interact. 2016; doi: 10.1016/j. cbi.2016.04.009.

71. Aguzzi A, O’Connor T. Protein aggregation diseases: pathogenicity and therapeutic perspectives. Nat Rev Drug Discov. 2010; 9(3): 237-48. 